\title{
IX. JEAN HEISS, ULRIC OBRECHT, L'ALSACE ET LA PROPAGATION DES TRAITÉS DE WESTPHALIE EN FRANCE (DE 1684 À 1739)
}

Étant donné que les ouvrages publiés entre 1684 et 1739 sont mis à contribution tout au long de notre livre, nous avons choisi de nous limiter dans ce chapitre à quatre grandes figures de l'époque, pour mettre en relief ses particularités: Heiss, Vayrac, Saint-Prest et Chemnitz, un auteur allemand de la première moitié du XVII siècle, qui influença l'image française du Saint-Empire à travers les traduc-

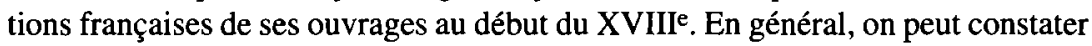
que ce sont ces auteurs qui prédominent en France à cette époque. Toutefois, commençons par une analyse des principaux fonds d'archives qui permettent de cerner, en particulier, l'apport d'Ulric Obrecht, un Alsacien qui enseigna le droit public germanique aux Français. L'apport principal, en particulier de Heiss et d'Obrecht, était leur enseignement du droit constitutionnel des traités de Westphalie en France.

\section{Les manuscrits conservés au dépôt des archives, $>$ mémoire` des Affaires étrangères: \\ l'exemple des travaux d'Ulric Obrecht sur l'Allemagne}

En créant des archives au sein du secrétariat des Affaires étrangères, au XVIIe siècle, la diplomatie française se constitue une mémoire qui représente à la fois le souvenir de la politique étrangère passée de la France et une base de données dans laquelle on va puiser à partir de la deuxième moitié du XVII ${ }^{\mathrm{e}}$ siècle et surtout au XVIII ${ }^{e}$ quand la situation politique exige un travail de mémoire sur le passé et quand on cherche des documents pouvant servir à former les jeunes diplomates. Comme pour la période antérieure, traitée dans le chapitre précédent, la série la plus importante pour notre problématique reste celle qui regroupe les "Mémoires et documents«. Non seulement elle reste la plus intéressante, mais son importance va encore croissant ${ }^{1}$. La nécessité d'apprendre à fond le droit public germanique aboutit même à des réflexions méthodologiques sur les principes de son étude, alors qu'après la disparition de l'académie de Torcy ${ }^{2}$ et avant la fondation de

1 À titre d'exemple, le volume AE, MD All. 48, composé vers 1690, renferme plusieurs »Mémoires historiques sur l'Allemagne «; ce volume comprend des mémoires sur les droits des états de l'Empire, l'autorité et les forces de l'empereur, du roi des Romains, etc. Le volume $\mathrm{AE}, \mathrm{MD}$ All. 49 offre des sommaires détaillés de la correspondance d'Ulric Obrecht, de l'année 1698 au 2 août 1701 . Cette correspondance est étudiée de manière détaillée dans ce chapitre.

2 Signalons que le manuscrit BNF, Coll. Clairambault 519 (intitulé »Droit public et affaires étrangères«) contient plusieurs projets de travaux historiques et de classement des archives 
l'école diplomatique de Strasbourg, vers $1752^{3}$, la France ne disposait pas d'une véritable école d'administration.

L'un des principaux auteurs est Ulric Obrecht, un intermédiaire essentiel entre l'Allemagne et la France, qui était de souche alsacienne. La famille Obrecht a profondément marqué la culture alsacienne, à la fin du Moyen Âge aussi bien qu'aux Temps modernes, dans les domaines de l' art et dans celui du droit et des pratiques administratives. Frédéric Ulric Obrecht naquit à Strasbourg, le 23 juillet 1646, et mourut dans la capitale de l'Alsace le 8 août 1701. Il était le fils du juriste strasbourgeois Georges Ulric Obrecht et d'Anne Marie Boecler, fille du célèbre professeur de droit Johann Heinrich Boecler.

Obrecht était donc issu d'une famille de juristes et de magistrats alsaciens, et il perpétua cette tradition: son fils Jean Henri (1675-1728) lui succéda et devint le second préteur royal de Strasbourg ${ }^{4}$. Sa carrière et sa biographie correspondent en quelques points essentiels à celle d'autres publicistes alsaciens que nous rencontrons dans ce livre. Ulric était un homme polyglotte, d'une grande intelligence et d'une vaste culture. Il parlait, outre l'allemand, sa langue maternelle, et les langues anciennes, le français, l'espagnol et l'italien. Il avait appris le français au collège de Montbéliard. Obrecht était donc, par ses connaissances linguistiques et la tradition savante de sa famille, prédestiné à jouer le rôle de médiateur entre la culture allemande et la culture française, surtout dans les domaines qui étaient ceux de sa famille tout entière, l'histoire et le droit. Après avoir étudié les belleslettres, l'histoire et le droit à Altdorf, Bâle et Strasbourg, et séjourné à Vienne (en Autriche) et à Venise, au cours d'un long voyage à travers l'Europe en sa qualité de précepteur du fils d'un ambassadeur russe, en 1676, il retourna dans sa ville natale, où il succéda, en 1682, à son beau-père, le célèbre publiciste Boecler, à la double chaire d'éloquence et d'histoire; charge à laquelle il ajouta plus tard le

des Affaires étrangères, pièces relatives à la fondation de l'académie de Torcy, par exemple une "Instruction sur les négociations estrangères et domestiques « (p. 285-305, début: »Dès que la seule naissance fait d'un homme un ministre, il y a asseurance qu'il ne sera qu'un sot «), un »Projet sur l'estude et les ouvrages des papiers du ministère « (p. 317-319) et un mémoire »De la manière d'estudier l'histoire par monsieur l'abbé le Grand « (p. 353-384); cf. THUILLIER, La première école d'administration. Pour la culture de la diplomatie au XVIII siècle, cf. également Corneliu S. BLAGA, L'évolution de la technique diplomatique au dixhuitième siècle (idéologie, mœurs et procédés), Paris 1937. Pour l'évolution de la diplomatie en général, cf. la synthèse d'Anuschka TISCHER, article »Diplomatie«, dans: Friedrich JAEGER (dir.), Enzyklopädie der Neuzeit, publié sous les auspices du Kulturwissenschaftliches Institut (Essen), t. II, Stuttgart, Weimar 2005, col. 1027-1041.

${ }^{3}$ Cf. Jürgen Voss, L'École diplomatique de Strasbourg: l'ÉNA de l'Ancien Régime?, dans: Bernard VoGLER, Jürgen Voss (dir.), Strasbourg, Schoepflin et l'Europe au XVIII' siècle. Actes du colloque organisé en coopération avec l'université des sciences humaines de Strasbourg (Strasbourg, 15-17 septembre 1994), Bonn 1996 (Pariser Historische Studien, 42), p. $205-214$.

${ }^{4}$ Pour cette institution, cf. Georges LIVET, Institutions, traditions et sociétés, dans: Strasbourg de la guerre de Trente Ans à Napoléon, 1618-1815, Strasbourg 1981 (Histoire de Strasbourg des origines à nos jours, sous la direction de Georges LIVET et Francis RAPP, t. III; Histoire des villes d'Alsace), p. 255-375. 
droit public et les Institutes. Obrecht se fit remarquer par un grand nombre d'ouvrages de jurisprudence et comme éditeur de Quintilien et de Grotius ${ }^{5}$; auteur d'un livre sur l'histoire provinciale, le »Prodromus rerum alsaticarum “, publié en 1681 , il était surtout un très bon connaisseur de la condition juridique de l'Alsace et des archives de ce pays ${ }^{6}$. À ce titre, ses services devaient donc être très précieux au roi de France. En effet, bien que son père eût été décapité, en février 1672, pour avoir cherché à livrer Strasbourg à l'empereur et pour avoir dénoncé la corruption par le roi de France de la municipalité en place 7 , en 1684, Obrecht se convertit au catholicisme, sous l'influence de Bossuet, après l'occupation de la ville par les Français, en $1681^{8}$, et se mit au service de l'administration française; à cet effet, Louvois l'avait fait convoquer à Versailles. En 1684, Obrecht publia une édition de Pufendorf intitulée "Severinus de Monzambano. De statu Imperii germanici [...] illustratus«. En 1685, il fut nommé préteur royal à Strasbourg; on lui confia plusieurs missions diplomatiques au nom du roi de France dans l'Empire. Au dire de Georges Livet, excellent connaisseur d'Obrecht, cet ancien luthérien devint »la pierre angulaire sur laquelle s'édifièrent, à Strasbourg, un nouveau régime et une nouvelle sociétée; pour Bossuet, ce personnage était »un abrégé de toutes les sciences et un homme de toutes les nations ${ }^{9}$. Comme ce fut le cas au siècle suivant, les Alsaciens jouèrent, à partir de la deuxième moitié du XVIIe siècle, un rôle de médiateurs culturels essentiels entre le Saint-Empire et la France, en particulier les juristes et les historiens d'origine alsacienne ${ }^{10}$.

5 Sur ses auvres, cf. Nouvelle Biographie générale, t. 38, col. 405-506. Cf. également Catalogue général des livres imprimés de la Bibliothèque nationale, t. 126 (1934), col. 300-306. Pour les ouvrages de son père, Georg Obrecht, ibid., col. 306-308.

6 LAGUille, Histoire de la province d'Alsace, édition in-folio, seconde partie, p. 301.

7 Cf. Marcel ThOMANN, article »Obrecht, Georg «, dans: NDBA, t. 28 (1996), p. 2884-2885.

8 Cf. Fr. J. WERNERT, La conversion d'Ulric Obrecht, préteur royal de Strasbourg, dans: Revue catholique d'Alsace 35 (1920), p. 483-490.

9 Georges LivET, article »Obrecht, Frédéric Ulric «, dans: NDBA, t. 28 (1996), p. 2885-2886 (bibliographie des œuvres et des études). Pour la biographie d'Ulric Obrecht, cf. également Biographie universelle, t. XXXI, p. 476-477; Nouvelle Biographie générale, t. 38, col. 405406; Albert METZENTHIN, Ulrich Obrecht und die Anfänge der französischen Prätur in Straßburg (1684-1701), Strasbourg 1914 (Beiträge zur Landes- und Volkeskunde von ElsaßLothringen und den angrenzenden Gebieten, 46); Jules ScHwARTZ, Un manuscrit retrouvé d'Ulric Obrecht, dans: Revue d'Alsace 76 (1929), p. 109-119, 231-236 et 376-384; LIVET, L'intendance, passim (voir l'index, p. 1055); Ingeborg STREITBERGER, Der königliche Prätor von Straßburg 1685-1789. Freie Stadt im absoluten Staat, Wiesbaden 1961 (Veröffentlichungen des Instituts für Europäische Geschichte Mainz, Abteilung Universalgeschichte, 23), en particulier p. 89-96; Georges LIVET, Une institution peu connue de la monarchie absolue. Le préteur royal de Strasbourg Frédéric Ulrich Obrecht (1646-1701), professeur d'Université, administrateur, historien, diplomate, dans: Joël FouILLERON (dir.), Sociétés et idéologies des Temps modemes. Hommage à Arlette Jouanna, vol. II, Montpellier 1996, p. $419-446$.

10 Pour la France, leur connaissance de l'allemand était très utile, même si, dans une lettre du 14 novembre 1731 , le cardinal de Rohan s'étonnait »que l'usage de la langue allemande se soit si fort conservé et l'usage de la langue françoise si peu introduit « en Alsace; original de sa lettre envoyée à Chauvelin: AE, MD Alsace 40 fol. 123-125, citation fol. 124. Pour le rôle des Alsaciens comme médiateurs culturels, cf. Voss, Das Elsaß als Mittler. Pour l'université 
C'est aussi le cas de Boecler. En effet, en juin 1716, Jean-Henri Boecler, petitfils du célèbre publiciste alsacien Johann Heinrich Boecler, envoya une lettre au gouvernement français ${ }^{11}$, en réponse d'une demande de renseignements qu'on lui avait adressée ${ }^{12}$. Boecler y donne des informations sur les ouvrages de droit public à utiliser. Le juriste Jean-Henri Boecler fut professeur de droit à Strasbourg, comme son célèbre grand-père ${ }^{13}$. Comme »meilleurs auteurs « qui ont écrit sur le droit public d'Allemagne ${ }^{14}$, Boecler recommande, dans sa lettre, $l^{\prime} \gg$ Introductio in

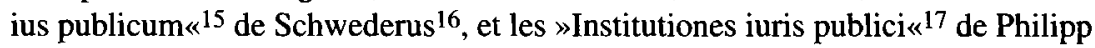
Reichard Vitriarius (1647-1720, professeur de droit public à Genève puis à Leyde) ${ }^{18}$. Boecler ajoute, entre autres, des remarques sur le projet d'un commentaire de la paix de Westphalie qu'Obrecht n'avait pas pu terminer avant sa mort, rendant honneur à ce célèbre publiciste qui avait tant fait pour faire connaître la paix de Westphalie et le droit public allemand à la France, estimé tant en France qu'en Allemagne ${ }^{19}$. Selon Boecler, les ouvrages qu'il vient de citer »sont à peu près les meilleurs livres qui puissent servir pour le droit public en général «20. Que peut-on dire de son choix? Certainement, il n'allègue que des auteurs qui sont aussi très estimés ou du moins très connus dans l'Empire même; son choix com-

de Strasbourg et l'activité littéraire en Alsace, cf. Henri DuBLED, L'activité littéraire en Alsace aux XVII e et XVIIIe siècles, dans: Les Lettres en Alsace, Strasbourg 1962, p. 209-237. 11 Boecler, de Strasbourg, 24 juin 1716; original, de toute évidence manu propria: AE, MD All. 12 fol. 272-275. La lettre est adressée »à Vostre Grandeur«; il devrait s'agir du secrétaire d'État aux Affaires étrangères. Une note, écrite par une autre main, en indique le sujet: "Droit public d'Allemagne«, ibid., fol. 272.

12 La lettre commence par ces mots: "Je me done l'honneur d'envoyer à Vostre Grandeur le catalogue des livres de droit public les plus estimés, qu'elle m'a fait la grâce de me demander $\ll$; ibid.

13 Jean-Henri Boecler (1679-1732), secrétaire de son oncle Ulric Obrecht, préteur royal à Strasbourg, il obtint la chaire des institutions et du droit public en 1701; il connaissait parfaitement le Saint-Empire et ses institutions (séjour à Wetzlar et à Ratisbonne entre 1701 et 1703); doyen-professeur de code et de droit féodal en 1730; à plusieurs reprises recteur de l'université, cf. Marcel ThomanN, article »Boecler, Jean-Henri (3)«, dans: NDBA, t. 4 (1984), p. 275. Comme il est souvent confondu avec son grand-père, nous ne traduisons pas en français le prénom de ce dernier.

14 AE, MD All, 12 fol. 272.

15 Gabriel Schweder (1648-1735) publia en 1681 son »Introductio in jus publicum Imperii Romano-Germanici novissimum«, dix fois éditée jusqu'en 1733; cet ouvrage connut un succès particulièrement remarquable parmi les étudiants, cf. STOLLEIS, Geschichte des Öffentlichen Rechts, t. I, p. 243.

16 AE, MD All. 12 fol. 272-272'.

17 Pour cet auteur et ses »Institutiones iuris publici« cf. STOLLEIS, Geschichte des Öffentlichen Rechts, t. I, p. 250-251. Les Affaires étrangères possèdent de la plume de son fils Johann Jacob (1679-1745, également professeur à Leyde) un manuscrit français intitulé "Dissertation sur l'étude du droit public d'Allemagne«; AE, MD All. 72 fol. 2, 3-110. La date de »1748« ne peut pas être celle de la rédaction du texte, compte tenu de la mort de Vitriarius survenue en 1745 .

18 AE, MD All. 12 fol. 272'.

19 Ibid., fol. 273'.

20 Ibid. 
prend des ouvrages qui peuvent être utiles à plusieurs égards (commentaires de lois fondamentales, interprétations du status Imperii, etc.). Les noms célèbres absents de son catalogue sont certainement à chercher parmi ceux des défendeurs des prérogatives de l'empereur, tel un Reinking. Premièrement, cette lettre de Boecler montre que le gouvernement éprouvait le besoin d'obtenir des informations sur les auteurs du droit public allemand, et que l'on s'adressa à un Alsacien pour les avoir; cela veut dire qu'à Paris on ne disposait pas, en 1716, d'informations suffisantes à cet égard, et que, de plus, on ignorait où puiser ces renseignements; en effet, on sait bien que la longue absence des diplomates français des terres de l'Empire, causée par la guerre de la Succession d'Espagne, provoqua une certaine rupture des voies de renseignements traditionnelles, bien que tous les liens n'aient point été coupés ${ }^{21}$. Dans ce contexte, les Alsaciens, surtout les professeurs de l'université de Strasbourg, s'avèrent des médiateurs indispensables de connaissances sur l'Allemagne. Deuxièmement, on peut noter que Boecler s'abstient de citer des ouvrages plutôt polémiques ou à caractère plus politique que proprement juridique, mentionnant pourtant, parmi eux, celui de Chemnitz, par ailleurs assez bien connu en France et trop important pour l'histoire de la science du droit public en Allemagne pour qu'on puisse l'omettre; et, surtout, il ne mentionne que peu d'ouvrages en allemand, signalant comme un défaut la rédaction d'un livre en cette langue, car il savait très certainement qu'on ne saurait pas le lire à Paris ou à Versailles, ou qu'il n'y aurait eu que très peu de lecteurs pour le lire ou le traduire en France.

Selon un mémoire daté de 1747 , le dépôt des archives possédait au milieu du XVIII ${ }^{e}$ siècle "beaucoup de volumes imprimez qui contiennent des collections des principaux jurisconsultes allemands sur le droit public et les affaires de l'Europe « ${ }^{22}$. Très certainement, ils constituaient un excellent instrument de travail 23 .

Les fonds des archives diplomatiques, à l'enrichissement desquels des familles alsaciennes, comme les Boecler et les Obrecht, contribuaient beaucoup, notamment dans le domaine du droit germanique, nous fournissent, on l'a déjà vu, des éléments importants pour notre problématique. Si la période de la Régence a déjà été minutieusement étudiée, tout récemment, dans une étude sur les relations franco-allemandes de 1715 à $1723^{24}$, nous nous sommes particulièrement intéressés aux papiers d'Ulric Obrecht et de ses contemporains (1698-1701)25, et tout

21 Cf. UlBert, Frankreichs Deutschlandpolitik, p. 58-61.

22 AE, Dépôt des Archives 1 fol. 128-133': "Sur le Dépost des Affaires étrangères établi au Louvre«; »Remis à monsieur le marquis de Puisieux le 30 mars 1747« (citation fol. 132).

${ }^{23}$ En revanche, d'après un »Mémoire sur le Dépost des Affaires étrangères« du 10 juillet 1746, il n'y avait »pas au Dépost un seul dictionnaire pour les langues étrangères. Ils seroient très utiles pour le cas où l'on pourroit charger les commis du Dépost de faire quelque traduction «, ibid., fol. 124-127 (citation fol. 127).

${ }^{24}$ Cf. Ulbert, Frankreichs Deutschlandpolitik.

${ }^{25}$ Les relations franco-allemandes et les négociations politiques de cette époque ont déjà été très bien analysées par Anna Sinkolı, Frankreich, das Reich und die Reichsstände 1697 1702, Francfort/M. et al. 1995 (Europäische Hochschulschriften, série III: Geschichte und ihre Hilfswissenschaften, 652). 
particulièrement aux correspondances diplomatiques de la sous-série "Allemagne «26. Il faut noter que cette série n'est pas uniquement composée de correspondances. mass qu elle contient aussi des mémoires sur des questions juridiques, envoyés avec les lettres d'Allemagne à la cour. Les volumes concernant la mission d'Obrecht contiennent, outre des lettres (entre autres celles qui furent rédigées par Obrecht en 1699 et parfois en 1698), les pièces jointes à la correspondance d'Obrecht lui-même (il se trouvait à Strasbourg puis à Francfort), ainsi qu'à celle de Rousseau (en poste à Ratisbonne) ${ }^{27}$, de Frischmann (résident près de l'évêque de Münster et envoyé extraordinaire vers le chapitre d'Osnabrück ${ }^{28}$ ), et de Phélypeaux (envoyé à l'assemblée de Cologne) ${ }^{29}$; elles traitent de la question de la formation d'un neuvième électorat ${ }^{30}$, de la navigation sur le Rhin, de l'état de la religion dans certains diocèses, et d'autres problèmes du droit allemand. Les sujets abordés dans ces correspondances sont caractéristiques des problèmes auxquels se trouve constamment confrontée la diplomatie française en Allemagne, de son spain quotidien < politique et juridique. Ces problèmes expliquent la nécessité de l'analyse de la Constitution allemande, nécessité à laquelle les diplomates et les hommes politiques essayaient de répondre par le développement d'une véritable culture juridique dans la diplomatie. Celle-ci se manifestait concrètement dans les mémorandums rédigés régulièrement sur des questions de droit germanique.

C'est ainsi qu'un mémoire d'Ulric Obrecht se penchait sur la distinction entre souveraineté (absolue) et souveraineté limitée (ou "supériorité territoriale«, pour employer le terme technique utilisé par Obrecht, mais qui est un peu maladroit ${ }^{31}$ ). Certains problèmes concrets auxquels la diplomatie se trouvait confrontée aboutissaient à des conclusions fondamentales sur la nature du Saint-Empire; par

26 Nous désignons par là plus brièvement la sous-série Allemagne origine-1870 ( $\mathrm{AE}, \mathrm{CP}$ All.). Pour le début de la mission d'Obrecht, cf. en particulier les vol. 335 et 336.

${ }^{27}$ Louis Rousseau de Chamoy représenta la France à la diète du cercle de Franconie de 1699 à 1701 et à la diète de Ratisbonne de 1698 à 1702 .

28 Jean-Casimir Frischmann (né vers 1650 , mort à Bonn en avril 1721) résida à Münster de 1698 à 1702. Il était le fils du juriste Johann Frischmann (1612-1680), qui s'était mis au service de la France, cf. Ludwig BITrNER, Lothar GROSs (dir.), Repertorium der diplomatischen Vertreter aller Länder seit dem Westfälischen Frieden (1648), vol. I: 1648-1715, Oldenburg 1976 (réimpression de l'édition de 1936), p. 225; UlBERT, Frankreichs Deutschlandpolitik, p. $444-445$.

29 Raymond Balthazar, marquis de Phélypeaux du Verger était envoyé extraordinaire du roi de France aux conférences de Cologne qui portaient sur la navigation du Rhin; il présenta ses lettres de créance en juin 1699. De 1698 à 1700, il fut également résident français auprès de Cologne, ville libre de l'Empire, et auprès de son prince électeur. Sa correspondance de 1699 montre qu'il s'intéressa beaucoup aux rapports tendus entre l'électeur et le chapitre au sujet de l'administration du pays; cf. AE, CP Cologne 48.

30 Évidemment, ce problème intéressa beaucoup les Français, comme toutes les questions relatives au droit de l'élection impériale. Après 1727, Le Dran rédigea une importante $» H i s-$ toire de l'érection du neuvième électorat en faveur de la maison de Brunswic «; ce mémoire de 343 folios constitue le volume AE, MD All. 47 au dépôt des archives.

31 AE, CP All. 335 fol. 142-149 (copie incomplète). Cf. l'annexe de notre livre. La minute se trouve par ailleurs à la bibliothèque de l'Arsenal, ms. 6516 fol. 80-91', et l'original envoyé à la cour, dans AE, CP Palatinat/Deux-Ponts 21 fol. 57-70. 
exemple, un »Mémoire fait par ordre du Roy à l'occasion du chapitre des péages, et de la navigation sur le Rhin, pour monsieur Phélypeaux, mareschal des camps et armées du Roy, envoyé extraordinaire de Sa Majesté à la cour de Coiogne«. signé Pontcnartrain ${ }^{32}$, témoigne de la position souvent prise par la cour de France pour trancher ses litiges avec les princes de l'Empire: on ne mit aucunement en doute que la question (il s'agissait de la perception d'une certaine taxe, le »droit d'étape «, sur le Rhin) ne dût se résoudre selon le droit public allemand. Or, la France en tant que >monarchie véritable< réclamait pour son roi dans ces sortes de litiges les mêmes droits qui revenaient soit à l'empereur, soit à l'Empire en Allemagne, >État< que l'on considérait à l'époque en France très souvent comme une »monarchie mixte«, marquée par un partage du pouvoir entre l'empereur et la diète. Il est intéressant de voir ce que l'on entendait du côté français par »Empire «: c'était souvent la diète considérée comme l'émanation des états de l'Empire. Si cette dernière position n'est pas défendue très clairement dans ce mémoire, mais bel et bien dans d'autres documents de l'époque ${ }^{33}$, le recours aux anciens droits de l'empereur dans le but de justifier les prétentions françaises semble remarquable, puisqu'il fait de la France, garante étrangère de la Constitution de l'Empire, une partie qui se soumet aux règles de cette même Constitution. Sur cet arrière-plan, l'on comprend bien pourquoi la France s'intéresse à l'Empire; les relations avec ses voisins les princes allemands la forcent quotidiennement, pour le règlement des conflits, à se tenir au courant des évolutions dans l'Empire, à influencer le cours des événements, à défendre ses droits cédés par les traités, ce qui exige une bonne connaissance du système politique et du droit allemands. Ces sortes de mémoires qui traitent d'un problème fiscal particulier touchent donc parfois à des questions de droit plus fondamentales. Dans le contexte de ces discussions sur les droits de navigation sur le Rhin, certains mémoires renvoient à des dictionnaires de droit allemands pour expliquer les termes juridiques employés dans les négociations; on peut donc constater que des dictionnaires de juristes allemands furent utilisés du côté français pour s'en informer.

D'ailleurs, parmi la correspondance diplomatique, on trouve un certain nombre de traductions d'actes impériaux, par exemple une »conclusion « du Corps évangélique du 23 septembre 169934 , ou le procès-verbal d'une session du Collège électoral du 18 novembre 169935 . Il est donc évident, par la présence de ces documents dans les archives du Quai d'Orsay, que ces discussions ont retenu l'intérêt des diplomates français au point qu'ils en ont établi une version française destinée à être communiquée au gouvernement. Ces traductions permettent de saisir le vocabulaire par lequel la terminologie de la diète de l'Empire fut transposée en fran-

${ }^{32}$ Sans doute Louis Phélypeaux, comte de Pontchartrain (1643-1727), contrôleur général des Finances, secrétaire d'État, avec les départements de la Marine et de la Maison du roi, depuis le 5 septembre 1699 chancelier de France, cf. Nouvelle Biographie générale, t. 40 (1862), col. 774-776.

33 Par exemple, ledit mémoire d'Obrecht du 5 mai 1699 que nous analysons ci-dessous.

34 AE, CP All. 335 fol. 378-378'.

35 AE, CP All. 336 fol. 13-18. 
çais, et complète ainsi les informations que l'on peut tirer des traductions des lois fondamentales et des traités. On peut constater que le phénomène de la traduction était très répandu dans la diplomatie française. Dans leurs dépêches, les diplomates français utilisaient fréquemment des expressions françaises traduisant les termes techniques du droit public allemand relatifs au fonctionnement de la diète. Or, toutes ces expressions techniques calquées sur le vocabulaire latin ou allemand ne sont pas entrées dans le langage commun, comme par exemple »corrélation «, désignant le processus de recherche d'un compromis entre les décisions prises par les différents collèges de la diète.

Parmi la correspondance de la fin du XVII e siècle, une lettre adressée par Obrecht à la cour, le 9 juillet $1698^{36}$, est particulièrement significative. Il en résulte notamment qu'Obrecht, sans qu'aucun office spécial ne fût créé à cet effet, jouait le rôle d'un conseiller informel de la cour en matière de politique allemande. Obrecht explique que, puisque la cour lui avait fait part de son désir qu'il lui communiquât ses avis sur les affaires d'Allemagne, toutes les fois que ce pourrait être utile au service du roi, il s'était décidé à s'adresser à la cour pour lui proposer d'envoyer des agents français aux diètes des cercles dans l'Empire. Il s'ensuit un abrégé historique et un exposé sur la fonction actuelle des assemblées des cercles, qui mettent en relief le droit de celles-ci d'accorder ou de refuser à l'empereur les »mois romains « (budget militaire) que celui-ci leur demande; Obrecht ne cache pas les résistances que l'envoi d'agents français pourrait entraîner du côté allemand, mais en propose en même temps les solutions, et les prétextes qu'il faudrait alléguer pour calmer les Allemands.

En tant que "jurisconsulte du roi pour le droit germanique « avant la lettre ${ }^{37}$, Obrecht exerça donc, avec ses avis transmis à la cour, une influence sur la politique étrangère française, que nous allons encore examiner plus en détail. Il est en général difficile de mesurer l'ampleur effective de l'influence des conseillers juridiques plus ou moins officiels dont le gouvernement se servit déjà avant 1648 dans ses relations avec le Saint-Empire, mais cette empreinte d'Obrecht sur la politique française est relativement bien documentée et peut ainsi être évaluée d'une manière plus précise que dans la plupart des cas. De toute façon, au sujet de la proposition faite à l'égard des assemblées des cercles, la cour répondit à Obrecht, le 18 juillet 1698, que le roi avait déjà décidé de l'envoi d'un agent auprès du cercle de Souabe avant qu'on eût reçu sa lettre ${ }^{38}$, mais qu'il avait généralement »fort approuvé la proposition de faire entrer ses envoyés dans les assemblées des cercles«, et qu'il tenait les solutions imaginées afin de surmonter d'éventuelles résistances contre ce projet pour $»$ très plausibles « ${ }^{39}$.

36 AE, CP All. 335 fol. 299-304'.

${ }^{37}$ La création du poste de jurisconsulte du roi pour le droit germanique date seulement de (1722 ou) 1723.

38 Signalons que, de 1689 à 1700 , la France fut représentée auprès du cercle de Souabe par Jacques Vincent Languet, comte de Gergy.

${ }^{39}$ AE, CP All. 335 fol. 305-305'. 
Quoi qu'il en soit, il est sûr que les mémoires sur les cercles de l'Empire qui ont été établis par Obrecht en 169940 découlent de ces discussions sur une politique française plus active auprès des cercles. Obrecht jugeait ces derniers trop faibles pour s'opposer seuls aux prétentions et demandes de l'empereur, celui-ci cherchant à contourner, par le moyen de leurs assemblées, le pouvoir budgétaire de la diète impériale, dominée par l'opposition des puissants princes de l'Empire et la présence étrangère. Les mémoires d'Ulric Obrecht servaient par conséquent à définir les objectifs et les moyens de la politique allemande de la France à la fin du XVIIe siècle, c'est-à-dire à un moment où celle-ci fut à la recherche de nouveaux contrepoids pour équilibrer le pouvoir impérial.

Avant même que l'institutionnalisation progressive dans l'administration n'entraînât la constitution d'un poste de conseiller aux affaires allemandes, créé pour Pfeffel en 1722 et $1723^{41}$, la diplomatie française disposait donc de personnalités fiables pour se procurer les informations nécessaires à une politique étrangère adaptant son action aux évolutions récentes dans l'Empire. Les progrès de l'institutionnalisation sont, on vient de le dire, progressifs; leur degré dans un secteur aussi précis que le nôtre n'est donc pas toujours identifiable avec certitude. Si Obrecht n'occupe pas un poste particulier qui l'oblige à transmettre ses informations et avis à la cour, il le fait pourtant régulièrement de 1698 jusqu'en 1701, année de sa mort; de plus, durant cette période, il fut chargé de la grande mission diplomatique à Francfort. On pourrait donc parfois se demander en quelle qualité Obrecht s'adresse au roi (en tant que plénipotentiaire, préteur royal ou conseiller à qui on a demandé des renseignements) si cette question n'était superflue, puisque ces deux qualités - la troisième n'ayant même pas un caractère officiel - ne sont pas distinguées dans la correspondance. Ce qu'il faut en revanche noter, c'est qu'Obrecht s'acquitta avec régularité de sa tâche, qui marque la transition entre une politique française cherchant à se renseigner seulement face à l'urgence d'une situation précise et l'institutionnalisation accomplie. Cette action répond d'ailleurs à la demande explicite de l'État.

Il en résulte une correspondance régulière entre la cour et Obrecht, dont les lettres sont parfois de véritables abrégés sur un point du droit public allemand, comme l'exemple déjà cité du mémoire adressé à Louis XIV, à la demande explicite du souverain d'être renseigné sur la différence entre la souveraineté et la Landeshoheit, le 5 mai 1699. À une époque où la politique étrangère française fut, d'un côté, dans une large mesure une affaire personnelle du roi, et qu'elle entra,

40 AE, CP All. 336 fol. 62-106; un mémoire général intitulé »De l'estat de l'Empire. 1699« sert d'introduction aux mémoires particuliers relatifs aux différents cercles; tous ces mémoires ne semblent pas revenir à Obrecht; l'auteur peut être identifié avec certitude seulement pour ceux qui sont signés; d'autres copies ou des minutes des mémoires rédigés par Obrecht ou à son époque se trouvent parmi ses papiers à la bibliothèque de l'Arsenal, carton 7093: un »Mémoire concernant la cour de Vienne « (relatif au projet d'une ligue de six cercles), des mémoires sur le landgrave de Hesse-Cassel, sur les cercles du Haut-Rhin, du Bas-Rhin, de la Franconie et de la Souabe (6 avril 1698).

41 Cf. ULBERT, Les Affaires étrangères françaises et la Constitution. 
de l'autre, dans une période plus pacifique vis-à-vis de l'Allemagne, de sorte que le recours au droit l'emporta plus souvent qu'auparavant sur le recours à la force, ces lettres et mémoires rédigés par Obrecht sont autant de leçons de droit public allemand pour le monarque. On notera en outre, dans cette correspondance, un mémoire d'Obrecht, explicitement commandé par la cour lui aussi, sur l'article IV de la paix de Ryswick, un autre grand sujet auquel la diplomatie française était alors confrontée ${ }^{42}$.

Bien que tous les manuscrits de la correspondance politique ne soient pas aussi riches en renseignements sur le droit public allemand, l'analyse des dépêches d'Obrecht témoigne de l'importance extraordinaire des éléments qu'on peut en tirer. En particulier, elles permettent de saisir le rôle primordial de cet auteur, qui mettait l'explication de la paix de Westphalie au centre de ses renseignements sur le droit public allemand.

\section{Ulric Obrecht comme informateur de l'administration française} et du secrétaire d'État à la Guerre

Or, Obrecht n'écrit pas seulement pour le roi et n'envoie pas uniquement ses dépêches et ses mémoires au secrétariat des Affaires étrangères. Bien au contraire, ses correspondants sont nombreux ${ }^{43}$, et d'autres administrations peuvent aussi tirer profit des précieuses informations qu'il fournit. D'abord, il ne faut pas oublier que tous les papiers Obrecht n'ont pas été rendus au dépôt des Affaires étrangères. C'est ainsi qu'une partie de sa correspondance politique et de ses mémoires juridiques se trouve à la bibliothèque de l'Arsenal. Si c'est le hasard qui décide parfois du lieu et du fonds où un document est conservé, la dispersion de la correspondance d'Obrecht résulte aussi de la variété de ses correspondants.

Retenons d'abord qu'une partie de celle-ci a été versée au »Contrôle général des Finances «, aux Archives nationales. Si ces lettres concernent majoritairement des sujets qui font bien partie de l'administration financière de l'Alsace, on y trouve aussi un certain nombre de documents qui traitent d'une manière plus générale des problèmes juridiques qui se posent dans les relations avec le Saint-Empire. Parmi ces documents, on note la présence de lettres d'Ulric Obrecht dont il résulte, surtout, que celui-ci faisait régulièrement traduire les actes de la diète perpétuelle de Ratisbonne à Strasbourg, pour les envoyer à Paris ${ }^{44}$. De plus, Obrecht entretenait de la même manière une correspondance régulière avec l'administration militaire ${ }^{45}$. Il ne renseignait pas seulement les diplomates mais aussi les mi-

42 AE, CP All. 335 fol. 398-401', daté octobre 1699.

43 Ses mémoires sont souvent très longs, cf. par exemple, dans le manuscrit BNF, Coll. Clairambault 283, p. 41-125, un $\gg$ Avis du sieur Obrecht à un prince d'Allemagne concernant l'élection du roy des Romains faite en 1690 «.

44 Cf. Archives nationales, série $\mathrm{G}^{7}$, ici les cartons 79 et 80 .

45 L'Alsace comme pays situé à la frontière intéressait les militaires pendant toute la période que nous étudions. C'est la raison pour laquelle non seulement les archives diplomatiques, 
litaires, et ces derniers n'étaient pas uniquement informés des événements qui pouvaient intéresser la poursuite ou la préparation de la guerre au sens propre, mais, à part cela, ils recevaient des informations sur les évolutions politiques générales en Allemagne, qui pouvaient modifier la donne politico-militaire au sens large, et sur les problèmes qui résultaient de l'évolution constitutionnelle de l'Empire, comme la création du neuvième électorat, puisque ces problèmes étaient censés influencer la situation politique générale avec d'éventuelles répercussions sur les relations entre la France et le Saint-Empire ou bien ses États territoriaux ${ }^{46}$. En particulier, Obrecht rendait compte des délibérations du cercle de Souabe ${ }^{47}$. Mais la plupart des informations étaient d'ordre militaire ou concernaient la publication de brochures de propagande exploitant les succès des armées ${ }^{48}$. Il est certain qu'en les transmettant à Versailles, Obrecht répondait à une demande explicite des autorités ${ }^{49}$. Pendant les négociations de paix, il était censé envoyer à Versailles des informations sur la manière dont les Allemands réagissaient aux propositions que le roi faisait à ses adversaires ${ }^{50}$. Il prêtait attention non seule-

mais aussi les archives de la guerre contiennent de nombreux mémoires sur ce pays et sur sa situation militaire; cf., par exemple, Vincennes, service historique de la Défense (SHD), archives de l'Armée de terre (AAT), A1.1181 (titre: »Diverses pièces utiles «; note: »Un grand nombre des pièces de ce volume sont écrites de la main de monsieur de La Faye, premier commis du Dépôt de la guerre de 1719 à 1748«), no 51: »Mémoire sur l'Alsace«. Pour les Français, il importait de mieux connaître l'Alsace pour le protéger et l'administrer; au sujet de l'image de l'Alsace en France, cf., par exemple, Georges LiveT, Comment les Français du XVIle siècle voyaient l'Alsace et comment les Alsaciens voyaient la France, dans: XVII siècle $25 / 26$ (1955), p. 103-130.

46 Cf., par exemple, SHD, AAT, Al.1216 (1693), $\mathrm{n}^{\circ} 28$ (original d'une lettre d'Obrecht au ministre, Strasbourg, 19 octobre 1693, concernant, entre autres sujets, la diète de Ratisbonne).

47 Cf. ibid., no 76, »Monsieur Obrecht, à Strasbourg, fait part des matières qui doivent être traitées à l'assemblée d'Ulm. L'électeur palatin offre au cercle deux régimens d'infanterie, un régiment de cavalerie et un de dragons « (résumé selon la table des matières au début du volume); lettre au ministre, Strasbourg 23 novembre 1693, original: Obrecht rend compte des dix-huit sujets dont le cercle de Souabe doit discuter (fol. $1^{\prime}-5$ ), et ajoute: $» J$ 'espère d'aprendre les résolutions qui seront prises dans cette assemblée, par la mesme voye par laquelle j'ay receu l'estat des délibérations qui y sont agitées, et je prendray la liberté de les adresser à Vostre Grandeur « (fol. 5').

$48 \mathrm{Cf}$. ibid., $\mathrm{n}^{\circ} 28$ (voir ci-dessus), $\mathrm{n}^{\circ} 29$ (copies de deux lettres sur les affaires militaires actuelles; il s'agit probablement de pièces jointes à la correspondance d'Obrecht) et $\mathrm{n}^{\circ} 107$ (Obrecht au ministre, Strasbourg, 14 décembre 1693, original; nouvelles militaires).

49 Cf. ibid., no 54 , »Le Ministre à monsieur Obrecht, en réponse à sa lettre du 30 . Lorsqu'il aura un état exact des troupes des alliés, il lui fera plaisir de le lui envoyer« (résumé selon la table des matières au début du volume), ordre envoyé de Versailles, le 10 novembre 1693 (copie): "J'ai reçu avec votre lettre du 30 du mois passé, l'estat qui l'accompagnoit de la répartition des quartiers d'hiver des troupes du cercle de Franconie et de Saxe-Gotha; lorsque vous en aurés un exact de toutes les troupes des alliés, vous me ferés plaisir de me l'envoyer, comme aussi de m'adresser la traduction en françois de l'escrit qui vient d'être distribué dans les cours d'Allemagne concernant le différent qui est entre monsieur le duc de Wirtemberg et celui d'Hanovre pour raison de la charge de grand gonfanonier d'Empire «.

50 Cf. SHD, AAT, A1.1323 (1695), no 47 (Obrecht au ministre, Strasbourg, 26 juillet 1695 , original), ici fol. 1, et no 112 (Obrecht au ministre, Strasbourg, 10 août 1695, original). 
ment aux délibérations du cercle de Souabe, mais aussi à celles du cercle de Franconie, entretenant tout un réseau de correspondants auprès des diètes circulaires dont il tirait ses informations ${ }^{51}$. De plus, il avait un correspondant à Ratisbonne ${ }^{52}$. Parmi les sujets de ses lettres envoyées au secrétaire d'État à la Guerre, on retrouve les thèmes des grands débats constitutionnels dans l'Empire, notamment la création d'un neuvième électorat en faveur du duc de Hanovre, que l'empereur cherchait à faire accepter par les états de l'Empire, ou la réadmission du roi de Bohême au collège électoral ${ }^{53}$. Qui plus est, Obrecht suggérait aussi à Versailles quelles étaient les propositions de l'empereur auxquelles le roi pouvait avoir intérêt à s'opposer ${ }^{54}$. Obrecht s'intéressait aussi au droit public impérial en Italie ${ }^{55}$. Comme on vient de le dire, il envoyait régulièrement des traductions de documents allemands à la cour (résolutions des diètes des cercles de l'Empire, écrits de propagande, etc. $)^{56}$, qui permettaient au gouvernement de mieux comprendre la situation politique en Allemagne en général et les débats constitutionnels en particulier, dont Obrecht était un grand spécialiste ${ }^{57}$. En outre, il rendait compte des

${ }^{51}$ Cf. ibid., $n^{\circ} 47$ fol. 1'-2: "Les estats du Cercle de Franconie ont fini le<urs> séances à Nurenberg. Le correspondent que j'y a $<y>$ me mande qu'il m'adresse le résultat de leur as < semblée > qui est de plus de trente rôles, et que cela l'a $0<$ bligé $>$ de se servir de la voye de Zuric pour me l'envoyer. J'en feray part à Vostre Grandeur incessament «.

52 Cf. ibid., no 74 (Obrecht au ministre, Strasbourg, 3 août 1695, original).

$53 \mathrm{Cf}$. ibid. et, pour la création du neuvième électorat, également no 135 (Obrecht au ministre, Strasbourg, 17 août 1695, original); au sujet de l'admission du roi de Bohême, cf. aussi $\mathrm{n}^{\circ} 47$ fol. 2: "L'Empereur est en marché avec les électeurs pour les faire consentir à ce qu'il puisse assister à toutes les assemblées en qualité de Roy de Bohême. L'électeur de Bavière luy demande à cet effet la comté de Burgau, dont le prince Louis de Bade a présentement la jouissance. Mais on luy propose à la cour impériale de le payer par des lettres de survivance sur quelque principauté de l'Empire, comme on a faict à l'esgard de l'électeur de Brandebourg à qui on a donné pour le mesme sujet la survivance sur le duché de Meckelbourg «.

54 Cf., par exemple, ibid., fol. 2-2', après le passage cité dans la note précédente: »Il [sc. l'empereur] faict en cecy contre le serment qu'il a juré à sa capitulation de ne plus donner de survivance sur les fiefs vacants de l'Empire, mais de les incorporer au domai<ne $>$ de l'Estat. Et il ne seroit pas difficile de monstrer au pu<blic $>$ les inconvénients qui résulteront tant de ces co $<$ ncessions $>$ de survivance, que de la réception du Roy de $<$ Bohême $>$ aux assemblées des électeurs, s'il estoit de l'i<ntérest $>$ du Roy que l'on réveillât les princes de l'Empi<re> là-dessus«.

55 Cf. SHD, AAT, Al.1501 (1701), no 44 (lettre d'Obrecht à »Monsieur«, Francfort/M., 25 janvier 1701 , original).

56 Cf., par exemple, SHD, AAT, A1.1323, no 168 (Obrecht au ministre, Strasbourg, 24 août 1695, original) et $n^{\circ} 185$ (Obrecht au ministre, Strasbourg, 29 août 1695, original), ici fol. 11': »J'ay eu l'honneur de donner advis à Vostre Grandeur en dernier lieu d'une lettre que les estats du cercle de Suabe ont escrite à l'Empereur pour s'oposer à la cession de la ville de Strasbourg. On vient de me mander que ladite lettre a esté projettée à la cour de Stoutgart déjà au mois de décembre dernier, de concert avec l'évêque de Constance et le prince Louis de Bade seulement, et qu'elle n'a esté communiquée aux autres estats qu'à la dernière assemblée d'Ulm. Comme il m'a paru qu'il pourroit importer au Roy d'en sçavoir précisément le contenu, afin de destruire auprès des médiateurs les raisons sur laquelle se fonde ladite position, je la joins icy en allemand comme elle a esté expédiée avec la traduction que j'en ay faict faire $\ll$.

${ }^{57}$ LIVET note: »Le préteur [royal Obrecht] reste au premier chef interprète et traducteur«, 
publications d'articles dans la presse périodique allemande qui pouvaient intéresser le gouvernement ${ }^{58}$. D'ailleurs, pendant l'absence d'Ulric Obrecht, son fils prit le relais comme informateur du secrétaire d'État à la Guerre ${ }^{59}$. Les Obrecht sont une véritable >dynastie` de spécialistes de l'Allemagne au service du roi de France.

\section{Le mémoire d'Obrecht sur la distinction entre »souveraineté« et »supériorité territoriale« (1699)}

Ulric Obrecht était aussi l'un des propagateurs les plus importants en France de la connaissance du droit constitutionnel fixé par les traités de Westphalie. Sa correspondance générale a été présentée dans les paragraphes précédents. Il s'agira maintenant d'analyser de plus près l'une des sources qu'il nous a laissée et d'étudier l'image du Saint-Empire qu'il y développe. Dans ce contexte, nous étudierons surtout l'un des mémoires qu'il rédigea en 1699 au sujet de la distinction entre souveraineté et Landeshoheit, mémoire sur lequel nous avons déjà attiré l'attention de la communauté des historiens il y a quelques années ${ }^{60}$. Même dans l'article biographique qu'il a consacré à Ulric Obrecht, Georges Livet souligne, parmi les mérites du diplomate et du savant Obrecht, que celui-ci »définit avec netteté la distinction fondamentale entre ssouverainetér et >suprême domaine (pour les territoires de Basse-Alsace) et précisa les droits de la Palatine, duchesse d'Orléans «61. C'est son mémoire de 1699 que nous avons choisi comme seul texte reproduit en annexe.

En 1699, Ulric Obrecht, chargé des négociations avec l'électeur palatin dans le cadre d'un différend qui opposait le roi de France à ce prince, rédigea un mémoire

ID., Une institution peu connue, p. 433, n. 1; cf. aussi ibid., p. 438-439. Sur Obrecht comme traducteur d'un ouvrage français en allemand, voir STREITBERGER, Der königliche Prätor, p. 92.

58 Cf. SHD, AAT, Al.1323, no 185 , ici fol. 1'.

59 Cf. sa première lettre au nouveau ministre, Strasbourg, 25 janvier 1701, SHD, AAT, A1.1501, no 46 (original): "J'ay receu une lettre de mon père par laquelle il me fait espérer que Vostre Grandeur ne trouvera pas mauvais que je me donne l'honneur de luy envoyer les nouvelles que je reçois toutes les semaines d'Allemagne et que j'ay envoyé à feu Monseigneur de Barbezieux depuis que mon père n'est pas icy. C'est ce qui me fait prendre la liberté de supplier très humblement Vostre Grandeur, de vouloir bien me permettre de me servir de cette occasion pour luy témoigner le zèle que j'auray toujours pour son service, en attendant qu'il luy plaise de m'honorer de ses ordres dans quelque chose de plus important; je les recevray toujours comme des grâces très particulières«. La pièce jointe à cette lettre (ibid., $n^{\circ} 47$ ) contient les informations de Ratisbonne du 10 janvier 1701 (création du $9^{e}$ électorat, art. IV du traité de Ryswick, etc.). L'ancien secrétaire d'État à la Guerre, Louis-FrançoisMarie Le Tellier, marquis de Barbezieux (fils de Louvois, né en 1668), était décédé le 5 janvier 1701, cf. M. PrevosT, article »Barbezieux (Louis-François-Marie Le Tellier, marquis de)«, dans: Dictionnaire de biographie française, t. V (1951), col. 310-311.

60 Cf. Braun, Traductions.

61 Livet, Frédéric Ulric Obrecht, p. 2885. 
"Sur la distinction du droit de domaine supreme d'avec celuy de la superiorite territoriale«, qui paraît effectivement être »sur ce point un précis du droit public de l'Empire «62. Ce mémoire est pour l'essentiel fondé sur l'interprétation de l'article VIII du traité d'Osnabrück. Rédigé par Obrecht au cours de sa mission à Francfort, il est d'un intérêt particulier pour saisir le sens qu'il accordait aux termes »souveraineté « et »supériorité territoriale « et pour comprendre de quelle manière il interprétait la paix de Westphalie.

Pour comprendre ce document, il est nécessaire de le replacer d'abord dans son contexte historique ${ }^{63}$. Louis XIV demanda cette expertise à Obrecht dans un litige qui l'opposait à l'électeur palatin. Ce désaccord découlait d'une interprétation différente des articles IV et VIII du traité de Ryswick de 1697, qui avaient stipulé que l'électeur devait être rétabli dans ses possessions et droits situés sur la rive gauche du Rhin, alors que la province d'Alsace resterait sous la souveraineté du roi de France. Or, la France défendait une définition très extensive de l'espace juridique alsacien, qui incluait les possessions palatines, et Louis XIV prétendait que les lieux restitués au palatin devaient bien être placés sous la Landeshoheit de ce prince, mais rester sous la souveraineté du roi de France. Mécontent de cette interprétation française du traité, le palatin refusa le payement de 200000 livres qu'il devait en vertu de ce même traité à la duchesse d'Orléans, Élisabeth-Charlotte, qui était la fille de l'électeur palatin Charles Ier Louis et avait épousé, en 1671, Philippe Ier duc d'Orléans, frère du roi. Après la mort du prince électeur Charles II, frère de la princesse Palatine, en 1685, Louis XIV avait revendiqué en son nom une partie de l'héritage palatin. En effet, quand la branche masculine électorale de Simmern s'était éteinte en 1685, l'électorat devait passer, conformément à l'ordre de succession définie par la Bulle d'or, à Philippe-Guillaume, prince palatin de la branche de Neubourg. L'empereur lui donna l'investiture. La duchesse d'Orléans, søur du dernier électeur de la branche de Simmern, ne contesta pas, pour sa part, cette succession électorale et féodale, mais elle réclama la succession allodiale de son frère; or, celle-ci était difficile à établir, et PhilippeGuillaume refusa nettement cette distinction. Par conséquent, cette prétention française provoqua la guerre de la ligue d'Augsbourg (nommée justement Pfälzischer Erbfolgekrieg, guerre de la Succession palatine, en allemand).

Pour justifier son refus de payer les 200000 livres, après la paix de Ryswick, l'électeur Jean-Guillaume alléguait le fait qu'il n'avait pas encore été restitué dans tous ses droits. Une conférence à Francfort, à laquelle fut envoyé Obrecht par la France, devait régler ce différend ${ }^{64}$. Zachmann, député de l'électeur, soutint d'abord que la restitution déjà faite à son maître le palatin »ne pouvoit être suffisante, à moins qu'il ne possédât sous la Souveraineté de l'Empereur et de l'Em-

62 LAGUille, Histoire de la province d'Alsace, édition in-folio, seconde partie, p. 300.

63 Cf. à ce sujet ibid., p. 297-303. Cf. aussi Sinkol, Frankreich, das Reich und die Reichsstände.

64 Ces négociations furent par la suite continuées à Paris, sous la médiation du nonce apostolique Delphino. 
pire, les droits \& lieux qu'on luy avait rendus « 65 . Mais comme le député de l'empereur insista pour que "la Souveraineté de l'Empereur \& de l'Empire ne [dût] point entrer en discussion « 66 , la négociation se centra sur la question de savoir quels droits devaient échoir respectivement au roi de France comme souverain sur ce pays et au palatin en vertu de sa supériorité territoriale. Il fut question de certains droits dans les villes de Seltz, d'Hagenbach et d'Altenstat ${ }^{67}$. L'électeur reprochait en particulier au roi de l'empêcher d'y déployer ses troupes et se plaignait de ce que Louis XIV tenait garnison dans Hagenbach et de ce qu'il levait des impôts et percevait des péages à Altenstat.

Au cours de cette négociation, où l'électeur, dépourvu du soutien de l'empereur, dut finalement reconnaitre les droits de la couronne de France, Louis XIV, soucieux de ce qu'on ne mît point en question sa souveraineté, demanda dans une lettre à Obrecht du 22 avril 1699 des éclaircissements sur les termes juridiques cruciaux »souveraineté« et »supériorité territoriale«. L'intérêt de cette affaire réside avant tout dans sa construction juridique spécifique: du point de vue du droit, le roi se considérait en effet comme successeur de l'empereur et de l'Empire, qui lui avaient cédé leur souveraineté sur les lieux en question. Le problème qui se posait était donc le suivant: quels droits l'empereur et l'Empire ont-ils dans les États territoriaux, et quels droits échoient au seigneur du territoire? Nul ne mettait en doute que cette question dût se résoudre selon le droit public allemand. À ce moment précis, les Français entendaient, par le terme "Empire«, la diète, qui était perçue comme l'émanation des états de l'Empire. La formule „l'empereur et l'Empire « signifiait donc, dans la vision française de la forme du gouvernement de l'Allemagne, "l'empereur et la diète d'Empire «. C'est le dualisme entre ces deux pouvoirs qui caractérisait effectivement la vie politique du Saint-Empire, avant et après 1648. Si les Français s'interrogeaient sur les droits de l'empereur et de la diète dans les territoires qui dépendaient de l'Empire, c'est qu'ils voyaient dans la Constitution de l'Empire la synthèse d'éléments monarchiques et d'éléments aristocratiques. Leur vision de l'Empire ne se réduisait donc ni à celle d'une confédération d'États indépendants, ni à celle d'une simple république aristocratique, comme le pensait Bodin. Pourtant, au XVIII e siècle, le rôle accordé à la diète devait notablement diminuer, dans la perception française du Saint-Empire.

65 LAGUille, Histoire de la province d'Alsace, édition in-folio, seconde partie, p. 298.

66 Ibid.

${ }^{67}$ Pour l'identification des noms de lieux et pour des informations plus précises sur les différents aspects juridiques, cf. notre commentaire du mémoire d'Obrecht (voir l'annexe). Au sujet des droits prétendus par Louis XIV dans les villes impériales situées en Alsace, cf. aussi l'»Addition au mémoire touchant les droits du Roy sur les villes impériales en Alsace«, 1696; copie: AE, MD Alsace 27 fol. 149-159'. Au sujet des prétentions des dix villes impériales qui constituaient la Décapole, cf. Information sommaire et historique, touchant les dix villes imperiales en Alsace, \& cela au regard de la préfecture provinciale d'Hagenau. [S.l.] Le 24. d'Août 1697; brochure imprimée. 
Obrecht, qui se trouvait alors à Francfort-sur-le-Main, répondit au roi le 5 mai 169968. Avant de trancher les problèmes particuliers dont on discutait à Francfort, il exposa la signification que les termes »souveraineté« et »supériorité territoriale« avaient en général dans le droit public de l'Empire. Obrecht explique que: »Généralement parlant la supériorité territoriale comprend tous les droicts appellez seigneuriaux en France, et en outre la pluspart de ceux de souveraineté, à l'exception de quelques-uns qui sont réservez à l'Empereur «69. Et d'ajouter que: »Le domaine suprême, ou la véritable souveraineté s'étend sur ces mêmes droicts, avec cette différence que le domaine suprême ou la souveraineté est indépendente, et que la supériorité territoriale luy est soumise et subordonnée dans l'exercice de tous les droicts qu'elle renferme « 70 .

Retenons que, premièrement, Obrecht considère les termes »souveraineté« et »domaine suprême « comme synonymes. Deuxièmement, il développe une doctrine selon laquelle les droits qu'on exerce en vertu de la supériorité territoriale et ceux qu'on exerce en vertu de la souveraineté sont grosso modo identiques. Il ajoute toutefois deux restrictions: premièrement, certains droits de souveraineté sont exclus du pouvoir d'un seigneur territorial et réservés à l'empereur. Obrecht ne précise cependant pas quels droits il entend être réservés à ce dernier; il n'aurait d'ailleurs pas été possible d'en dresser une liste exhaustive, l'empereur ayant toujours soigneusement évité d'accorder aux états la fixation d'un catalogue précis de ses »droits réservés « (iura reservata) qui eût limité son pouvoir. Deuxièmement, la supériorité territoriale n'est pas indépendante, c'est-à-dire qu'elle est soumise à la souveraineté. Il en résulte qu'il y a »un certain concours entre la souveraineté et entre la supériorité territoriale, qui fait que ce que les estats de l'Empire peuvent dans leurs territoires en vertu de ladite supériorité, l'Empereur et l'Empire le peuvent dans ces mêmes territoires en vertu de la souveraineté«. Pour illustrer cette concurrence entre les droits du seigneur territorial et les droits impériaux, Obrecht allègue un cas exemplaire concernant le ius belli ac pacis des ordres:

Par exemple [dit-il] un prince de l'Empire en vertu de la supériorité territoriale peut fortifier une place qui luy appartient, et y mettre garnison, mais ce pouvoir n'est pas indépendant; parce que l'Empereur et l'Empire peuvent luy faire deffense de continuer ces fortifications, ou en ordonner même la démolition, en cas qu'elles donnent de la jalousie aux voisins, qu'elles soyent préjudiciables au repos, ou à la seureté de l'Empire, ou qu'il y ait quelque autre raison d'Estat de ne les pas souffrir.

De plus, il note que:

68 Le mémoire a été publié chez LAGUILLE, Histoire de la province d'Alsace, édition in-folio, troisième partie, p. 175-178. Il est réédité dans l'annexe. Toutefois, comme les ouvrages renvoient en général à l'édition de Laguille, tout en respectant la teneur et l'orthographe de notre propre édition du texte, nous renvoyons aussi à ses citations afin de faciliter les comparaisons.

69 Ibid., p. 175.

70 Ibid. 
Ce même pouvoir [celui du seigneur du territoire] n'est pas sans concours, parce que, si on le trouve utile à l'Estat, la même place peut estre fortifiée et pourveue de guamison de l'autorité de l'Empereur et de l'Empire, sans que le prince à qui elle appartient y puisse former aucune opposition $^{71}$.

Le déploiement de troupes dans l'Empire est effectué, selon Obrecht, "par l'autorité souveraine de l'Empereur et de l'Empire« qui fait »chômer « la supériorité territoriale. Obrecht souligne, en outre, que les états de l'Empire ne jouissent de leurs privilèges et libertés que par droit féodal. Il en résulte que pour lever des impôts ou percevoir des péages dans ses possessions alsaciennes, l'électeur palatin devrait demander l'inféodation par le roi de France en tant que successeur de l'empereur, qui était suzerain des fiefs d'Empire, et demander son accord, puisque les nouveaux impôts étaient généralement discutés à la diète ${ }^{72}$.

Obrecht prouve d'ailleurs, en citant plusieurs cas récents, que »la supériorité territoriale [doit le] céder en tout à la souveraineté ou au domaine suprême « ${ }^{73}$. Si la vie constitutionnelle de l'Empire est marquée par un dualisme empereur/états, la qualité de véritable monarchie de la France fait que le roi réunit entre ses mains les droits qu'avaient exercés auparavant l'empereur et la diète; comme dit Obrecht, »Vostre Majesté [est] au droict de l'Empereur et de l'Empire, et par conséquent en celuy de la diète générale des estats $^{74}$.

Un mémoire sur l'organisation politique du Saint-Empire, qui date du règne de Charles VI (1711-1740), montre également que les Français connaissaient bien la différence entre la »souveraineté« et la »supériorité territoriale«:

On entend par le mot de supériorité territoriale dont les estats jouissent en Allemagne, la puissance d'exercer en leur propre nom la jurisdiction et ce qui en dépend dans toute l'étendue de leur territoire, de mesme que les autres droits de majesté, en tant que l'intérest de l'Empereur et de l'Empire ne s'y trouve point engagé. Cette limitation fait voir que ces estats quoy que ressemblans en tous aux parfaits souverains à cause de la conformité de leurs droits et privilèges, ne le sont pourtant que analogiquement estant sous la dépendance de l'Empereur et de l'Empire. Plusieurs des princes gouvernent leurs pays de leur pleine volonté; d'autres sont obligés dans les grandes affaires d'avoir le consentement des estats de leurs provinces qui ont plus ou moins d'autorités selon la diversité de leurs privilèges ${ }^{75}$.

71 Ibid.

72 Cf. ibid., p. 177 (citation) et 178.

${ }^{73}$ Ibid., p. 177. Dans une lettre datée de Strasbourg, le 4 octobre 1697, Obrecht traduit Landeshoheit par deux termes différents: »jurisdiction « et »supériorité territorielle [sic]«; original: bibliothèque de l'Arsenal, ms. 6613 fol. 203-206' (citations fol. 205).

74 LAGUILle, Histoire de la province d'Alsace, édition in-folio, troisième partie, p. 176.

${ }^{75}$ Et d'ajouter: "Cette supériorité des estats de l'Empire a pris son commencement après l'extinction des Empereurs carlovingiens; car les ducs, les comtes et autres gouverneurs, qui auparavant n'estoient que de simples officiers, gouvernants leurs départements au nom et sous l'autorité de l'Empereur, se mirent alors en liberté, s'emparèrent de leurs provinces, et obligèrent Conrad Ier duc de [Franconie] qu'ils avoient élu Roy de Germanie, de leur laisser les gouvernements en héritages, et de se contenter qu'ils luy en prêtassent hommage et fidélité «, cf. Archives nationales, M 861, première liasse (»Papiers du P. Echard. Mémoires politiques et philosophiques. Éléments de chronologie, de géographie, de physique, de géométrie; fragments divers. XVII $-X V I I I^{e}$ siècle $\left.\ll\right), \mathrm{n}^{\circ} 1$ fol. 35-114', ici fol. 83-84). Après 1765, sous le règne de Joseph II, la copie manuscrite d'une Histoire d'Allemagne précisait: »Les 
Si certains auteurs utilisaient le terme de "souveraineté « au lieu de celui de »supériorité territoriale«, ils ne confondaient pas toujours leurs significations respectives ${ }^{76}$.

\section{Digression: La signification du concept de "souveraineté« en France dans la deuxième moitié du XVIIe siècle}

Nous avons vu qu'Obrecht définit la supériorité territoriale comme une somme de droits, qui comprend à la fois les droits seigneuriaux tels que les définit le droit français et, à l'exclusion de quelques-uns d'entre eux, les »droits de souveraineté«, parmi lesquels il cite notamment, par la suite, le droit de guerre et de paix (ius pacis ac belli). Or, ce ne sont pas les droits eux-mêmes qui déterminent la condition juridique de leur détenteur, mais la source dont ils découlent. Autrement dit, la nature de ces droits dépend de leur origine, soit la supériorité territoriale, soit la souveraineté. Obrecht ne commet donc pas de faute définitionnelle quand il emploie l'expression »droits de souveraineté« en définissant la supériorité territoriale. Ce terme de »droits de souveraineté « sert seulement à délimiter le pouvoir des princes de l'Empire, sans en faire des souverains dans le sens moderne du mot. Car, bien entendu, ce pouvoir était pour Obrecht restreint, limité, puisqu'il dépendait de la souveraineté, qui, elle, est a priori illimitée. Ce n'est là, bien évidemment, que le principe tel qu'il apparaît dans l'expertise d'Obrecht et chez la plupart des publicistes allemands; en contrepartie, les juristes se sont souvent interrogés sur l'étendue réelle de ces restrictions, considérée comme très large par Obrecht ${ }^{77}$, et ont apporté des jugements différents à ce problème. Il reste que l'axiome même de la dépendance des états ne fut mis en question que très rarement par les publicistes allemands des XVII e et XVIII ${ }^{e}$ siècles. Il est aussi à noter que la jurisprudence allemande recourait de même fréquemment aux termes »summa potestas« et »summum imperium« lorsqu'il s'agissait de délimiter les compétences des princes ${ }^{78}$.

publicistes entendent par supériorité territoriale le pouvoir qu'ont les états de l'Empire d'exercer dans leur territoire les droits de souveraineté en tant qu'ils ne sont point limités par les Loix de l'Empire. [...] De cet article on peut tirer deux principes de droit public: $1^{\circ}$ ) que

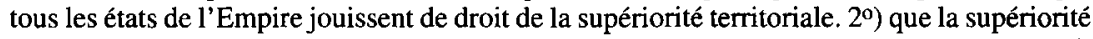
territoriale comprend tous les droits de souveraineté en tant qu'ils ne sont point limités soit par les loix de l'Empire soit par des conventions particulières «, cf. la version française du "Tableau de l'histoire d'Allemagne par Bürger. Tome $2^{2}{ } \ll$, copie non paginée: bibliothèque Mazarine, ms. 1874 (citation: livre V, chapitre II).

76 Pour certains traducteurs, c'était simplement une variante stylistique, cf., par exemple, la traduction française de l'»Abrégé du droit public moderne de l'Empire d'Allemagne « de Jean-Jacques Moser; BNF, F.fr. 12113; cette traduction date de 1740, ici p. 393: "L'Empereur doit aussi contraindre les sujets des états de l'Empire à demeurer dans l'obéissance qu'ils leurs doivent à cause de leur supériorité territoriale (ou souveraineté)«.

77 Il faut, dans ce contexte, prendre en considération le fait qu'Obrecht cherchait dans son mémoire à trouver des arguments en faveur de son souverain et non pas en faveur des états, tout en donnant cependant une image juste des données juridiques et des droits du palatin. 78 Cf. Helmut QuariTsCH, Souveränität. Entstehung und Entwicklung des Begriffs in Frank- 
Certes, prise au pied de la lettre, la formule »droits de souveraineté « renferme tous les droits d'un souverain, même chez Obrecht, et c'est pourquoi celui-ci en exclut expressément les droits réservés à l'empereur. Mais il n'y avait pas, en français, de terme plus commode pour désigner les droits de la Landeshoheit des princes allemands que »droits de souveraineté«; le terme de »supériorité territoriale« est presque toujours resté un mot étranger dans la langue française ${ }^{79}$, qui devait s'utiliser quand c'était indispensable, mais s'éviter partout où c'était possible.

Or, quel était le sens du mot »souveraineté« pour un Français du XVII ${ }^{\mathrm{e}}$ siècle? Les dictionnaires en donnent une idée très précise. En premier lieu, il convient de souligner que les dictionnaires généraux du XVII' siècle ne connaissent pas l'emploi du mot »supériorité« dans le sens de Landeshoheit, ni dans un autre sens juridique précis. Richelet définit la supériorité comme »avantage qu'on a par dessus les autres, qui est de commander, de diriger, et de gouverner « 80 . Or, ce n'est point le »gouvernement civil« que vise Richelet par cette définition, puisqu'il précise que le mot s'emploie surtout au sens religieux ${ }^{81}$. De même, le "Dictionnaire de 1'Académie « en donne la définition suivante: »prééminence, élevation, excellence au dessus des autres [...] Dignité de Superieurs dans un Couvent «82.

Le mot $\gg$ souveraineté $« 83$ est, du point de vue étymologique, très proche de $\gg$ supériorité«. Si ce dernier vient en effet du comparatif latin superior, le mot »souverain «, attesté en français depuis le milieu du $\mathrm{XI}^{\mathrm{e}}$ siècle ${ }^{84}$, est emprunté au bas latin * superanus, dérivé de super, ou à *supranus, de supra ${ }^{85}$. On en a formé le substantif "souveraineté« dès 1283 . Or, au XVIIe siècle, "souverain« et "souveraineté« couvraient un champ sémantique beaucoup plus large que leur >cousin ger-

reich und Deutschland vom 13. Jh. bis 1806, Berlin 1986 (Schriften zur Verfassungsgeschichte, 38), p. 79. Pour l'origine du concept de souveraineté au Moyen Âge, cf. également le livre très important de Francesco CALASSo, I glossatori e la teoria della sovranità. Studio di diritto comune pubblico, Milan ${ }^{3} 1957$.

79 Le terme »mot étranger« ne signifie pas forcément que le mot lui-même doit avoir été emprunté à une langue étrangère, mais peut aussi exprimer que son emploi dans un domaine précis est dû à l'influence d'une autre langue, par exemple le mot »supériorité« dans le sens juridique sous l'influence du latin. C'est dans ce sens qu'il faut entendre le terme »mot étranger « ici.

80 RICHELET, Dictionnaire françois, t. II, p. 409.

81 Ibid.

82 Le Dictionnaire de l'Académie françoise dedié au Roy, 2 vol., Paris 1694 (réimpression 1901), t. II, p. 516.

${ }^{83}$ Sur ses origines, cf. Jürgen DENNERT, Ursprung und Begriff der Souveränität, Stuttgart 1964 (Sozialwissenschaftliche Studien. Schriftenreihe des Seminars für Sozialwissenschaften der Universität Hamburg, 7), p. 8-55 (période avant Jean Bodin), p. 56-72 (apport de Bodin).

${ }^{84}$ Le mot »supériorité« est beaucoup plus jeune, puisqu'il date de 1409 (cf. Trésor de la langue française, t. 15, p. 836-837, pour »souverain« et »souveraineté«, ainsi que p. 1107 s.v. »supériorité «).

85 Pasquier voyait d'ailleurs en »superior « l'étymon de souverain (cf. Antoine FURETİ̀RE $(\dagger)$, Diction[n]aire universel [...], 3 vol., La Haye, Rotterdam 1690 [réédition 1978], t. III, s.v. "Souverain «). 
main<. »Souverain " pouvait s'appliquer et aux choses, et aux hommes, et à Dieu et exprimait seulement »le plus haut degré«. Ce mot n'était aucunement limité au domaine du droit tandis que son équivalent allemand l'est encore aujourd'hui largement. Comme substantif, »souverain« ne désignait pas seulement les rois et les princes, mais se disait aussi »des Juges qui ont pouvoir du Roy, ou du Prince, de terminer les procés de leurs sujets en dernier ressort « ${ }^{86}$. L'usage du mot était donc moins restreint qu'en allemand; tout au contraire, c'était un mot véritablement entré dans l'usage commun. Il en va de même, quoique dans une moindre mesure, pour »souveraineté «. Ce dernier signifiait: »Qualité et authorité du Prince souverain. [... L L'estat, l'estenduë du pays ou commande un Prince souverain «87.

Or, comment définissait-on »Prince souverain«? Furetière donne une définition très intéressante de »souverain «:

Souverain, à l'égard des hommes, se dit des Rois, des Princes qui n'ont personne au dessus d'eux qui leur commande, qui ne relevent que de Dieu et de leur épée. On le dit aussi de ceux qui ont des droits qui n'appartiennent qu'aux Souverains 88 ; de battre monnoye, d'envoyer leurs Agents aux Diettes pour traitter de guerre et de paix, comme les feudataires de l'Empire, les tributaires du Grand Seigneur ${ }^{89}$.

La dénomination "souverains" pour les seigneurs territoriaux de l'Empire est donc bien fondée sur l'usage du siècle. Même si l'on parlait des princes de l'Empire comme souverains, cela ne prouve nullement qu'on les confondait avec un roi de France ou un roi d'Espagne. Furetière distingue clairement les deux emplois du mot »souverain«; le »Dictionnaire de l'Académie« fait de même:

Souverain (s.m.). Prince indépendant, et qui ne releve d'aucune autre puissance [...]. On appelle aussi, Souverain, Les princes qui joüissent des droits regaliens, comme, de battre monnoye, donner grace, eriger des charges, faire la paix et la guerre, etc. quoy qu'ils relevent d'un autre Souverain, comme sont les Princes d'Allemagne, et autrefois en France les ducs de Normandie, de Guyenne, etc ${ }^{90}$.

Il est possible que l'ambivalence du mot »souverain« en français ait favorisé l'essor d'une vision bodinienne ou même indépendantiste du Saint-Empire en France; les dictionnaires parlent cependant un langage on ne peut plus clair. De toute façon, dans le français du XVII e siècle, le mot »souverain« et le terme »souveraineté « n'avaient pas toujours le sens unique que leur ont prêté certains historiens aux $\mathrm{XIX}^{\mathrm{e}}$ et $\mathrm{XX}^{\mathrm{e}}$ siècles, des deux côtés du Rhin, tant certains Allemands, qui pensaient que les Français n'avaient pas bien compris la Constitution du Saint-Empire, que les Français eux-mêmes, qui, à l'époque de gloire de l'Étatnation, voulaient parfois, à leur tour, voir dans tous les princes allemands de petits souverains. Cela dit, tous les auteurs qui parlent de »souveraineté« à l'égard des seigneurs territoriaux allemands n'ont certainement pas bien compris la Consti-

86 Ibid.

${ }^{87}$ Le Dictionnaire de l'Académie françoise (1694), t. II, p. 500.

$88 \mathrm{Ce}$ sont les fameux »droits de souveraineté« que nous avons déjà rencontrés à plusieurs reprises.

89 FURETIÈRE, Dictionnaire universelle, t. III, s.v. »Souverain «.

90 Le Dictionnaire de l'Académie françoise (1694), t. II, p. 500. 
tution du Saint-Empire. Mais la même constatation s'impose aussi face aux auteurs qui utilisent le terme de »supériorité territoriale «; c'est-à-dire qu'on ne peut pas juger de la bonne ou mauvaise compréhension de la Constitution de l'Empire sur la seule base de l'utilisation de l'un de ces deux mots pour traduire Landeshoheit.

D'ailleurs, on peut bien se demander si Obrecht était >Allemand ‘ ou >Français`. La »Nouvelle Biographie générale« en fait, peut-être à cause de ses mérites au service du roi, un Français, tandis que son père et son frère cadet passent pour Allemands. Quoi qu'il en soit, dans la négociation avec le palatin, la France faisait sienne la vision du Saint-Empire qui était développée par Obrecht. Le roi, en commandant l'expertise, avait explicitement demandé d'être renseigné sur les droits de l'empereur et de l'Empire. De plus, après avoir reçu ce mémoire, Louis XIV le communiqua à Chamoy, son résident auprès de la diète de Ratisbonne, afin qu'il le montrât aux princes allemands et légitimât de cette façon les prétentions françaises ${ }^{91}$. Il est donc incontestable que si l'on se demande qui était considéré comme le souverain de l'Empire à la cour de France, au moment des négociations franco-palatines de 169992, la réponse est la suivante: l'empereur et la communauté des états représentés à la diète ${ }^{93}$. En outre, il est évident que les questions juridiques qui se posaient au cours d'un tel différend avec un prince du Saint-Empire exigeaient que les négociateurs et les hommes d'État français se soumissent à une exactitude terminologique qui ne pouvait pas s'inspirer du vocabulaire flou utilisé par certains philosophes et théoriciens politiques. La terminologie développée à cet effet, sous l'influence (comme nous l'avons vu à plusieurs reprises) de publicistes alsaciens, était très proche des termes latins qui figuraient dans les traités de paix. À ce propos, il est intéressant de noter que les quelques phrases qu'Obrecht cite du traité d'Osnabrück (en particulier de l'article VIII paragraphes 1 et 2) semblent bien être tirées de la traduction de Heiss.

Qu'on ait publié l'expertise d'Obrecht, en 1727, prouve par ailleurs qu'on lui attribuait un intérêt général, et que certains milieux en France, confrontés aux questions pratiques de la politique et du droit, étaient bien conscients de la nécessité de bien définir les termes cruciaux du langage politique. Il est à noter que, encore en 1750, deux mémoires rédigés au ministère des Affaires étrangères considérèrent les explications fournies par Obrecht comme »les seuls [principes] qui puissent régler en pareille matière «94. Dans un mémoire intitulé $» D i s t i n c t i o n ~ d u$

91 Cf. Lagullle, Histoire de la province d'Alsace, édition in-folio, seconde partie, p. 301. 92 Pour le problème en général, cf. la synthèse de MALETTKE, La conception de la souveraineté; ID., La perception de la »supériorité territoriale«.

93 Cependant, au sujet de la condition juridique des membres de l'Empire, il faut souligner que les collaborateurs du dépôt des archives s'intéressaient non seulement aux états de l'Empire représentés à la diète de Ratisbonne, mais aussi à la noblesse immédiate de l'Empire, cf., par exemple, le volume AE, MD All. 98, qui contient des mémoires divers sur la noblesse immédiate rédigés entre 1749 et 1753 , surtout en 1752.

94 »Avis sur le mémoire de monsieur de Vanolles du 27 may 1750, au sujet des limites de 
droit de domaine suprême et du droit de supériorité territoriale «95, daté $» 1741 \ll^{96}$, l'on a aussi inséré des dépêches d'Obrecht à ce sujet.

En 1760, Nicolas-Louis Le Dran définit la »supériorité territoriale«; »Selon les jurisconsultes d'Allemagne, la supériorité territoriale est le pouvoir et la jurisdiction que les princes, les comtes et les états de l'Empire exercent dans l'étendue du pays qui leur est soumis. Cette puissance n'est pas une véritable souveraineté« «77. Dans son mémoire, Le Dran cite la lettre d'Obrecht du 5 mai 169998. C'est-à-dire que l'interprétation qu'Obrecht fait du droit public germanique passe, dans ce domaine, pour celle qui fait foi.

L'importance qui revient à Obrecht et l'influence qu'il exerça sur la vision française du Saint-Empire vers 1700 sont encore attestées par des extraits de sa correspondance, qu'on a recopiés et conservés au dépôt des archives des Affaires étrangères ${ }^{99}$. Â l'époque de la paix de Ryswick, le public européen était déjà in-

l'Alsace«, par Le Dran; copie: AE, MD Alsace 8 fol. 298-299' (citation fol. 299); »Précis d'un grand mémoire pour prouver que les limites d'Alsace s'étendent jusqu'à la Queich et que le Roi a sur la totalité de la province le suprême domaine ou la souveraineté absolue«, 27 mai 1750, note marginale: »Observations de monsieur Bischoff«, autre note: „Ce mémoire a été envoyé à monsieur de Puysieulx par monsieur de Vanolles, intendant d'Alsace, le 27 may 1750 «; copie: ibid., fol. 283-297', ici fol. 291' (cf. aussi les citations d'Obrecht dans les »Remarques et observations sur la troisième proposition relative à la cession de l'Alsace faite au Roy par le traité de Munster en pleine et absolue souveraineté et sans aucune exception« [AE, MD Alsace 4 fol. 87-100] et dans les »Observations sur la lettre de monsieur de Vanolles du 27 may 1750« [ibid., fol. 141-143]); Barthélemy de Vanolles (Nantes 1684 Paris 1770) fut intendant d'Alsace de 1744 à 1750, puis conseiller d'État à partir du 21 juillet 1750, Georges LIVET, article »Vanolles, Barthélemy de«, dans: NDBA, t. 38 (2002), p. 3972-3973. Pour les contestations entre la France et les princes de l'Empire possédant des terres en Alsace, dans la première moitié du XVIII siècle, cf. également les mémoires contenus dans les volumes AE, MD Alsace 11 et 12 .

95 AE, MD All. 12 fol. 162, 163-183, note: »Allemagne. 1741 «; ce mémoire est fondé sur les lettres d'Obrecht de 1699 et de 1700.

96 La datation et le titre (ibid., fol. 162) ne sont pas de la même main que la copie (ibid., fol. 163-183).

97 Mémoire intitulé »Sur l'étendue des droits régaliens ou de supériorité territoriale dont peuvent ou doivent jouir en Alsace, sous la souveraineté du Roy, les seigneurs possesseurs de fiefs immédiats situez dans cette province«, et rédigé par N.-L. Le Dran, le 30 septembre 1760 (AE, MD Alsace 13 fol. 285-355). Les droits régaliens ne se confondent pas avec la »régale «. En effet, en droit français, la régale était »ung droict que le Roy a sur les éveschez vacquantes«, cf. bibliothèque de la Sorbonne, ms. 933, fol. 321'-323, ici fol. 321 '.

98 Cf. AE, MD Alsace 13 fol. 309.

99 Il y a plusieurs compilations d'extraits de la correspondance d'Obrecht: $1^{\circ} \mathrm{AE}, \mathrm{MD}$ All. 12 fol. 103-111: „Extrait de quelques dépêches de monsieur Obrecht «, du 9 juillet 1698 jusqu'au 21 mars 1699; les extraits concernent de nombreuses affaires politiques et juridiques, entre autres la liberté de la navigation sur le Rhin, les moyens proposés pour établir la souveraineté du roi de France sur certains bailliages en Alsace appartenant à l'électeur palatin, et ceux qu'Obrecht recommande pour établir la souveraineté du roi sur l'Alsace en général, l'origine des électeurs du Saint-Empire (ce dernier extrait est tiré des mémoires qu'Obrecht avait envoyés de Francfort à Paris, en janvier 1699 , au sujet de la création du neuvième électorat), etc.; $2^{\circ}$ ibid., fol. 112,113-128': »Extrait de quelques dépêches de monsieur Obrecht, 1700 «, du 4 mai 1700 jusqu' au 20 juillet 1701 ; ces lettres concernent elles aussi de nombreuses questions politiques et juridiques, notamment les moyens qu'Obrecht propose pour amé- 
formé du rôle extraordinaire qu'Obrecht jouait comme conseiller juridique du roi de France. Dans les »Actes de la paix de Ryswick « fut publiée l'une de ses dissertations sur la souveraineté française en Alsace, tirée de son ouvrage »Prodromus rerum alsaticarum« de $1681^{100}$.

\section{Les réflexions de la diplomatie française sur une méthode pour étudier le droit public d'Allemagne (1729)}

Quel usage les commis et les diplomates faisaient-ils à l'époque étudiée des livres et des manuscrits sur le Saint-Empire? Au ministère même, on voulait établir une véritable méthodologie pour l'apprentissage de son droit public. En effet, en 1729 , le ministre des Affaires étrangères ordonna »de faire en françois un mémoire sur la méthode qu'on pourroit suivre pour apprendre le droit public d'Allemagne par les grands principes et les grandes maximes les appliquant aux décisions qui en différens tems ont été faites dans les grandes matières « ${ }^{101}$. Il s'agit donc d'un mémoire commandé non pas pour obtenir des renseignements devant servir dans une occasion précise mais pour se faire une idée générale du droit public allemand, de ses »grands principes « et "grandes maximes «102. À ce momentlà, le »ministre « plénipotentiaire Anne-Théodore de Chavigny fut le représentant

liorer les relations entre la France et les états de l'Empire, ou la création du neuvième électorat, pour lequel, selon Obrecht, la participation des trois collèges était nécessaire, l'empereur et les électeurs ne pouvant pas en décider seuls; elles concernent également la succession d'Espagne, etc.

$100 \mathrm{Cf}$. les Actes et mémoires des négociations de la paix de Ryswick (édition de 1725, réimprimée en 1974), t. II, p. 413-428: "Decision De Monsieur Ulrich Obrecht Prevôt Royal de la Ville de Strasbourg sur la question par laquelle on demande sur quelles parties de l'Alsace la France a droit en vertu de la Paix de Westphalie; Et si ces parties comprennent l'Alsace entiére«, document publié à La Haye, $1^{\text {er }}$ août 1697, traduit du latin. Dans les »Actes de Ryswick «, on trouve plusieurs documents concernant le même sujet, cf. ibid., p. 428-436, 501516 et 516-525.

101 »Dissertation par raport à une méthode sur le droit public d'Allemagne«; copie: AE, MD All. 67 fol. 10-35; le titre ainsi que la datation " 1729 décembre 31 « et la mention »<A>llemagne, diette de l'Empire « ont été ajoutés d'une autre main (fol. 10). Ce document n'est pas unique. En effet, la bibliothèque nationale universitaire de Strasbourg possède un mémoire intitulé »Raisonnement sur l'étude du droit public d'Allemagne et sur la connoissance fondamentale de l'état de l'Empire (ms. 564), rédigé cinq ans après la publication du livre "Syntagma iuris publici« de Burkhard Gotthelf Struve (première édition léna 1711, deuxième édition 1720 et troisième édition 1738); cf. STOLLEIS, Geschichte des Öffentlichen Rechts, p. 308. L'auteur de ce mémoire commente les ouvrages et les sources du droit public allemand. Il se fait une image très positive de l'Empire, et insiste sur le caractère spécifique de sa Constitution: "L'on voit par tout ce qui vient d'être dit généralement de l'État d'Allemagne, qu'il n'y a pas son pareil au monde par rapport au grand nombre des Roys, électeurs, princes et états de l'Empire, qui le constituent et c'est pour cela aussi que le droit public d'Allemagne surpasse tous les autres droits publics (car chaque république a le sien à part) par la quantité et sublimité des matières« (citation fol. 21').

102 Voir la citation ci-dessus. 
français auprès de la diète (de 1726 à 1731) ${ }^{103}$. Mais il n'est pas sûr que le ministre des Affaires étrangères se soit adressé au résident français auprès de la diète de Ratisbonne ${ }^{104}$.

Les difficultés de l'auteur de définir une méthode pour apprendre le droit public allemand sont liées à deux problèmes fondamentaux: un problème de perception et un problème intrinsèque du droit public de l'Empire. Au sujet du premier problème, il explique, à juste titre, que les »idées ordinaires qu'on se forme en France du droit public ne conviennent pas toujours à sa nature et [que] les plus habiles dans la connoissance de ce droit n'ont jamais pu s'en faire un sistème assez asseuré pour pouvoir y rapporter les causes de toutes les négociations publiques, des loix fondamentales, ny des décisions suprêmes « ${ }^{105}$. Cette incertitude est la conséquence d'un deuxième problème, qui touche à la nature même du droit public de l'Empire, c'est-à-dire son extrême complexité, qui se reflète dans son histoire ${ }^{106}$. En effet, les différentes traditions du droit public de l'Empire et ses nombreuses particularités échappaient à la rigidité des principes du droit naturel et du droit international tels qu'ils furent définis surtout à partir du XVIIe siècle, ainsi qu'à celle du droit romain. Selon cet auteur, l'étude du droit naturel et celle du droit international doivent précéder celle du droit public allemand; il recommande la lecture de Samuel Pufendorf et de Hugo Grotius dans le cadre de cette étude préliminaire ${ }^{107}$. Cet apprentissage du droit naturel et du droit international, fondé sur les deux autorités unanimement reconnues de Pufendorf et de Grotius, doit être suivi de l'étude de la science politique en général: en cette matière, Lipsius et Boecler servent d'auteurs de référence ${ }^{108}$. Après la politique, l'on est invité à étudier l'histoire ainsi que la géographie et la généalogie ${ }^{109}$. Non seulement l'histoire d'Allemagne, mais aussi l'histoire universelle sont à apprendre avant d'aborder l'étude du droit public; c'est avec l'histoire universelle que l'on doit commencer $^{110}$, suivie de l'histoire générale d'Allemagne depuis l'époque mérovin-

103 Cf. Auerbach (éd.), Recueil des instructions, t. XVIII: Diète germanique, p. 115-178 (p. 120-121 pour le titre de $»$ ministre $\ll$ ).

104 En effet, l'identité de l'auteur du document est incertaine. Mais on peut supposer qu'il se trouvait auprès de la délégation française à Ratisbonne ou qu'il travaillait pour celle-ci.

105 AE, MD All. 67 fol. 10-10'.

106 "L'histoire de l'origine, du progrès et de l'état présent de l'Empire d'Allemag<ne> fournit une infinité d'événemens qui justifient que le droit public n'est peu<t>-être fixé à aucun principe stable et permanent tiré des règles du droit naturel et des gens«, ibid., fol. 10'.

107 Cf. ibid., fol. 30’ : "Le droit de nature et des gens doit en être le préliminaire, le petit traité de Puffendorf de l'office de l'homme et du citoyen pourra donner les premier<s> principes de cette science, ensuitte on y joindra la lecture de Grotius et du grand ouvrage du même Puffendorf «.

108 Cf. AE, MD All. 67 fol. 30': »Après cette préparation [l'étude du ius gentium et du ius naturae] on s'appliqu<era> à la politique de Lipsius qui est abrég<ée> et puis à celle de Boeclerus qui est plus ample et plus étendue«.

109 Nous avons déjà souligné que la généalogie était un élément fondamental de l'histoire et du droit de l'Ancien Régime, de sorte que les traités historiques et juridiques accordaient en général une place de prédilection aux problèmes généalogiques.

$110 \mathrm{Cf}$. AE, MD All. 67 fol. $30^{\prime}-31$. 
gienne 111 , et enfin de l'histoire des principaux princes et territoires du Saint-Empire. L'étude de l'histoire des princes et des territoires comprend aussi les problèmes héraldiques et géographiques ${ }^{112}$. Elle doit conduire à une première approche du système constitutionnel et du droit public du Saint-Empire ${ }^{113}$; sa connaissance doit, ensuite, être perfectionnée ${ }^{114}$.

Trop vaste pour un diplomate qui doit s'informer rapidement du droit public du Saint-Empire, ce programme est, de toute évidence, conçu pour la formation de spécialistes servant le roi de France à Paris ou en Allemagne. Autant que nous sachions, une telle formation n'a pas été assurée depuis l'académie de Torcy jusqu'à la création de l'école diplomatique de Strasbourg. Mais le fait qu'on y ait réfléchi dans les cercles diplomatiques français témoigne de la prise de conscience que l'on avait de son caractère indispensable au cours de la première moitié du XVIII siècle. Le programme proposé est, en effet, exhaustif. Selon ce mémoire, l'étude du droit public d'Allemagne était censée être complétée par le droit féodal - qui devait être étudié en même temps que le droit public, avec la condition juridique des territoires de l'Empire ${ }^{115}$ - et par le droit lombard ${ }^{116}$. Fort de ces connaissances théoriques et historiques, l'élève pouvait passer à l'étude de la pratique. Enfin, cet auteur propose de perfectionner la formation des spécialistes du droit public d'Allemagne en étudiant les documents concernant les relations diplomatiques avec le Saint-Empire. Leur lecture n'est pas envisagée comme dernière étape de l'apprentissage des futurs diplomates; ils devaient être étudiés en même temps que le droit public, afin de conjuguer la théorie et la pratique ${ }^{117}$. On note que, dans la tradition pufendorfienne, cet auteur qualifie la Constitution du Saint-Empire d'irrégulière.

111 Cf. ibid., fol. 31: »Avec ces dispositions, on viendra à l'histoire générale de l'Empire d'Allemagne, on s'attachera d'abord à y distinguer quel a été son état avant Charlesmagne, quel est celuy que cet Empereur luy a donné et les différens changemens qui y sont survenus successivement sous les autres Empereurs«.

112 Cf. ibid., fol. 31'.

113 Cf. ibid., fol. 31-31': "Par cette application à l'histoire d'Allemagne, les principes du droit public se représenteront aisément et cela conduira avec facilité à se former un sistème de ce droit, surtou $<$ t>si l'on est déjà imbu des préceptes du droit de nature et des gens et des règles de la politiques [sic]«.

114 Ce mémoire insiste en particulier sur l'importance de l'histoire, cf. ibid., fol. 31': "L'étude de l'histoire ne peut être trop recommandé, c'est la moitié du chemin du droit public«.

$115 \mathrm{Cf}$. ibid., fol. 33: »Ce ne sera pourtant pas le tout; le droit féodal ne laisse pas d'avoir plusieurs connexités avec le droit publiq, et il faut s'en instruire vers le milieu du cours de celuy. cy, ou quand on en sera aux états et à leurs territoires en général «.

116 Le droit féodal lombard était, en effet, appliqué dans certaines régions du Saint-Empire; cependant, les régions allemandes avaient leur droit féodal particulier, ce qui compliquait le droit féodal de l'Empire. Cf. ibid., fol. 33-33'.

117 Cf. ibid., fol. 34-34': »Mais pour arriver encore à un plus haut degré des connoissances et d'habileté, il faut outre tout cela, la lecture des négotiations et des mémoires qui ont été dressés à leur sujet. Il ne faudra pas même attendre si longtems à les parcouri<r $>$. Il ne peut être que d'une très grande utilité de la faire de bonne heure affin que la théorie et la pratique s'apprennent en même tems«. 
Le contexte et le mobile de la démarche ne sont pas évoqués dans ce mémoire. La deuxième partie évoque clairement le projet d'un cours pour former des spécialistes du droit public allemand, mais il n'est pas sûr que cela corresponde à la demande du ministre. En effet, on peut supposer que cette demande ait visé la préparation de certains diplomates ou de collaborateurs du dépôt des archives à des missions ou à des tâches particulières concernant les négociations avec l'Allemagne, sans que le ministre ait envisagé d'instaurer un véritable cursus de formation.

\section{Jean Heiss et la connaissance des clauses constitutionnelles des traités de Westphalie en France}

Au chapitre précédent, nous avons souligné qu'au début des années 1680 la France attendait encore qu'on lui donnât »le premier résumé lucide de l'histoire si embrouillée de l'Empire «118, tâche dont put finalement s'acquitter avec dignité Johann (ou Jean, comme on l'appelait en France) Heiss. Né à Clèves, en Allemagne, dans la première moitié du XVIIe siècle, Jean Heiss, plus tard fait seigneur de Kogenheim, était diplomate et historien; en tant que tel, il fut bien accueilli en France, mis au service de la couronne, et naturalisé Français ${ }^{119}$. Il ne représenta pas seulement, à Paris, divers princes allemands, dont le duc de Wurtemberg, ou, pendant plusieurs années, en tant que résident, l'électeur palatin à la cour de France, mais se vit confier également des missions diplomatiques dans l'Empire au nom de Louis XIV ${ }^{120}$. Ainsi fut-il "chargé d'entamer avec le cardinal de Furstenberg la négociation qui eut pour résultat de l'attacher à la cause de la France «121. Il fut aussi nommé intendant de l'armée française en Allemagne, grâce au soutien de Louvois. Heiss mourut à Paris en 1688.

Étant donné que nous nous intéressons surtout à Heiss comme historien du droit public germanique, nous évoquerons seulement un exemple de sa double carrière de diplomate, au service de la France et des princes de l'Empire. Nous avons étudié son rôle comme représentant des intérêts du duc de Wurtemberg à Paris, un poste que Heiss obtint en $1673^{122}$. Tenant compte du crédit que Heiss

118 C'est, selon un article biographique du milieu du XIX'e siècle, le grand mérite de Heiss de l'avoir donné à la France, cf. Nouvelle Biographie générale, t. 23 (1861), col. 804-805.

119 Ses lettres de naturalisation, qui datent du mois de décembre 1643, se trouvent aux Archives nationales, $\mathrm{K} 173 \mathrm{n}^{\circ} 67$.

120 Les instructions qu'il reçut ont été publiées dans: Georges LiveT (éd.), Recueil des instructions, vol. XXVIII: États allemands, t. I: L'électorat de Mayence, Paris 1962, p. 47-53; t. III: L'électorat de Trèves, Paris 1966, p. 91-97. Livet attribue l'»Histoire de l'Empire« au fils de Jean Heiss, qui s'appelle également Jean, sans apporter de preuve, ibid., t. I, p. 48, n. 1.

121 Selon les articles biographiques de la Nouvelle Biographie générale et de la Biographie universelle (voir ci-dessus).

122 D'abord comme correspondant, à la recommandation du comte palatin Christian [Palatinat-Bischweiler], en remplacement de Pawel von Rammingen. Heiss fut de 1673 au moins jusqu'en 1688 au service du duc de Wurtemberg; dans les actes, il est qualifié de correspon- 
avait à la cour, le duc le chargea de l'informer des actualités politiques de Paris et voulut lui confier également des négociations diplomatiques ${ }^{123}$. À travers les lettres que Heiss envoya à Stuttgart, nous apprenons qu'il avait des entretiens avec Louvois, Pomponne ${ }^{124}$ et Colbert de Croissy ${ }^{125}$, au cours desquels il leur parlait des intérêts de Wurtemberg. Cependant, à côté de son rôle politique, qui était somme toute assez modeste, Heiss devait aussi s'acquitter de tâches quotidiennes encore plus modestes; comme la plupart des agents ou des résidents aux XVIIe et XVIIIe siècles, il était chargé d'acheter ou de faire fabriquer des produits de luxe pour son maître (en l'occurrence, un carrosse), et de lui transmettre un cadeau du roi de France. La plupart des informations que Heiss transmettait à Manteuffel concernaient des affaires militaires et politiques et des nouvelles de la cour; au moins occasionnellement, il lui envoyait aussi la »Gazette «126. Sa dernière lettre date du 25 septembre $1688^{127}$. Forstner l'estimait beaucoup: »Je vous assure que monsieur le résident Heiss [...] est fort porté pour le service de S.A.S.; je le trouve très honneste homme et bien rompu dans les affaires «128.

dant, d'agent ou (vers la fin de sa vie) de résident; cf. la liasse Stuttgart, Hauptstaatsarchiv, Geheimer Rat I, A 202, Büschel 1188, qui contient un dossier de 41 feuillets portant le titre moderne $» D i e$ Annahme des Residenten Heiss zu Paris als württembergischer Korrespondent 1673 und Berichte von ihm mit Konzepten der Erwiderungen 1673-1688«, en particulier la lettre de recommandation envoyée par Christian [au duc de Wurtemberg], Rappoltsweiler, 10/20 août 1673 , présentée le 14[/24] août, original, fol. 2-1' [liasse numérotée à l'envers]: »recommendirt an statt des verstorbenen Chur Pfältzischen Residenten Monsieur Paveln, einen Teutschen, Nahmens Heiss, zu Füehrung [sic] der Correspondentz «.

123 Cf. ibid., fol. 6-6', Manteuffel, ministre d'État du duc de Wurtemberg, »an Herrn Heiß zu Paris« (selon une note, fol. 5'), Stuttgart, 15/25 août 1673, minute: »Je n'ay pas manqué de faire très humble rapport à Monseigneur mon Maître, à mon retour, des bonnes offres que vous avez fait de vostre correspondence, et du zèle très sincère que vous avez témoigné pour son service. Son Altesse Sérénissime Monseigneur l'a appris avec joye; et est bien informée de vostre crédit à la cour, et de vostre vigilance. C'est pourquoy il m'a commandé de vous asseurer, Monsieur, de son amitié, et de vous protester que vostre correspondence luy sera très agréable; et qu'il se promet que vous l'advertirez de ce qui se passe; principalement de ce qui le touche; et qui peut concerner ses Estats: mesme que vous négocierez soigneusement ce qu'il trouvera de ses intérests. Monseigneur vous en tesmoignera la même recognoissance qu'il a fait à feu monsieur Paul de Remminghen, qui a esté par an de cent escus. Je ne manqueray pas, Monsieur, de vous écrire, si tost que je seray à Strasbourg, et vous supplie de commencer, s'il vous plaît, vostre correspondence, le plutost qu'il se le [sic] pourra et de nous advertir de ce qui se passe, principalement de la marche et descente des trouppes royales, et leur passage, afin que nous puissions icy prendre nos mesures dessus et guarentir le pays«.

$124 \mathrm{Cf}$. Heiss à Manteuffel, Nancy, 17 septembre 1673, présentée le 15 octobre, original: ibid., fol. 16-16', 12; copie: ibid., fol. 15-14; copie partielle: ibid., fol. 13.

125 Cf. Heiss à [Manteuffel], Paris, 20 avril 1680, original: ibid., fol. 30-30'; Heiss au [duc de Wurtemberg], Paris, 13 février 1682, original: ibid., fol. 34-33.

126 Cf. Heiss à [Manteuffel?], Paris, 18 septembre 1688, original: ibid., fol. 39-39'.

127 Cf. Heiss à [Manteuffel?], Paris, 25 septembre 1688, original: ibid., fol. 41-40. Heiss signe »Heiss « jusqu'au 10 avril 1688, mais »de Heiss « à partir du 28 août 1688; cf. ses lettres à [Manteuffel?], Paris, 10 avril et 28 août 1688, originaux: ibid., fol. 36-35' et fol. 38-38'.

128 Cf. ibid., Büschel 1889, le dossier intitulé »Akten betr. die Philippsburger Kontributionen und Bemühungen zu ihrer Ermässigung. 1675-1680«, lettre de Fr. Chr. Forstner à Man- 
Mais, en France, Heiss (de même qu'Obrecht) servait également le secrétaire d'État à la Guerre, auquel il transmettait des informations politiques et militaires en provenance d'Allemagne, en particulier de Cologne ${ }^{129}$. De toute évidence, son fils prit son relais comme informateur du secrétaire d'État à la Guerre ${ }^{130}$. Ce fils était également un intermédiaire qui proposait au ministre les services de ses anciens compatriotes ${ }^{131}$, et lui transmettait des messages de la part des princes de l'Empire ${ }^{132}$.

L'»Histoire de l'Empire « de Jean Heiss parut pour la première fois dans la capitale, en $1684^{133}$. Heiss a profondément imprégné, à travers ses neuf éditions françaises, non seulement la vision française du Saint-Empire, mais aussi, par ses traductions anglaises ${ }^{134}$, la pensée des juristes anglais. Ce n'est que vers la fin des années 1730 que son ouvrage fondamental perd de son importance et qu'on lui fait une critique anachronique. La vision que Heiss développe du Saint-Empire dans son »Histoire de l'Empire « est très répandue dans l'Allemagne de son temps. Il voit en fait dans l'Empire, tout comme Du May, un État à constitution mixte, où les éléments monarchiques prévalent.

Heiss soutient »que le gouvernement de l'Empire tient du Monarchique et de

teuffel, Paris, 15/25 janvier 1676, fol. 53-52, citation fol. 53'-52. Ce dossier contient d'autres lettres relatives à Heiss et à sa collaboration avec Forstner (audience chez Pomponne, etc.); cf. également ibid., le dossier intitulé "Akten betr. die französischen Kontributionen für St. Georgen und Hornberg und Verhandlungen um ihre Ermässigung. 1676/77《.

129 Cf., par exemple, SHD, AAT, A1.259 (1671), no 43 (Heiss au ministre, Paris, 9 août 1671, original, nouvelles de son correspondant de Cologne sur la levée de troupes par l'empereur, etc.), no 53 (Heiss au ministre, Paris, 16 août 1671, original, dispute entre l'archevêque de Cologne et la ville, etc.), no 100 (Heiss au ministre, Paris, 23 août 1671, original, même sujet, nouvelles militaires de Mayence et de Coblence), $\mathrm{n}^{\circ} 240$ (Heiss au ministre, Paris, 13 septembre 1671, original, dispute entre l'archevêque de Cologne et la ville, nouvelles militaires, navigation sur le Rhin), $\mathrm{n}^{\circ} 334$ (Heiss au ministre, Paris, 27 septembre 1671, original, nouvelles politiques et militaires diverses).

$130 \mathrm{Cf}$. ibid., Al.1501, nos 69, 71 et 140: lettres signées »de Heiss de Koguenheim« envoyées

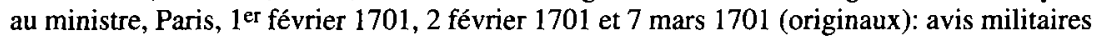
et politiques d'Allemagne, en particulier de la diète de Ratisbonne.

131 En 1701, il recommanda au secrétaire d'État à la Guerre un spécialiste de Bonn capable d'inventer et de construire des »machines en bois «, cf. Heiss au ministre, Paris, 19 février 1701, original: ibid., A1.1524 (1701), no 136.

$132 \mathrm{Au}$ moins de la part de l'électeur de Trèves. Cf. ibid., A1.2244 (1710), no 76: baron d'Heiss au ministre, Melun, 14 septembre 1710, original.

133 HeIss, Histoire de l'Empire, première édition en 1684; rééditée en 1685, 1694, 1711, 1715,1731 (éditions in- $8^{\circ}$ et in-40) et 1733 (éditions in- $8^{\circ}$ et in-40). Les éditions du XVIII' siècle ont été considérablement augmentées et continuées par $\mathrm{H}$. Bourgeois de Chastenet et le grand juge des gardes suisses, Vogel; cf. aussi Braun, Traductions, p. 137-138 et n. 30 . 134 Sur ces éditions anglaises (au moins trois éditions, parues entre 1727 et 1731), cf. aussi National Union Catalog (Pre-1956 Imprints). A cumulative author list representing Library of Congress printed cards and titles reported by other American Libraries. Compiled and edited with the cooperation of the Library of Congress and the National Union Catalog Subcommittee and of the Resources Committee of the Resources and Technical Services Division, American Library Association, Washington (DC) et al. à partir de 1970, ici t. 239 (1972), p. 191. 
l'Aristocratique «135, et accorde au fond plus de poids aux éléments monarchiques. Selon lui, l'empereur est »souverain Monarque « dans l'Empire ${ }^{136}$. Heiss dresse une liste impressionnante des droits de l'empereur. Leur division est devenue classique: Heiss distingue iura reservata et iura comitialia, sans utiliser ces deux termes. Il inventorie les droits appartenant à la première catégorie dans un paragraphe intitulé »Ce que l'Empereur peut faire de son chef«. La deuxième catégorie est subdivisée en »Ce que l'Empereur fait avec la participation des Princes Electeurs « et 》Ce que l'Empereur fait avec la participation de tous les Etats de l'Empire» ${ }^{137}$. La deuxième liste, regroupant les droits exercés conjointement par l'empereur et les électeurs, est de loin la plus courte, ce qui est une conséquence des traités de Westphalie, qui avaient rendu obligatoire l'accord des états de l'Empire dans presque toutes les affaires d'intérêt général. Toutefois, à certains égards, cette liste tient encore compte des réalités constitutionnelles ayant existé avant la paix de 1648. Heiss parle bien de "souveraineté« à propos des électeurs et des princes de l'Empire en général, mais il précise qu'ils ne sont que des "Souverains dépendans«, puisqu'ils dépendent de l'Empire, de sa juridiction, et que leurs droits sont »bornez«, comme dit Heiss, c'est-à-dire limités »par les concessions qui leur ont été faites, et par des constitutions qui sont intervenües sur ce sujet«138. Les droits ne découlent donc pas de leur propre autorité, mais de la concession d'autrui.

En décrivant la condition juridique des princes, Heiss utilise le terme »droits de Supériorité« dans le même sens qu'il emploie celui de »droits de Souveraineté« à leur égard. Selon lui, les états immédiats de l'Empire exercent »les grans droits de Jurisdiction, et autres droits regaliens, dont ils sont en possession « en vertu de leur "Superiorité provinciale «, concept par lequel Heiss désigne ce que l'on appelait généralement la "supériorité territoriale«. Il est à noter qu'il désigne aussi les droits des princes par »superioritez « au pluriel ou par "[suprême] jurisdiction Provinciale «139. D'une manière générale, Heiss décrit correctement la condition juridique des états de l'Empire, l'autonomie relative dont ils jouissaient dans l'administration interne de leurs territoires, leur participation à la législation et leur représentation au niveau du droit international. Toutefois, sa définition de l'Empire comme status mixtus avait déjà été réfutée par certains auteurs dans l'Empire, surtout par Pufendorf, qui avait constaté qu'Aristote ne pouvait pas fournir la clé pour comprendre la Constitution du Saint-Empire. Par contre, Heiss cherche encore dans sa théorie des formes de gouvernement des éléments propres à définir le status Imperii. Mais il est vrai que, à cette époque, de nombreux auteurs allemands propageaient encore cette même théorie du status mixtus.

Nos études nous ont permis d'évaluer l'influence primordiale que ce singulier personnage exerça sur la vision que ses contemporains se faisaient de l'Empire.

135 HeIss, Histoire de l'Empire, deuxième édition (1685), t. II, p. 14.

136 Ibid., p. 12.

137 Ibid., p. 25, 29-30.

138 Ibid., p. 61.

139 Citations ibid., p. 85-87. 
Bien que celle-ci ne soit jamais uniforme, Heiss est l'auteur le plus proche des sentiments d'une assez grande partie des auteurs français du temps de Louis XIV jusqu'aux années 1730 . Toutefois, une minorité d'auteurs le contredit franchement. De toute façon, tous les auteurs postérieurs se sentent obligés de donner leur avis sur ses travaux. C'est ainsi, d'une manière positive ou bien négative, l'esprit de toute une époque, au regard du sujet »l'Allemagne vue par les Français«, qui est présent dans cet ouvrage. Il n'est donc pas étonnant que, abstraction faite de deux éditions françaises de l'auteur le plus éloigné de Heiss, Chemnitz, en $1712^{140}$ et en $1720^{141}$, et des rééditions des ouvrages déjà cités, aucun auteur ne se hasardât plus à entreprendre une nouvelle "Histoire de l'Empire «, jusqu'à ce que, au début des années 1740, les remaniements de l'œuvre de Heiss ne suffissent plus pour combler le retard que ce livre avait pris sur les évolutions de l'Empire. Cependant, Vayrac, en même temps grammairien et théoricien de l'État, avait déjà publié, en 1711, une critique minutieuse de l'ouvrage de Heiss ${ }^{142}$, sans pouvoir toutefois remettre en cause le succès de cet auteur. Il faut aussi souligner la critique avancée par les rééditeurs mêmes de l'»Histoire de l'Empire«, Bourgeois du Chastenet et Vogel. En effet, au lieu d'adhérer aux positions de Heiss, ceux-ci le contredisent souvent dans leurs commentaires glissés dans les notes de bas de page qu'ils ont ajoutées à l'»Histoire de l'Empire«.

\section{Le »siècle de Heiss « se prolonge jusqu'à la fin des années 1730: les rééditions du XVIII ${ }^{e}$ siècle et la critique avancée par Bourgeois du Chastenet et Vogel}

La première »Nouvelle édition« de l'»Histoire de l'Empire«, publiée à Paris en 1711, puis à La Haye en 1715, est généralement attribuée à Bourgeois du Chastenet $^{143}$. En effet, à la fin de la préface de cette nouvelle édition, cette attribution est

140 [Bogislaus Philippe DE ChEmnitz], Interets des princes d'Allemagne [...], 2 vol., Freistade [i.e. Paris] 1712.

141 Nous n'avons pas retrouvé cette édition in-12, parue également à »Freistadt«, en 1720, traduite par Bourgeois du Chastenet et signalée par PÜTTER, Litteratur des Teutschen Staatsrechts, t. I, p. 213; par contre, pour l'édition de 1712, Pütter ne signale pas Bourgeois du Chastenet comme traducteur (cf. ibid.). La dernière édition française de Chemnitz date de 1762: [Bogislaus Philippe DE ChEMNITZ], Les Vrais Intérets de l'Allemagne [...], 3 vol., La Haye 1762; avec une préface et des notes du traducteur. En 1761, cet ouvrage avait encore été traduit du latin en allemand (cf. PÜTTER, Litteratur des Teutschen Staatsrechts, t. I, p. 213), de sorte qu'il n'est pas étonnant que les Français s'y soient intéressés aussi pour leur part.

142 Voir ci-dessous.

143 Avec une exception; en effet, Lenglet, dans la première édition de sa »Méthode«, parue seulement deux ans après la »Nouvelle édition« de Heiss et donc très proche des événements, l'attribue à l'abbé de Vertot, [Nicolas abbé LENGLET-DUFRESNOY], Methode pour etudier l'histoire [...], 2 vol., Paris 1713, ici t. II, p. 195. 
confirmée ${ }^{144}$. Bourgeois du Chastenet ajouta l'histoire de la fin du règne de Ferdinand III et celles des règnes des empereurs Léopold Ier et Joseph Ier à l'histoire des empereurs précédents rédigée par Heiss ${ }^{145}$. Ce dernier s'était arrèté en 1648. L'histoire des états de l'Empire fut également mise a jour, afin de montrer au lecteur »quel est l'Etat actuel de l'Empire «146. Bourgeois du Chastenet commenta les documents publiés en annexe, principalement les traités de Westphalie, considérés comme »la piece fondamentale de la Liberté Germanique «147, mais aussi les autres lois fondamentales. Il y ajouta la trêve de 1684 ainsi que la capitulation de Joseph Ier. Pour sa part, Bourgeois du Chastenet s'arrêta en 1711, au moment de la mort de Joseph Ier, ajoutant à son récit historique quelques réflexions sur la future élection du successeur de l'empereur défunt ${ }^{148}$.

Vogel prolongea la partie historique du livre de Heiss jusqu'en 1724. Son histoire du règne de Charles VI occupe 210 pages in-40149. Il s'agissait donc d'un véritable livre ajouté à celui de Heiss. En 1733, les éditeurs hollandais y ajoutèrent le récit de l'histoire de l'Empire de 1724 à $1732^{150}$. De toute évidence, la nouvelle édition de 1731 fut préparée de longue date. En effet, le privilège de cette édition date de 1720. L'approbation accordée par l'ordre du garde du Sceau est datée du 16 mars $1730^{151}$. Pour les Français, l'»Histoire de l'Empire« avait donc gardé tout son intérêt.

Pourtant, les idées que les successeurs de Heiss professaient au sujet du status Imperii divergeaient souvent des siennes. En effet, les notes ajoutées aux nouvelles éditions de Heiss servaient souvent aux éditeurs pour marquer leur désaccord avec ses positions. Bourgeois du Chastenet se moquait du titre d'»Empire Romain«. Alors que Heiss admettait que, dans l'»Empire moderne«, il était »resté

144 Cf. Heiss, Histoire de l'Empire, édition de 1715 , t. I, »Avis« sur la nouvelle édition, p. *3-*3', ici p. *3', n. 1: „Les Notes, les Additions, \& la continuation de cette nouvelle Edition, ont été faite par le Sieur Bourgeois Du Chastenet, Plénipotentiaire Subdelegué de leurs A. R. Monsieur \& Madame d'Orléans, aux Conferences de Francfort, pour les Affaires Palatines«. Il s'agissait donc d'un ancien collaborateur d'Ulric Obrecht.

145 Pour Ferdinand III, cf. ibid.,p. 119-158 (à partir de la p. 156: continuation par Bourgeois du Chastenet, qui commence avec les difficultés que pose l'exécution de la paix de Westphalie depuis 1648); pour Léopold I ${ }^{\mathrm{er}}$, ibid., p. 158-215; enfin, pour Joseph Ier, ibid., p. 215-257. 146 Ibid., t. I, p. *3.

147 Ibid., p. * 3 '.

148 L'édition de 1715 ne racconte pas la suite des événements, mais reproduit ses réflexions datant de 1711, cf. ibid., t. II, p. 256-257.

149 Cf. Heiss, Histoire de l'Empire, édition de 1731 (in-4\%), t. II, p. [1]-210 (première pagination).

150 Cf. ID., Histoire de l'Empire, édition de 1733 (in-4º), t. II, p. 674-690. Comme pour le "Discours préliminaire« et les »Remarques« sur les lois fondamentales du Saint-Empire, également ajoutés en 1733, il est difficile d'identifier l'auteur de cette addition: Vogel ou plutôt un autre auteur chargé par les éditeurs d'Amsterdam, Wetsteins \& Smith. Étant donné que le nom de Vogel ne figure pas dans la nouvelle édition de 1733, la deuxième hypothèse est plus plausible.

151 Cf. HeIss, Histoire de l'Empire, édition de 1731, privilège et approbation reproduits à la fin du t. III de l'édition in-40; ces documents ne se trouvent pas dans le dernier tome du tirage in- $8^{\circ}$. 
peu de chose de l'ancien Empire Romain «152 - c'est-à-dire que cet auteur y trouvait quand même toujours quelques vestiges de cet ancien empire - Bourgeois du Chastenet s'insurgeait contre cette prétention, en déclarant:

Les plus habiles Jurisconsultes Allemans, \& qui ne donnent point dans la vision, se mocquent de cette dénomination d'Empire Romain; même beaucoup parmi les Modernes ne lui donnent point ce titre, \& se contentent de l'appeler l'Empire d'Allemagne. Il n'est nullement à souhaiter pour les Allemans \& pour les Princes de l'Empire que leurs Empereurs deviennent plus puissants, \& encore moins qu'ils entreprennent de se rendre Maître de Rome \& de l'Italie. Ce seroit toûjours à leurs dépens \& la constitution présente de leur Etat ne le demande point. L'étenduë des Roïaumes ne contribuë pas toûjours à leur solidité, ni à la felicité des peuples ${ }^{153}$.

On constate que Bourgeois du Chastenet est plus profondément imprégné des idées de Pufendorf que de celles de Heiss. Pufendorf est cité au sujet du pouvoir limité de l'empereur ${ }^{154}$ et surtout à l'égard du droit de déposer ce dernier réclamé par les électeurs. Dans ce contexte, Bourgeois du Chastenet, qui prend toujours position dans les débats opposant les juristes allemands que Heiss évoque dans son »Histoire«, se démarque plus clairement de son prédécesseur, en adhérant ouvertement à la définition du Saint-Empire proposée par Pufendorf. À propos du droit de déposition, que Heiss ne voyait pas fondé sur les lois de l'Empire, Bourgeois du Chastenet note:

Ce dernier raisonnement de M. Heiss détruit tout ce qu'il avoit avancé pour établir la souveraineté Monarchique de l'Empereur, pour laquelle il fait tout ce qu'il peut. Il ne faut pas s'en étonner, il étoit né Allemand, \& quelque intérêt secret, ou sa prévention pour la Maison d'Autriche, lui inspiroient le dessein d'en relever les avantages au préjudice des droits de sa Patrie. Mais il est certain que ce pouvoir qu'ont les Princes de l'Empire ou les Electeurs qui les representent, de déposer un Empereur qui contrevient à ce qu'il a promis par sa Capitulation, restraint beaucoup cette Souveraineté. Si les Princes de l'Empire n'ont point de titres pour prouver leur droit, les exemples de ce qu'ils ont fait $\&$ la possession où ils se trouvent, présupposent qu'ils en ont eu, \& leur en tiennent lieu.

Et d'ajouter: "L'Empire, dit Samuel Pufendorf de Statu Imperii Germanici Cap. VI. est un Corps composé de plusieurs Associez sous differentes conditions, qui sont tous obligez d'avoir pour leur Chef un grand respect «155. Pour sa part, Vogel reproduisit également le commentaire de Bourgeois du Chastenet ${ }^{156}$. En confrontant le récit de Heiss à ce commentaire, les Français apprenaient du moins que le status Imperii était contesté. Or, Heiss trouva aussi des adeptes en France dans la première moitié du XVIII siècle.

152 Cf. ID., Histoire de l'Empire, édition de 1715, t. II, p. 271.

153 Ibid., p. 271-272, n. 1.

154 Cf. ibid., p. 273, n. 1.

155 Citations ibid., p. 285-286, n. 1.

156 Pour les notes citées ci-dessus, cf. HeIss, Histoire de l'Empire, édition de 1731 (in-4º), t. II, p. 8, 9 et 15 (deuxième pagination). 


\section{Le »Tableau de l'Empire germanique« ou Heiss ressuscité}

$\mathrm{Si}$, après 1733 , l'»Histoire de l'Empire« n'a plus été rééditée intégralement, on publia encore en 1741 un résumé de plusieurs de ses chapitres ${ }^{157}$, auquel l'éditeur ajouta une traduction française de la Pragmatique Sanction de Charles VI et plusieurs documents concernant la candidature bavaroise ${ }^{158}$. L'auteur de cette édition partielle n'a pu être identifié avec certitude. Selon Cioranescu, il s'agirait de Desfontaines ${ }^{159}$, alors que Morris attribue l'ouvrage à Thiriot ${ }^{160}$. Quoi qu'il en soit, les deux écrivains sont illustres. Pierre François Guyot Desfontaines (ou Des Fontaines) naquit à Rouen, en 1685, et mourut à Paris, en 1745. Il était le fils d'un conseiller au parlement de Normandie. Après une carrière ecclésiastique ratée (il quitta la Compagnie de Jésus, puis abandonna sa paroisse en Basse-Normandie), Desfontaines devint critique littéraire, collaborateur, puis directeur du »Journal des Savants«. Connu pour ses mœurs dépravées et embastillé à plusieurs reprises, mais finalement libéré à la demande de Voltaire, Desfontaines fonda plusieurs revues de critique littéraire à partir de 1731, après avoir abandonné la direction du "Journal des Savants«, par suite des conflits qui l'avaient opposé à ses collaborateurs. À partir de 1738, une vive polémique l'opposa à Voltaire. Desfontaines se fit connaitre comme historien de la ville de Paris et de don Juan de Portugal161.

N. Thiriot (ou Thieriot), né en 1696 et mort en 1772, était également un ami de Voltaire. Bien qu'il ne prît pas position en faveur de son ami dans sa polémique avec Desfontaines, Voltaire continua à soutenir Thiriot. Ce dernier relisait certains ouvrages de Voltaire avant leur impression et devint correspondant littéraire de Frédéric de Prusse en 1736 grâce à son ami philosophe. Pourtant, Thiriot, qui passait pour paresseux et gourmand, laissa peu de traces littéraires ${ }^{162}$.

Ce »Tableau de l'Empire germanique « est l'œuvre d'un épigone qui a paraphrasé la deuxième partie du livre de Heiss, dans laquelle sont exposés les princi-

157 Cf. [Pierre François Guyot DesfonTAINEs], Tableau de l'Empire germanique [... ], [s.l.] 1741. Apparemment, l'ouvrage est incomplet, puisqu'on lit p. 212: »Fin de la premiere partie«.

158 Pour la Pragmatique Sanction, cf. ibid., p. 154-194; pour les documents relatifs à la candidature du prince électeur de Bavière, c'est-à-dire les »Remarques Sur la prétention de son Altesse Electorale de Baviere à la succession de la Maison d'Autriche, Traduites de l'Ecrit d'un Jurisconsulte Allemand « et l'extrait d'une lettre de Munich du 14 décembre 1740, cf. ibid., p. 195-212. Dans le texte même de l'ouvrage, il n'y a que peu de passages qui ne semblent pas être tirés du livre de Heiss.

159 Cf. Alexandre Cioranescu, Bibliographie de la littérature française du dix-huitième siècle, 3 vol., Paris 1969, ici t. I, p. 650-653, en particulier p. 651.

$160 \mathrm{Cf}$. Thelma Morris, L'abbé Desfontaines et son rôle dans la littérature de son temps, Genève 1961 (Publications de l'institut et musée Voltaire. Studies on Voltaire and the eighteenth century, 19), p. 374; sur Desfontaines comme historien, ibid., p. 352: »Quant à l'histoire proprement dite, Desfontaines n'est qu'un vulgarisateur qui travaille de seconde main«.

161 Cf. F. MARouIs, article »Des Fontaines (Pierre-François Guyot)«, dans: Dictionnaire de biographie française, t. X (1965), col. 1341-1342.

162 Cf. Nouvelle Biographie générale, t. 45 (1866), col. 202-203. 
pes fondamentaux du droit public allemand après 1648 et où l'auteur décrit les différents membres de l'Empire, en commençant par les électeurs. De toute évidence, il s'agit d'un ouvrage de circonstance. Très certainement, sa publication s'explique par la vacance du trône impérial, qui stimulait la demande de livres sur le droit constitutionnel allemand en France. Les pièces reproduites en annexe montrent que cet ouvrage était destiné en particulier aux lecteurs qui désiraient se renseigner sur le droit de l'élection impériale.

Dans ce livre, après avoir parlé de l'Empire en général, l'auteur abordait notamment les sujets suivants: l'élection impériale; la Bulle d'or; les droits de l'empereur; le problème de la déposition éventuelle de celui-ci; le collège électoral; le collège des villes; les diètes; le ban de l'Empire ${ }^{163}$. Puis il parlait des différents membres de l'Empire en particulier. Malgré la médiocrité du travail de l'auteur, qui plagiait seulement le livre de Heiss, son ouvrage n'est pas sans intérêt. En effet, il est important de noter que, à travers sa publication, la vision de l'Empire que Heiss avait défendue dans l'»Histoire de l'Empire « fut perpétuée en France, car Desfontaines (ou bien Thiriot) ne tenait pas compte des notes des continuateurs de Heiss, mais suivait l'opinion de l'auteur de l'original. Pour cette raison, il définissait l'Empire comme un status mixtus et sa forme de gouvernement comme $»$ monarchico-policratique ${ }^{164}$.

\section{La réception de Heiss en France}

Or, Heiss était, comme nous l'avons dit, originaire d'Allemagne; et bien qu'il ait ensuite été naturalisé Français, l'on doit se demander s'il a bien été lu en France, s'il a été compris par ses lecteurs français et, le cas échéant, de quelle façon. Si les nombreuses rééditions et le plagiat de 1741 donnent déjà une réponse satisfaisante à la première question et permettent d'affirmer que sans aucun doute Heiss doit avoir été l'un des auteurs les plus lus en France, en ce qui concerne l'histoire d'Allemagne, aux alentours de 1700 , l'on doit se demander si d'autres ouvrages ou bien des manuscrits attestent la façon dont cette lecture s'est faite et quels résultats elle a produits.

Notons que, malgré leurs critiques, les auteurs postérieurs ont souvent utilisé l'»Histoire de l'Empire« de manière exhaustive. Selon Barre, c'était la seule véri-

163 Cf. [DESFONTAINES], Tableau de l'Empire germanique, respectivement p. 1-6; p. 7-16; p. 17-24; p. 24-30; p. 37-39; p. 43-59; p. 67-68; p. 68-70; p. 74-75.

164 Ibid., p. 2: »Le gouvernement Germanique est mixte: il tient de la monarchie \& de l'aristocratie; \& on peut l'appeler, monarchico-policratique. L'Empereur est le chef du corps Germanique, \& tous les princes \& états de l'Empire, lui sont soumis. Mais son pouvoir n'est pas indépendant; il ne peut faire de son chef aucun réglement sur les affaires d'état, sans assembler une diete. Il ne peut même faire la guerre comme Empereur, sans le consentement de l'Empire «. Au sujet de l'empereur, cf. aussi ibid., p. 24-30, le chapitre »Des Prééminences de la dignité d'Empereur «; pour cet auteur, l'empereur était le premier monarque »de tous les princes de la chretienté, qui tous lui cedent le pas« (p. 24). 
table histoire d'Allemagne en langue française avant le milieu du XVIII' siècle $^{165}$. Des ouvrages de référence, comme le dictionnaire de Moréri, en ont copié certains passages presque littéralement (même dans l'édition de 1759) ${ }^{166}$. De plus, les notes de lecture conservées dans certains manuscrits de l'époque nous montrent que de nombreux lecteurs consultaient l'»Histoire de l'Empire« et que non seulement ils en faisaient un usage ponctuel, mais ils en résumaient aussi parfois des tomes entiers. Parmi les lecteurs de l'»Histoire de l'Empire «, on trouve l'auteur d'une »Histoire généalogique des maisons souveraines d'Allemagne «167 et d'éminents savants, comme le président Hénault, grand historien de la France, voire peut-être »le plus lu des historiens du XVIII ${ }^{\mathrm{e}}$ siècle«, à côté de Voltaire ${ }^{168}$. Hénault utilisait Heiss dans la partie de ses notes de lecture qui était consacrée à l'Allemagne. Il faisait un usage critique de cet auteur, dont il opposait les informations et les opinions à celles d'autres écrivains. Au début de ses notes, Hénault exposait le plan de son recueil, qui lui servait à son propre travail d'historiographe:

Ce receuil [sic] est le produit des lectures que j'ay faites sur toutes sortes de matières ecclésiastiques, profanes, historiques, philosophiques, etc. J'ay cru que l'on ne pouroit lire utilement qu'en crayonnant ce qu'on lisoit, et après avoir lu un livre, $j$ 'en tirois ce que $j$ 'avois cru y devoir remarquer; souvent même plusieurs lectures sur une même matière étoient une occasion de réfléchir, et alors non content des extraits que j'avois faits, j'écrivois mes réflexions et quelques fois cela me menoit à des dissertations ou à des traittés dans lesquels j'examinois à fond la matière qui m'avoi $<t>$ paru le mériter; c'est tout $c e<t>$ amas que j'ay

165 Au sujet de Barre, qui publia lui-même une histoire d'Allemagne dans les années 1740 , voir le chapitre suivant.

166 Cf. l'article »Allemagne«, dans: MORÉRI, Le Grand Dictionnaire (1759), t. L1, p. 383397.

167 Archives nationales, MM 684c. C'est un ouvrage impressionnant d'environ mille pages, sans nom d'auteur, rédigé très certainement entre 1715 et 1719 , et continué en 1763. Dans cette ouvre tout à fait singulière, on trouve beaucoup plus qu'une simple histoire généalogique; les considérations sur le droit d'État allemand - en particulier sur l'origine des électeurs -, qui n'y font pas non plus défaut, remontent presque littéralement aux définitions de Heiss; une bibliographie des livres utilisés par l'auteur complète cette »Histoire«. L'ouvrage montre la continuité des idées formulées dans les années 1680, ou même encore plus tôt, dans la France du XVIII ${ }^{c}$ siècle. Cet auteur cite Heiss, par exemple, p. 288, 437 et 807. Il connaît aussi l'Histoire de l'élection impériale de Wicquefort, qui, elle, est citée par exemple p. 806-808. L'auteur pense que l'Empire a »une espèce de gouvernement meslé du monarchique et de l'aristocratique « depuis le XIII' siècle, ibid., p. 2.

$168 \mathrm{Cf}$. Bibliothèque de la Sorbonne, ms. 283. D'après l'ex-libris, ce manuscrit appartenait au président Hénault, de l'Académie française. Il contient les notes de lecture de Hénault au sujet de l'histoire ancienne, de celle des empires de Rome et de Constantinople, de l'Empire turc, de l'histoire d'Italie, de Venise et de Malte, de Naples et de Sicile et, au début (fol. 1139), de l'histoire d'Allemagne. Pour Hénault comme historiographe, cf., entre autres auteurs, Sylvain Menant, Le président Hénault, la chronologie et l'histoire, dans: Marc FuMAROLI, Chantal GreLl (dir.), Historiographie de la France et mémoire du royaume au XVIII ${ }^{e}$ siècle. Actes des journées d'étude des 4 et 11 février, 4 et 11 mars 2002. Collège de France, Paris 2006 (Bibliothèque d'histoire moderne et contemporaine, 18), p. 307-318, citation p. 307. 
mis ensemble, et qui m'a été d'une grande ressource lorsque que [sic] j'ay cru être assés instruit pour pouvoir me faire un plan de travail et composer mon histoire ${ }^{169}$.

Tout en se disculpant des erreurs que les auteurs qu'il lisait avaient pu commettre ${ }^{170}$, Hénault comparait les indications de Heiss aux récits des autres historiens ${ }^{171}$. Or, le président Hénault utilisait non seulement l'»Histoire de l'Empire « de manière ponctuelle, dans le cadre de certains problèmes historiques ou historiographiques, mais il possédait aussi un résumé manuscrit de cent soixante-cinq pages de toute la première partie historique de l'ouvrage de Heiss ${ }^{172}$, qui était composé - rappelons-le - d'un récit historique du Saint-Empire et d'un exposé thématique du droit public de ce dernier après les traités de Westphalie. Ce résumé se termine avec la protestation du pape contre la paix de 1648 .

Malgré cette lecture critique, on constate que Hénault ne remet pas fondamentalement en cause la vision de l'Empire de Heiss. Or, nous savons que PierreLouis Rœderer (1754-1835), conseiller d'État sous Napoléon Ier et l'un des spécialistes de l'empereur des Français pour l'Allemagne, a lu les ouvrages du président Hénault ${ }^{173}$.

De plus, d'autres lecteurs se contentaient de prendre des notes de l'»Histoire de l'Empire«, sans la confronter à d'autres ouvrages. C'est le cas des »Remarques sur l'Empire«, un résumé de la deuxième partie du livre de Heiss rédigé vers $1718^{174}$. Il faut en tirer la conclusion que Heiss marqua plus profondément l'esprit de ses lecteurs français que les réserves explicites émises par certains auteurs contemporains ou postérieurs ne semblent le suggérer.

169 Bibliothèque de la Sorbonne, ms. 283 fol. 6.

$170 \mathrm{Cf}$, ibid., fol. 6'.

171 Cf. ibid., fol. 19' au sujet de la mort d'Henri VII. Hénault cite encore Heiss fol. 36', en parlant d'Henri VI, et fol. 38-39 au sujet de l'élection impériale vivente Imperatore.

172 Bibliothèque de la Sorbonne, ms. 941; ex-libris imprimé, fol. [I'], du président Hénault, de l'Académie française; p. 1-165: »Histoire du nouvel Empire d'Occident extraitte de monsieur Heiss« (titre selon la table des matières, ici fol. [II'], de même sur le dos de la reliure). Le même manuscrit contient une histoire des empereurs romains et une autre histoire de l'Empire ottoman. Pour l'histoire des empereurs d'Occident de Charlemagne à Charles VI, cf. également bibliothèque Mazarine, ms. 2172 fol. 200-226, »Remarques sur l'histoire des Empereurs d'Allemagne«.

173 Cf. Archives nationales, 29 AP 100 (»Cabinet du comte P.L. Ræderer. Pièces et travaux antérieur à 1790. 2. Vol. 3《). Selon une note de Rœederer, ce manuscrit contient les »Extraits de différens ouvrages la plupart de ma jeunesse de 1770 à 1780 «, entre autres ceux de la "Chronologie de la législation française. Extrait de l'histoire du président Hainaut«, datés »juillet 1775 «. Pour l'Allemagne, Rœderer a fait l'»Analyse des Institutions du droit public d'Allemagne par Gérard «, datée »A Strasbourg, le 12 mars 1771 « (pour le livre de Gérard de Rayneval de 1766, réimprimé en 1771, voir le dernier chapitre). Cette »Analyse « (document $\mathrm{n}^{\mathrm{o}}$ [3] dans ce volume) montre la continuité de certaines idées en France, notamment sur le rôle prépondérant accordé à la paix de Westphalie parmi les lois constitutionnelles du SaintEmpire.

174 BNF, F.fr. 19875 (»Remarques sur l'Empire; seconde partie: De l'Empire moderne et des changemens qui y sont arrivés«), manuscrit daté d'abord de 1698, puis de 1718 (fol. [I]). L'auteur de ces notes ne mentionne pas le nom de Heiss, mais son résumé en trahit l'origine (les titres et l'ordre des chapitres correspondent très exactement à ceux de Heiss). 


\section{L'abbé de Vayrac ou l'>anti-Heiss‘}

Le plus farouche opposant à Heiss et à sa vision de l'Empire fut l'abbé de Vayrac. Jean de Vayrac (1664-1734) était l'auteur de plusieurs ouvrages de grammaire et d'histoire, dont une description de l'»État présent de l'Espagne« publiée en 1718. Né en Auvergne, il passa vingt ans en Espagne, avant de revenir à Paris, en 1710. Il se fit aussi connaître comme traducteur ${ }^{175}$.

Cet abbé publia en 1711 un »Etat present de l'Empire«, qui se veut déjà, d'après son titre, »une Critique de plusieurs points importants de l'Histoire de $M$. Heiss « 176 et qui est en fait un ouvrage qui n'est pas seulement dirigé contre Heiss, mais surtout contre la politique de la maison d'Autriche. Un "Avis« au lecteur ${ }^{177}$ explique plus particulièrement ce dessein. Si Vayrac note bien l'existence de plusieurs ouvrages qui ont été écrits »sur le Gouvernement de l'Empire«, il ne mâche pas ses mots pour accuser leurs auteurs de partialité:

Les uns, entierement dévoüez à la Maison d'Autriche, pour donner quelque couleur apparente aux prétentions énormes des Empereurs sur les autres Membres du Corps Germanique, ont répandu de si épaisses tenebres sur les anciennes Constitutions, qu'on ne les connoîtroit presque plus, si quelques Jurisconsultes \& Canonistes, zelez pour la défence de la liberté de leur Nation, n'en eussent conservé le souvenir par de sçavans ouvrages, dont toute l'autorité Autrichienne n'a pû arrêter le cours ${ }^{178}$.

Dès les premières pages, qui sonnent comme un credo politique, on voit bien de quelle manière Vayrac distribue ses faveurs: tout écrivain trop indulgent à l'égard de l'empereur et de la maison d'Autriche tombe en disgrâce; il est le partisan d'une certaine partie des publicistes qui défendent les prérogatives des princes et qui sont, pour Vayrac, les seuls vrais patriotes dans l'Empire. Car qui n'est pas dévoué à la maison d'Autriche, mais accorde à l'empereur un certain pouvoir réel, est dupe:

D'autres, ébloüis par des exemples d'une autorité despotique, que les Empereurs exercent depuis plus de deux siecles, ont pris les apparences pour la réalité, \& ont attribué à la dignité Imperiale, des droits qui ne sont fondez que sur la violence \& sur l'injustice ${ }^{179}$.

À cette dernière catégorie appartient, selon Vayrac, Jean Heiss, dont l'»Histoire de l'Empire« est publiée pour la quatrième fois, en 1711. C'est cette réédition qui

$175 \mathrm{Cf}$. Cioranescu, Bibliographie de la littérature française du dix-huitième siècle, t. III, p. 1750; Archives biographiques françaises, [microfiches, parties I (première publication par Susan BRADLEY en 1989-1991), II (première publication en 1998) et III, avec un index cumulé imprimé, en 7 vol.], compilé par Tommaso NAPPO, Munich 32004, ici I 1017, 15-17. $176 \mathrm{Cf}$. le frontispice du livre de l'abbé [Jean] DE VAYRAC, L'Etat present de l'Empire [...], Paris 1711. La citation que nous avons reprise de ce frontispice est mise en italique sur l'original.

177 Ibid., cinq pages non numérotées qui se trouvent entre le frontispice et la table des matières.

178 Ibid., p. [I-II].

179 Ibid., p. [II]. 
incita Vayrac à en publier sa critique ${ }^{180}$. Or, cette critique nous fournit aussi un témoignage du prestige dont jouissait l'ouvrage de Heiss, du moins jusqu'en 1711; car. selon Vayrac, c'est la bonne renommée de Heiss même qui nécessite qu'on dégage les erreurs qu'il a commises:

comme cet Auteur a eu jusqu'à present la réputation de sincere Historien, j'ay cru qu'il étoit important d'instruire le Public de plusieurs erreurs qu'il a répandu dans son Ouvrage, sur les points importans de l'Histoire de l'Empire, non seulement injurieuses aux Electeurs, mais même aux autres Souverains de l'Europe, par la supériorité qu'il donne aux Empereurs au dessus d'eux.

Ce n'est donc que »l'amour de la verité« qui aurait poussé Vayrac à rectifier ces fautes ${ }^{181}$; retenons que Vayrac n'est plus prêt à accorder à l'empereur le premier rang parmi les souverains d'Europe, ce que la plupart des auteurs précédents avaient encore fait, ne fût-ce qu'à l'égard du cérémonial.

Malgré sa critique, Vayrac ne veut pas décourager ses lecteurs de lire aussi l'»Histoire « de Heiss - au contraire, il les exhorte à la consulter - ouvrage auquel il réserve même certains propos positifs, puisque ses lecteurs »y trouveront des remarques sur les Familles d'Allemagne, que je n'ay vu dans aucun autre Auteur qui ait écrit en François«, avant d'en arriver à la conclusion que »son Histoire est un beau Canevas, auquel il ne manque qu'une main delicate pour corriger les défauts qui se sont glissez dans l'exécution du dessein«. Ces aimables propos ne doivent pourtant pas masquer l'essentiel: si Vayrac accorde à l'»Histoire de l'Empire « de Jean Heiss certains avantages, comme d'avoir donné des renseignements sur certaines familles d'Allemagne, sa vision de l'Empire reste opposée à celle de Heiss. Enfin, tout en tirant à boulets rouges sur son adversaire, Vayrac réclame l'indulgence des lecteurs pour lui-même, parce qu'il n'a pas eu l'occasion de bien réviser les épreuves de son »Etat $«$, et surtout en ce qui concerne le style de son livre, à cause de son "malheur d'être né dans une Province, où la delicatesse de la Langue Françoise, est presque aussi inconnuë que celle des Langues mortes, joint à prés de vingt années que j' ai passé dans les païs étrangers «182.

Vayrac a divisé son ouvrage en douze chapitres, en partie historique, et en partie (le plus souvent) thématique. Dans un premier temps, il reconstitue l'origine de l'Empire et l'histoire de celui-ci jusqu'à ce qu'il devienne électif. Après avoir déterminé la forme de gouvernement de l'Empire, il examine les pouvoirs respectifs de l'empereur et des états, puis il explique ce qu'est le roi des Romains. Ensuite, il examine l'origine du collège des électeurs, leurs droits et leurs privilèges, avant d'aborder le collège des princes, puis celui des villes impériales. Les trois chapitres suivants sont consacrés aux diètes et à leur origine, aux cercles de l'Empire et à ses tribunaux de justice. Le dernier chapitre explique l'élection et le couronnement de l'empereur. Entre le pénultième et le dernier chapitre, Vayrac a

180 Vayrac dit lui-même que »l'Histoire de l'Empire vient de voir le jour pour la troisiéme fois«, ibid. Mais la troisième édition date de 1694, de sorte qu'il est probable que Vayrac se trompe et qu'il parle de la quatrième édition, parue en 1711.

181 Ibid., p. [II-III] de la dédicace non paginée.

182 Ibid., p. [IV] (citations) et [V]. 
intercalé le texte de la Bulle d'or. Il commence son »Etat« par un discours préliminaire, dans lequel il allègue la mort de l'empereur Joseph Ier, le 17 avril 1711 , comme l'évènement qui lui a fourni l'occasion de publier son ouvrage sur le droit public allemand, car il suppose que le décès de l'empereur attirera l'attention du public sur cette matière. Ses remarques historiques à propos de ce sujet sont fondées sur la lecture des anciennes constitutions de l'Empire, de la Bulle d'or, des capitulations impériales et des »ouvrages des meilleurs Auteurs qui ayent écrit sur cette matière « - l'on remarquera qu'il ne cite pas la paix de Westphalie parmi les lois auxquelles il accorde la plus grande importance. Selon lui, l'Empire actuel n'a plus grand-chose à voir avec l'Empire romain; cependant, il promet de remonter "jusques au commencement de l'Empire Romain, $d$ 'où celui d'Allemagne fait gloire de tirer son origine, [mais ce dernier] est devenu électif, \& $[\ldots]$ a pris une forme de Gouvernement différente de celle qui s'observoit du temps des Empereurs de Rome, de Constantinople \& des Successeurs de Charlemagne«. Quand il se défend »qu'aucun motif de politique ni d'interêt soit capable de [lui] faire trahir la verité «, il prend une position claire, car cette recherche de la vérité même le conduit à "combattre l'opinion de quelques Auteurs«, qui, malgré leur érudition et leur talent, »n'ont pas laissé d'imposer au public en attribuant à l'Empereur des qualitez \& un pouvoir qu'il n'a pas «183. On sait déjà que ce combat, Vayrac le mène surtout contre Heiss. Si on compte le succès par le nombre des éditions, l'abbé semble bien l'avoir perdu, car aucune réédition de son »Etat« n'est connue. Or, ses idées ont bien trouvé d'autres propagateurs, mais ce fut surtout après 1740 qu'elles gagnèrent du terrain en France. En revanche, l'esprit de partialité dont il fait preuve quand il s'attaque aux Habsbourg reste bel et bien ancré dans le siècle de Louis XIV. D'ailleurs, il suit bien un modèle du XVIIe siècle, qui est même un modèle allemand, puisque Vayrac a bien lu et compris Chemnitz.

La vision de l'Empire que Vayrac défend est aux antipodes de celle de Heiss. Pour lui, il n'est pas question de voir dans l'Empire une constitution mixte, où les éléments monarchiques prévalent sur les éléments aristocratiques. Non, décidément, pour Vayrac, l'Empire est une république, et l'empereur n'est que son administrateur. Et pour affermir cette vérité ${ }^{184}$, l'abbé enterre l'histoire pluriséculaire de la théorie de la translatio Imperii ${ }^{185}$, pour faire de la continuité de l'Empire romain et de l'Empire germanique une simple idée que les Habsbourg ont imaginée afin de rendre l'Empire héréditaire dans leur famille. Or, les membres mêmes de »cet auguste Corps« de l'Empire ont trahi leurs propres intérêts en con-

183 Citations ibid., p. [1]-3

184 D'ailleurs, l'abbé utilise un langage pathétique et religieux dans son combat pour la vérité, en écrivant par exemple: »Opposons donc à ces Auteurs mercenaires [ce n'est d'ailleurs pas l'unique fois qu'il qualifie de >mercenaires les auteurs qui ne partagent pas ses idées] \& interessez, qui prodiguent leurs encens aux Empereurs, pour acheter leurs faveurs aux dépens des Droits les plus sacrez de l'Empire, le flambeau lumineux des Constitutions [c'est-àdire des lois fondamentales], pour dissiper les tenebres du mensonge qu'ils tâchent de répendre dans leurs écrits«, ibid., p. 31.

${ }^{185} \mathrm{Du}$ moins la continuité avec l'Empire romain s'est-elle arêtée après les Carolingiens, selon Vayrac. 
courant au dessein des Habsbourg. En particulier, ils les ont aidés à masquer »de titres fastueux « leur manque de puissance réelle ${ }^{186}$. Le modèle qu'il suit pour comprendre la Constitution du Saint-Empire est celui qu'un des auteurs allemands les plus célèbres du milieu du XVIIe siècle, Bogislaus Philipp von Chemnitz, avait imaginé, dans une situation où certains états de l'Empire se voyaient effectivement dans une crise existentielle et leur liberté mise en danger par la politique impériale. Or, cette situation, fondée sur la politique monarchique de Ferdinand II, était-elle aussi celle des états de l'Empire vers 1711? Vayrac ne se trompait-t-il pas en pensant pouvoir compter sur un sentiment anti-habsbourgeois aussi prononcé du côté des états? Ne répétait-il l'erreur de certains contemporains de Louis XIV, et probablement de Louis XIV lui-même, qui supposaient, en simplifiant les clivages internes, que les véritables intérêts des états de l'Empire demandaient qu'ils s'opposassent à l'empereur et à sa maison?

Quoi qu'il en soit, l'image que Vayrac se fait du Saint-Empire a l'avantage d'être sans équivoque, et elle prouve bien la force d'attraction que Chemnitz a possédée en France, qui ne se limite donc pas aux différentes versions françaises qui ont été publiées aux XVII et XVIII ${ }^{e}$ siècles. Pär ailleurs, Vayrac a lu Chemnitz en latin ${ }^{187}$. Il ne connaît pas le vrai nom de l'auteur; tantôt il utilise son pseudonyme (»Hypolite de la Pierre «188), tantôt il l'identifie avec un certain Stanislaus Orcichovius ${ }^{189}$. Pour Vayrac, comme pour son auteur de référence, les »noms pompeux « que l'empereur s'attribue, tels que »Sacrèe Majesté«, »Cesar «, »toûjours Auguste «, ne sont que des titres vains, mais ils »semblent égaler le Chef de la Republique d'Allemagne à Jules Cesar, à Constantin, à Theodose \& à Charlemagne, \& établir une Monarchie semblable à celle que possedent les plus grands Rois de l'Europe, c'est-à-dire absoluë, souveraine, despotique, indépendante de toute autre Puissance «. Or, d'après Vayrac, ces épithètes ne reviennent pas du tout à la personne de l'empereur. Ce ne sont encore que ses »mercenaires « qui prétendent »effrontément, que l'Empire est une de ces quatre Monarchies dont il est parlé dans l'Ecriture-Sainte«, et qui présentent

l'Empereur comme le Souverain Monarque des Princes \& des ordres de l'Empire, indépendant de leurs suffrages, Superieur aux Loix, \& ne reconnoissant que Dieu seul au dessus de lui, \& d'accuser de trahison, d'impieté \& d'heresie, ceux, qui contre le precepte de l'Evangile, ne rendent pas à Cesar ce qui appartient à Cesar, \& qui par un esprit de revolte refusent de reconnoître, que l'Empereur a un pouvoir absolu dans l'Empire ${ }^{190}$.

Or, l'abbé est trop habile prédicateur pour ne pas céder, un peu plus loin, à la tentation de retourner l'Évangile contre ce soi-disant empereur: »en rendant à Cesar ce qui appartient à Cesar, réduisons la puissance Imperiale aux bornes qui lui sont

186 Cf. VaYrac, Etat, p. 21 (citations) et 22.

187 Car c'est en latin qu'il le cite, cf., par exemple, ibid., p. 25 et 28-30.

188 C'est ainsi qu'il traduit Hypolithus a Lapide, cf., par exemple, ibid., p. 30.

189 Ibid., p. 28. L'auteur, Bogislaus Philipp von Chemnitz, a été identifié seulement beaucoup plus tard. En France, on connaît son identité au moins depuis 1762 (voir ci-dessous). 190 Ibid., p. 22-23. 
prescrites, \& ne ravissons pas aux autres membres de l'Empire, ce qui leur est légitimement dû«191.

Or, ces titres qui sont autant de "phantômes de Souveraineté « sont pernicieux, aux yeux de Vayrac, car ils "avilissent la Majesté de l'Empire«. En effet, d'après ce qu'il écrit, l'Empire n'a été monarchique que jusqu'au règne de Louis IV, dernier empereur issu de la dynastie des Carolingiens. La monarchie romaine avait commencé avec Jules César; Vayrac accepte donc l'idée d'une continuité de l'Empire romain, mais qui prit fin avec l'extinction de la race de Charlemagne. Le caractère électif que Vayrac attribue à l'Empire par la suite et surtout la Bulle d'or de Charles IV ont fait de lui »un Etat monstrueux formé d'un assemblage confus de plusieurs parties toutes contraires les unes aux autres, qui le rendent presque indéfinissable«. Tout en reprenant l'expression forgée par Pufendorf dans son sens propre, qui veut dire que la monstruosité de l'Empire consiste dans la difficulté de le définir en recourant aux formes de gouvernement enseignées par Aristote, Vayrac concède finalement que l'Empire est un État mixte. Si l'empereur est seulement »revêtu des toutes les marques exterieures de la Royauté«, sans que l'Empire devienne pour autant »une veritable Monarchie «192, car »les Electeurs \& les autres Princes d'Allemagne ordonnent[,] décretent \& gouvernent conjointement avec lui, \& pour lors cette idée de Monarchie ${ }^{193}$ se dissipe pour faire place à une idée d'un gouvernement Aristocratique«, Vayrac ne se résigne pas à qualifier simplement l'Empire d'aristocratie. En effet, la présence des villes impériales à la diète, en tant qu'elles représentent les peuples, semble »donner à l'Empire la forme d'un Etat Démocratique«. Et de conclure, à titre provisoire, que l'Empire n'est ni monarchique, ni aristocratique, ni démocratique. Il ne peut être qualifié de monarchique étant donné »que l'Empereur (quoy que revêtu de toutes les marques apparentes de Souveraineté \& couronné pour gouverner tout l'Etat selon les Loix \& les Constitutions Imperiales) ne peut rien ordonner sans le consentement des autres membres qui composent cet Etat «194. L'Empire n'est pas non plus aristocratique - et en cela Vayrac est en contradiction avec Bodin, qu'il ne nomme pas -, même si l'empereur, les électeurs et les princes de l'Empire y tiennent le premier rang; d'abord, la présence du peuple (représenté par les villes) exclut cette idée, puis il n'y a pas, dans l'Empire, d'après Vayrac, de sénat perpétuel, ni d'armée, ni de trésor public. Si ces deux derniers points sont contestables, il est intéressant de noter que la diète de l'Empire n'est, pour Vayrac, pas comparable à un sénat tel qu'on le trouve à Venise, et, pour cette raison, il réfute explicitement la comparaison du Saint-Empire avec la Repubblica di San Marco. En revanche, si tout le peuple est représenté à la diète et qu'il y jouit du droit de vote, »les principaux de ces Citoyens sont des Souverains $\&$ des Monarques, ce qui est contraire

191 Ibid., p. 31.

192 Citations ibid., p. 23.

193 Idée que les marques extérieures de la royauté dont l'empereur dispose pourraient faire naître.

194 VAYraC, Etat, p. 24. 
au gouvernement Démocratique tel qu'est celui de la Republique d'Hollande, où le peuple gouverne «195.

Pour toutes ces raisons, Vayrac conclut que »l'Empire [...] est en partie Aristocratique [...] \& en partie Démocratique«. Mais surtout - et Vayrac en appelle encore à Chemnitz - l'Empire n'est point monarchique. Ne disposant pas d'un pouvoir »plus absolu que celui du Doge de Venise «, l'empereur est réduit au rôle de »Chef ministeriel de l'Empire, dont il fait executer les déliberations en vertu du pouvoir que les Etats lui ont accordé«. Pour Chemnitz tout aussi bien que pour Vayrac, il est incontestable »que l'autorité souveraine réside dans le corps de l'Empire, dont l'Empereur n'est que l'Oeconome \& l'Administrateur «, depuis l'époque de Frédéric Barberousse dont on dit qu'il a clairement accepté ce principe, de sorte que l'empereur n'est au fond qu'un »Administrateur des affaires de la Republique « et doit se contenter seulement des signes extérieurs d'un monarque, dont le globe en tant que »simbole de la Monarchie universelle«, qui ne constituent toutefois »qu'un noble phantôme de Majesté qui n'a rien de réel«196.

Par conséquent, tous ceux qui ne suivent pas ce principe que Vayrac pense avoir bien établi, et notamment »Monsieur Heiss, d'ailleurs si recommandable par sa profonde érudition, \& tous les Auteurs qui prétendent, que l'Empereur ait une puissance souveraine, sont dans une erreur d'autant plus grossiere, qu'en lui voulant attribuer un droit qu'il n'a pas, ils détruisent celui de l'Empire«. Si Vayrac n'accuse pas explicitement les partisans d'une monarchie (partielle) de crime de lèse-majesté à l'égard de l'Empire, l'idée semble bien être dans l'air, car prétendre que l'Empire est monarchique est pour lui, qui suit encore Chemnitz, »comme une infraction manifeste, faite aux Constitutions Imperiales, \& comme une injuste usurpation ${ }^{197}$.

S'il n'y a pas monarchie, où réside donc la souveraineté de l'Empire? À considérer »les Loix fondamentales de l'Etat Germanique «, Vayrac trouve que les principaux droits, et surtout »ceux qui constituent l'essence de la Majesté, n'appartiennent qu'au Corps seul des Etats légitimement assemblez dans les Dietes«, mais que les électeurs s'en sont successivement attribués un certain nombre, et qu'ils les ont en partie abandonnés à l'empereur pour qu'il conservât »comme une ombre de l'ancienne Majesté Imperiale «198. La liste des droits dont Vayrac attribue l'exercice à l'empereur, seul ou bien avec le concours soit des électeurs, soit de tous les états de l'Empire ${ }^{199}$, reflète pourtant parfois la situation qui a existé avant la paix de Westphalie, puisque, après 1648 , tous les droits qu'il attribue à l'empereur avec le consentement des seuls électeurs n'ont pas été exclusivement réservés à ces derniers, mais revendiqués partiellement par les états de l'Empire en général. De toute manière, le fait que Vayrac semble faire bien peu de cas de la paix de Westphalie est peut-être une conséquence de son attachement à Chemnitz,

195 Ibid., p. 25.

196 Citations ibid., p. 25-27.

197 Ibid., p. 28, 30.

198 Ibid., p. 29.

199 Cf. ibid., p. 31-34. 
qui a écrit avant 1648 . Nous ne pensons pas que Vayrac, tout en faisant sienne une expression de Pufendorf, ait avancé dans la compréhension du Saint-Empire par rapport à Chemnitz. Ce livre aurait pu être écrit soixante-dix ans plus tôt. Pour l'essentiel, il ne fait que reproduire ce qu'un Allemand a déjà pu constater avant la fin de la guerre de Trente Ans, avec un retard de plus d'un demi-siècle et dans une situation qui n'est plus la même. Si Heiss, avec ses idées d'État mixte à caractère monarchique prédominant, ne peut pas passer pour un esprit fondateur, surtout au début du XVIII ${ }^{\mathrm{e}}$ siècle, l'ouvrage de Vayrac ne constitue pas une avancée par rapport à lui, mais bien une régression, car il néglige ce que Heiss avait quand même pu enseigner aux Français; le résultat en fut une bonne connaissance des traités de Westphalie; par contre, Vayrac écrit en 1711 comme si rien ne s'était passé en 1648 qui méritât une attention particulière ${ }^{200}$.

\section{Les traductions françaises de Chemnitz}

Le fait que nous ayons repéré de nombreuses citations de Chemnitz dans l'ouvrage de Vayrac pose le problème de la réception de cet auteur allemand en France. Comme nous l'avons déjà dit, Chemnitz fut traduit et publié en français à l'époque où Vayrac écrivait son >anti-Heiss`, en $1712^{201}$ et en $1720^{202}$, puis réédité au cours de la guerre de Sept Ans, plus précisément en $1762^{203}$, une année après que l'ouvrage eut été publié de nouveau en Allemagne. À cette dernière édition française, parue à La Haye, l'éditeur ajouta des remarques relatives à la situation politique de son époque ${ }^{204}$. C'est véritablement une nouvelle traduction du livre de Chemnitz. Bourgeois du Chastenet est le traducteur des éditions qui datent du début du XVIII ${ }^{\mathrm{e}}$ siècle. Comme, à cette époque, le vrai auteur du livre, publié sous le pseudonyme d'»Hippolitus a Lapide« n'était pas encore connu, Bourgeois du Chastenet l'identifia par erreur avec Joachim de Transée, ambassadeur suédois à Berlin à la veille de la paix de Westphalie ${ }^{205}$. À la différence de ce qu'il avait fait pour son édition de l'»Histoire de l'Empire« de Heiss, Bourgeois du Chastenet s'abstint de commenter l'ouvrage de Chemnitz.

Chemnitz, né à Stettin, en 1605, était l'un des plus célèbres historiens et publicistes luthériens de la guerre de Trente Ans et de la deuxième moitié du XVIIe siè-

200 Il connaît bien évidemment la paix de Westphalie et en cite même de longs passages, $c f$. ibid., p. 241-247. Or, dans tout son chapitre où il établit la forme de gouvernement du SaintEmpire, il ne l'évoque pas une seule fois, mais incite à penser que les rapports juridiques entre l'empereur et les états n'ont pas évolué considérablement depuis le Moyen Âge.

201 [CHEMNITZ], Interets des princes d'Allemagne (1712).

202 Cette édition est signalée par PÜTTER, Litteratur des Teutschen Staatsrechts, t. I, p. 213 (voir ci-dessus).

203 [CHEMNITZ], Les Vrais Intérets de l'Allemagne (1762).

204 Au début du volume, il publia la traduction française de la préface que le traducteur allemand avait ajoutée à son édition; ibid., t. I, p. $)\left(2-[)\left(8^{\prime}\right]\right.$.

$205 \mathrm{Cf}$. le frontispice de l'édition de 1712. Dans ses catalogues, la Bibliothèque nationale de France n'a toujours pas corrigé cette erreur. 
cle. Il mourut à Hallstaed, en Suède, en 1678. Il était issu d'une dynastie de juristes: son père, Martin (1561-1627), était docteur en droit et professeur à Rostock, sa mère, Margarethe (morte en 1650), était la fille de Heinrich Camerarius (15471601), également juriste et professeur à Rostock. Pourtant, Bogislaus Philipp ne termina pas ses études de droit et d'histoire qu'il avait commencées à Rostock et à Iéna. Ce fut peut-être à cause de difficultés financières que, après la mort de son père, il se mit au service de l'armée hollandaise. Quand Gustave-Adolphe eut débarqué en Allemagne, Chemnitz rejoignit ses troupes. Vers 1637, il travailla dans l'administration militaire suédoise et entama une carrière d'historiographe et de publiciste. Dans ses ouvrages, il prenait partie pour le luthéranisme et pour la politique suédoise. Au début des années 1640 , il publia sa "Dissertatio de Ratione Status in Imperio nostro Romano-Germanico«, répondant probablement à une demande du gouvernement suédois. L'interprétation que Chemnitz fit de la Constitution impériale était proche de celle de Dominicus Arumaeus, qui avait été son professeur à Iéna. Pourtant, Chemnitz aiguisa les positions d'Arumaeus pour dénoncer la politique de la maison d'Autriche et légitimer l'intervention suédoise dans l'Empire. En effet, Chemnitz refusait de reconnaitre la validité du droit public romain dans le Saint-Empire, qu'il tenait pour une république aristocratique constituée de princes souverains. Dans cette république (qui était une aristocratia monarchice administrata), l'empereur avait seulement des fonctions administratives (administratio accidentalis), alors que la souveraineté (administratio essentialis) résidait dans le corps des états de l'Empire. Cette conception correspondait donc à celle de Jean Bodin. Chemnitz accusait la maison d'Autriche de prétendre à l'établissement d'une monarchie absolue et préconisait son extirpation comme seul moyen de lui barrer la route. Cette solution radicale lui paraissait conforme à la raison d'État du Saint-Empire 206 .

C'est la traduction française de 1762 qui révèle au public francophone l'identité de l'auteur de la »Dissertatio de Ratione Status in Imperio nostro RomanoGermanico«, c'est-à-dire du livre qui avait attaqué le plus farouchement la maison d'Autriche au cours de la guerre de Trente Ans, dénonçant les inconvénients de la réalité constitutionnelle dans l'Empire et proposant des solutions concrètes pour les résoudre. En effet, bien que les savants n'aient pas encore identifié avec certitude l'auteur de cet ouvrage, qui s'était caché sous un pseudonyme, le traducteur allemand défend la bonne hypothèse: »Quelque partagées que soyent les opi-

206 Pour la vie et l'œuvre de Chemnitz, cf. Guido Braun, article »Chemnitz, Bogislaus Philipp von«, dans: CROXTON, TISCHER, The Peace of Westphalia, p. 55-57; Friedrich Hermann SCHUBERT, article »Chemnitz, Bogislaw Philipp (v.)«, dans: Neue deutsche Biographie, t. III (1957), p. 198-200 (bibliographie des œuvres et des études); Bernhard PAHLMANN, article "Bogislaus Philipp von Chemnitz«, dans: Gerd KLEINHEYER, Jan ScHRÖDER (dir.), Deutsche Juristen aus fünf Jahrhunderten. Eine biographische Einführung in die Geschichte der Rechtswissenschaft, Heidelberg 31989 (UTB für Wissenschaft. Uni-Taschenbücher, 578), p. 58-60; Rudolf HoKE, article »Hippolithus a Lapide«, dans: Michael StOLleIs (dir.), Staatsdenker in der frühen Neuzeit, Munich 1995, p. 118-128. 
nions au sujet de l'Auteur de ce Traité«, dit-il dans sa préface, »celle qui l'attribue à Bogislas Philippe de Chemnitz mérite manifestement la préférence «207.

À la différence de celle de Bourgeois du Chastenet, la traduction française de 1762 et la traduction allemande qui l'avait précédée ne se fondaient pas sur l'édition originale du livre de Chemnitz, mais sur sa version remaniée et augmentée publiée en 1647. En effet, le traducteur allemand estimait que les autres éditions du texte latin étaient $\gg$ tronquées ${ }^{208}$. Il connaissait aussi le travail de Bourgeois du Chastenet, qu'il signale dans sa préface, en parlant des différentes éditions de Chemnitz: »Il y a une Traduction Françoise, intitulée; Intérêts des Princes d'Allemagne sous le nom d'Hippolithe a Lapide, par Mr. Bourgeois de Chastenet ${ }^{209}$. Et d'ajouter: »Elle fut imprimé[e] en 1712. à Paris, sous le nom de Freistade, en deux Volumes grand in 12. Comme le Traducteur a suivi la premiere Edition de $1[6] 40$ cette Traduction est incomplette ${ }^{210}$. Il faut noter que Freistadt était également le lieu de publication indiqué sur l'édition latine de 1647.

Force est de constater que le traducteur, avec sa traduction qu'il publia au cours de la guerre de Sept Ans, poursuivait un but politique, qui correspondait à celui que Chemnitz s'était fixé à la fin de la guerre de Trente Ans, c'est-à-dire de dénoncer le prétendu despotisme de la maison d'Autriche ${ }^{211}$. Ce traducteur prétendait même que les dangers auxquels sa patrie était exposée au temps de l'empereur François I ${ }^{\text {er }}$ étaient plus considérables que ceux qu'elle avait encourus sous le règne de Ferdinand II. En effet, le traducteur dit dans sa préface:

on espère qu'en pesant attentivement les circonstances que Chemnitz met sous les yeux, on pourra se procurer une pleine conviction de l'extrème ressemblance qui se trouve entre la conduite \& les desseins de Ferdinand II. \& de toutes les démarches de S. M. I. François I. Je me retracte cependant: celui qui occupe aujourd[']hui le Thrône Impérial l'emporte de beaucoup sur celui qui l'occupoit alors. Les troubles qui désolent l'Empire sont incomparablement plus funestes que ceux de ces tems-là 212 .

En commentant la préface de Chemnitz, dans laquelle cet auteur avait expliqué l'état déplorable de l'Allemagne à la fin de la guerre de Trente Ans, le traducteur renchérissait sur ce tableau sombre en prétendant: "Dans le tems où Bogislas de Chemnitz écrivoit ceci, il s'en faloit bien que l'Empire d'Allemagne fut aussi bouleversé, \& d'une maniere aussi dangereuse qu'il l'est aujourd[']hui «213. Toutefois, le traducteur espérait que les patriotes allemands et les protestants rempor-

207 [CHEMNITZ], Les Vrais Intérets de l'Allemagne (1762), version française de la préface du traducteur allemand, p. $)(4$ '.

208 Ibid., p. )(4.

209 Ibid. [sic].

210 Ibid., p. )(4-)(4'. L'édition originale de Chemnitz est datée $» 1640 \ll$, mais elle fut probablement publiée en 1642 ou 1643.

211 Au sujet de la propagande politique en Allemagne pendant la guerre de Sept Ans, cf. Manfred SCHORT, Politik und Propaganda. Der Siebenjährige Krieg in den zeitgenössischen Flugschriften, Francfort/M. et al. 2006 (Europäische Hochschulschriften, série III: Geschichte und ihre Hilfswissenschaften, 1023)

212 [CHEMnITZ], Les Vrais Intérets de l'Allemagne (1762), p. [)(8].

213 Ibid., p. [I]-2. 
teraient une victoire encore plus importante que par la paix de Münster et d'Osnabrück ${ }^{214}$.

L'objectif politique du traducteur se manifeste surtout dans son commentaire du texte de Chemnitz; les notes sont souvent plus longues que le texte même. II n'en reste pas moins que les différentes versions françaises de Chemnitz publiées entre 1712 et 1762 montrent que cet auteur du temps de la guerre de Trente Ans était toujours d'actualité pour les contemporains du vieux roi Louis XIV et de Louis XV. Mais il fut aussi lu et utilisé par des savants sérieux dans leurs ouvrages de jurisprudence et d'histoire: par exemple, le père Barre le cite à propos de l'origine du Conseil aulique ${ }^{215}$. Même après 1774, »Hippolyte à Lapide de ratione status « est cité dans une »Introduction au droit public d'Allemagne $\ll^{216}$. Cette hostilité envers la maison d'Autriche qui caractérise l'ouvrage de Chemnitz marque aussi l'esprit d'un certain nombre d'auteurs français du début du XVIIIe siècle. Parmi ces derniers, il faut évoquer, sans aucun doute, Jean-Yves de Saint-Prest.

\section{L'éclatement du Saint-Empire vu par Saint-Prest}

En 1725 , Saint-Prest publia une »Histoire des traités de paix « en deux tomes ${ }^{217}$, à laquelle on doit attacher une importance particulière, puisque Saint-Prest avait auparavant participé à la formation de jeunes diplomates à l'académie de Torcy ${ }^{218}$. Il est donc probable que les idées dont il fait profession dans cet ouvrage sur l'histoire des traités correspondent au contenu des cours qu'il a dispensés à cette première école diplomatique française. Par ailleurs, une copie manuscrite de la partie de cette »Histoire des traités«, qui regarde la paix de Westphalie, est conservée parmi les papiers diplomatiques du Quai d'Orsay concernant l'Allemagne, de sorte qu'on doit supposer que cet ouvrage fut en particulier utilisé au dépôt des archives pour s'instruire de l'histoire des traités passés par la France avec l'Allemagne $^{219}$. Saint-Prest a aussi rédigé des mémoires pour le dépôt des archives des Affaires étrangères. Entre autres, on y a conservé son mémoire $\gg$ Du Palatinat du Rhin «220; dans ce mémoire, Saint-Prest donne aussi un résumé des articles de la

214 Ibid., p. [)(8]-[)(8'].

215 Cf. BARRE, Histoire générale d'Allemagne, ici t. VIII, première partie (1493-1532), »Eclaircissement« sur les origines du Conseil aulique, p. [I]-II.

216 BNF, F.fr. 13401; introduction rédigée après 1774, sous le règne de Joseph II (cf. p. 57, n.

* et p. 77); t. III de l'»Abrégé de l'histoire diplomatique des principaux Etats de l'Europe, manuscrits recueillis par J. Gaudin «; note, fol. [I]: "Destiné après ma mort pour mon amy Grandprey, grandjuge de la Martinique «, signée J. Gaudin.

217 [SAINT-PREST], Histoire des traités de paix.

218 Pour une copie manuscrite de la partie de l'ouvrage de Saint-Prest qui traite des traités de Westphalie, cf. bibliothèque de l'Arsenal, ms. 4580.

219 AE, MD All. 21.

220 Copie: AE, MD All. 12 fol. 41-86’; une autre main a ajouté, au début, la datation »1715 « et le nom de l'auteur: » Par monsieur de Saint-Prês«. 
Bulle d'or concernant le Palatinat du Rhin ${ }^{221}$. Il a de même rédigé un mémoire traitant des princes cadets de la maison palatine ${ }^{222}$, où il parle plus précisément des princes cadets de Bavière ${ }^{223}$ et d'autres branches palatines, examinant par exemple la séance des Bavarois dans les diètes d'Empire 224 .

Malgré les critiques que plusieurs contemporains de Saint-Prest ont émises à l'égard du non-respect des traités par les princes qui les ont conclus, cet auteur tient toujours l'étude de ces traités pour indispensable afin d'assurer le bien public $^{225}$, et reprend à son compte la vieille comparaison entre le combat par l'épée et le combat par la plume ${ }^{226}$. En effet, les négociations qu'un souverain et ses ministres sont obligés de mener exigent la connaissance des traités précédents; outre les informations concrètes qu'on doit en tirer, l'étude des anciens traités, estime Saint-Prest, peut servir à enrichir la réflexion politique et à mieux fonder ses propres prétentions envers les autres États; pour cette raison, il recommande la lecture non seulement des traités passés par l'État concerné, mais aussi de ceux qui ont été conclus par les pays étrangers. Ces remarques concernent aussi l'étude des traités de commerce. On sait que Saint-Prest ne fait pas ces observations, qui montrent très bien le rôle primordial des traités dans la pensée politique du XVIIIe siècle, dans la seule intention de justifier son sujet auprès de ses lecteurs. SaintPrest était un passionné de l'étude des traités, et profondément convaincu de l'utilité de celle-ci. Il l'avoue dans quelques remarques personnelles qu'il s'est permis d'insérer dans sa préface du premier tome de son »Histoire «; la passion pour l'étude des traités se joint à celle de servir le roi de France ${ }^{227}$. C'est pourquoi on ne doit point tenir son ouvrage pour impartial; au contraire, ses explications de certains traités franco-allemands défendent à pratiquement tous les égards l'interprétation qu'on en faisait en France.

Saint-Prest a écrit l'histoire des traités passés entre les États souverains d'Europe dans la période qui va de la paix de Vervins (1598) à celle de Nimègue (1679). Son ouvrage couvre donc l'espace de quatre-vingts années. En revanche, il ne parle qu'à titre exceptionnel des traités antérieurs, si ceux-ci sont restés en vigueur jusqu'à l'époque où il écrit, et rarement de ceux qui ont été passés avec les puissances non européennes puisqu'il les juge peu utiles ${ }^{228}$. Son "Histoire" ne veut pas faire un simple résumé des clauses des traités de paix, d'alliances et de

${ }^{221}$ Cf. ibid., fol. $47^{\prime}-48^{\prime}$.

222 Copie, avec un certain nombre de corrections, surtout au début: ibid., fol. 92-102'; une autre main a ajouté, au début, le nom de l'auteur: »Par monsieur de Saint-Prês«.

223 Ibid., fol. 92.

224 Cf. ibid., fol. 93-94.

225 Cf. SAINT-PrEST, Histoire des traités, t. I, préface, p. I.

226 Cf. ibid.: »Toutes ces circonstances [qui font que les traités évitent le bouleversement universel dans tous les États du monde par les précautions qu'on prend pour assurer leur respect] rendent l'étude des Traités de Paix la plus belle étude du monde \& la plus nécessaire par rapport au bien public. Ceux qui s'y appliquent sont du moins aussi utiles à leur Patrie \& la défendent aussi glorieusement par leur plume qu'un habile Général par son épée«.

227 Cf. ibid., p. II.

228 Cf. ibid., p. III. 
commerce. L'occasion à laquelle ils ont été conclus, les motifs respectifs des parties contractantes, les guerres qui les ont éventuellement précédés et l'exécution de ces traités sont étudiés au même titre que leur teneur. Il est à noter que SaintPrest prête une attention particulière aux manifestes publiés par les princes au début des guerres que les traités ont terminées, et notamment aux raisons et aux prétextes par lesquels ils justifient ces guerres.

Suivant la répartition géographique de l'Europe en neuf régions, Saint-Prest évite de toucher aux problèmes de préséance dans le plan de son ouvrage: en quatre parties et en dix livres, il parcourt l'Europe du Nord au Sud et de l'Ouest à l'Orient, commençant par la Grande-Bretagne et finissant par l'Empire ottoman ${ }^{229}$. Toutefois, Saint-Prest privilégie bel et bien la France: tous les traités qu'elle a passés avec les pays étrangers sont étudiés dans le livre qui lui est consacré230; cette règle est aussi valable pour les pays qui sont traités dans les livres I à III231. Deux particularités sont à signaler: étant donné que les accords étudiés sont conclus par des souverains (non pas par des nations, abstraction faite des quelques républiques), Saint-Prest commence l'exposé de chaque puissance avec une histoire des souverains qui l'ont gouvernée, surtout depuis la paix de Vervins; pour la même raison, il est attentif aux titres et aux qualités que ces princes prennent dans les préambules des différents traités qu'ils ont conclus, et explique leur signification ainsi que, le cas échéant, les contestations qui existent à leur égard.

Les traités conclus entre l'Empire et les princes allemands avec la France sont étudiés dans le livre IV, qui est consacré à la France. Quant aux traités de Westphalie et aux autres traités qui contiennent des clauses qui ne regardent pas directement la France, on doit aussi se reporter à d'autres livres pour retrouver les remarques de Saint-Prest à leur égard; car dans ce livre IV, il ne parle que des intérêts de la France, notamment des cessions territoriales qui sont faites à son profit. Étant donné que le traité de Munster, par exemple, concerne aussi d'autres puissances, comme la maison d'Autriche, la Suisse et un grand nombre d'États allemands, on doit chercher le résumé des stipulations respectives, et éventuellement leur histoire particulière, dans les livres où il en est question ${ }^{232}$. C'est-à-dire que le plan que Saint-Prest a donné à son ouvrage aboutit à un véritable éclatement des traités multilatéraux, ce qui fait que les remarques, notamment sur la paix de Westphalie ${ }^{233}$, se trouvent dispersées dans l'ouvrage entier ${ }^{234}$.

229 Pourtant, cette division en parties et livres ne reflète qu'imparfaitement la division de l'Europe en neuf secteurs géographiques. C'est ainsi que la Pologne (Europe centrale orientale) est traitée dans le même livre que le Portugal et l'Espagne (Europe méridionale occidentale); il s'agit du livre IX.

230 Il s'agit du livre IV, qui constitue à lui seul la deuxième partie.

${ }^{231}$ Livre I: Grande-Bretagne; livre II: Danemark; livre III: Suède, Moscovie.

232 Par exemple, pour ce qui est de la Suisse, au livre VI.

233 Certes, la paix de Westphalie se compose en principe de deux traités bilatéraux passés par l'empereur et l'Empire respectivement avec la France et la Suède, mais comme Saint-Prest ne regarde pas les états de l'Empire comme simples sujets de l'empereur ou de l'Empire, et leur accorde par conséquent un livre particulier, la paix de Westphalie (tout comme certains traités postérieurs, telle la paix franco-allemande de Nimègue) devient de facto un traité mul- 
Il est donc compréhensible que Saint-Prest ait ajouté, à la fin du deuxième tome de son »Histoire des Traités«, une histoire particulière des traités de Westphalie. Mais Saint-Prest évoque une autre raison pour justifier son choix de parler de cette paix dans un véritable ouvrage à part: dans le corps de l'histoire générale des traités, le récit des détails (par exemple le résumé des différentes propositions de paix) des négociations de Münster et d'Osnabrück n'eût pas pu trouver sa place. Or, cette paix est pour lui la plus importante de toutes, de sorte qu'il faut en avoir des notions très précises ${ }^{235}$. Cependant, cette histoire particulière de la paix de Westphalie ne répète pas tout ce que Saint-Prest dit à ce propos dans son histoire générale des traités, de sorte que pour avoir une vision complète de l'interprétation qu'il fait de cette loi fondamentale du Saint Empire romain germanique, il faut vraiment avoir lu presque tout l'ouvrage. Le livre consacré à la Suède se penche évidemment sur le traité d'Osnabrück, et analyse surtout les cessions territoriales de fiefs impériaux faites par l'Empire à la Suède: Poméranie; Wismar; Brême, Verden ainsi que la ville et le baillage de Wilshausen ${ }^{236}$. Saint-Prest en exclut formellement toutes les clauses qui ne concernent pas directement la Suède mais ses alliés allemands, car il considère ces articles véritablement comme des traités passés entre l'empereur et les états de l'Empire ${ }^{237}$. Le chapitre consacré aux traités conclus entre la France et la Lorraine évoque les négociations de Münster entre Louis XIV, d'un côté, et Ferdinand III et Philippe IV, de l'autre, au sujet de la Lorraine, en $1648^{238}$. Saint-Prest récapitule la question de l'attribution

tilatéral dans la perspective adoptée par cet auteur. L'éclatement de l'Empire est encore souligné par le plan de cet ouvrage: les traités passés par la maison d'Autriche avec les états de l'Empire et les puissances européennes sont étudiés au livre VII, qui appartient à la troisième partie; en revanche, les traités que les électeurs et les états de l'Empire ont conclus avec les princes qui ne relèvent pas de l'Empire sont classés au livre VIII, qui se trouve au début de la quatrième partie.

${ }^{234}$ Bien qu'une table des traités (qui n'est pourtant pas un index) permette au lecteur de mieux se repérer dans ces deux volumes, Saint-Prest a ainsi détruit la cohérence des traités mêmes et, dans une certaine mesure, obscurci leur essence.

${ }^{235} \mathrm{Cf}$. SAINT-PrEST, Histoire des traités, t. I, préface, p. V: „Ces particularitez [des négociations de Münster et d'Osnabrück] donnent une connoissance exacte de la situation de l'Europe au tems du Traité, \& rendent plus intéressante l'Histoire d'une Paix qui a été depuis le fondement de toutes les autres«. À part les traités de Westphalie, Saint-Prest parle, dans cette annexe à son histoire générale des traités, des négociations franco-espagnoles qui aboutirent à la paix des Pyrénées, et qui furent en quelque sorte la suite des pourparlers franco-espagnols qui avaient eu lieu à Münster, et des traités passés par le duc Charles IV de Lorraine entre 1630 et 1663 , ces derniers s'insérant au cœur des litiges franco-espagnols.

${ }^{236} \mathrm{Cf}$. ibid., p. 173-177; ces trois espaces géographiques constituent autant de paragraphes chez Saint-Prest; le règlement de la soi-disant satisfaction de l'armée suédoise est évoqué à la fin de celui concernant les évêchés sécularisés et Wilshausen.

${ }^{237} \mathrm{Cf}$. ibid.,p. 173, où Saint-Prest réserve tous les articles »qui regardent les Princes \& Etats de l'Empire« au livre VII (par erreur, Saint-Prest écrit »Livre cinquième«), car c'est là qu'il se propose de parler »des Traitez faits entre l'Empereur \& les Etats de l'Empire«, se justifiant par la raison suivante: »comme la Suéde n'avoit point d'autre intérêt dans ces articles que celui de ses Alliez, ils doivent être considérez comme s'ils avoient été passez entre l'Empereur \& chacun de ces Princes \& des Etats de l'Empire «.

238 Cf. ibid., p. 398-400. 
d'un éventuel passeport au duc de Lorraine depuis le congrès prévu à Cologne, et résume les différentes positions des deux parties au sujet d'un règlement du problème lorrain, qui s'était provisoirement achevé sur le constat d'un désaccord, en 1648; cet auteur estime que par l'exclusion du cercle de Bourgogne dans la paix de Münster ${ }^{239}$, le duc Charles de Lorraine fut "abandonné par l'Empereur \& par tous les Princes de l'Empire «240. Il va de soi que Saint-Prest s'intéresse de près au traité de paix de Münster conclu entre Louis XIV et Ferdinand III, le 24 octobre 1648 , et surtout aux clauses concernant le dédommagement de la France. À part ces intérêts français, Saint-Prest évoque aussi, au même sous-chapitre, le problème de la Savoie et celui de Mantoue ${ }^{241}$. Comme dans le cas du traité d'Osnabrück, cet auteur exclut expressément tous les règlements qui regardent les princes allemands de l'exposé du traité conclu entre le roi de France et l'empereur, en prétendant que ces clauses n'y avaient été insérées qu'à la demande de ce dernier, pour éviter la conclusion d'un traité particulier avec les états de l'Empire qui relevaient de lui. Néanmoins, ces états et l'empereur doivent, selon SaintPrest, être tenus pour les véritables parties contractantes ${ }^{242}$.

En réalité, l'empereur avait bel et bien conclu un traité particulier avec les états de l'Empire: la paix de Prague, en 1635. À cause de l'exclusion des couronnes étrangères de ce traité, la guerre avait continué et les affaires allemandes avaient été remises à l'ordre du jour des négociations en Westphalie. Il est vrai que l'empereur avait cherché à éviter la convocation des états de l'Empire au congrès et qu'il eût préféré régler tout ce qui touchait l'Allemagne sans la présence des puissances étrangères, au lieu d'en parler dans les traités conclus avec la France et la Suède. Mais, autant que nous sachions, le problème d'un traité particulier entre l'empereur et les états n'y fut jamais discuté.

En ce qui concerne le récit des négociations entre les plénipotentiaires de France et ceux de l'empereur au sujet du dédommagement territorial qui devait être accordé au roi de France, Saint-Prest fait une interprétation unilatérale de la cession des Trois-Évêchés, qui élude l'ambiguïté des termes employés dans les articles qu'on formula suite à l'accord de principe trouvé le 13 septembre $1646^{243}$.

239 Cf. le $\S 3$ du traité de Münster, OschmanN, APW III B 1/1, p. 5.

240 Cf. SAINT-PREst, Histoire des traités, t. I, p. 400. Sur l'exclusion de la Bourgogne, dont l'appartenance à l'Empire fut pourtant confirmée, cf. aussi le résumé du traité de Münster, ibid., p. 447. D' ailleurs, sur la question des passeports, le sous-chapitre relatif au traité de Nimègue (cf. ibid., p. 408-411) est en contradiction flagrante avec celui qui traite du problème lorrain en Westphalie, en ce qui concerne le congrès prévu à Cologne (en 1638): en effet, dans le sous-chapitre VIII, Saint-Prest dit que »le Roi ne fit point de difficulté d'accorder des passeports au Duc de Lorraine « pour le congrès de Cologne, mais que, pour des raisons particulières, il agit différemment au congrès de Westphalie; par contre, au sous-chapitre XVI, Saint-Prest établit une continuité entre 1638 et 1648 en disant: »Lorsqu'on s'assembla à Cologne pour la Paix, le Roi avoit refusé des Passeports au feu Duc de Lorraine qui vouloit y envoyer ses Plénipotentiaires; on avoit fait la même chose pour le Congrès de Munster«.

241 Cf. ibid., p. $443-450$.

242 Cf. ibid., p. 443.

243 Contrairement à ce qu'on peut parfois lire dans certains ouvrages, cet accord ne fut 
Selon son opinion, les Impériaux et les états de l'Empire avaient tacitement accepté la cession des diocèses en renonçant à l'insertion de tout terme qui limitât la cession au domaine temporel des évêques; en réalité, les clauses de cession parlaient des évêchés sans préciser si ce terme s'appliquait à leur district spirituel, donc aux diocèses (plus vaste), ou à leur district temporel (plus restreint). Par leur refus de la clarification proposée par les Impériaux, les Français avaient donc obtenu que la clause restât ambiguë sur ce point, mais ils n'avaient pas pour autant imposé leur propre interprétation, comme Saint-Prest veut le suggérer ${ }^{244}$. D'ailleurs, la déclaration présentée par les états de l'Empire à Abel Servien, limitant l'exercice de la juridiction royale dans les Trois-Évêchés au statu quo ante (bien que refusée par ce dernier), fait voir qu'il n'en était rien.

En ce qui concerne la cession de l'Alsace en toute souveraineté, les raisons apportées par Saint-Prest pour justifier le choix de la souveraineté, au détriment d'une éventuelle session du roi de France à la diète de l'Empire, sont concluantes, mais, comme nous avons pu le constater, la politique française au congrès de Westphalie s'était montrée hésitante sur ce point, de sorte que ce furent plus les Impériaux qui en décidèrent, les Français entérinant en général la proposition qui leur fut faite. Cependant, Saint-Prest allègue les raisons suivantes: premièrement, le rang modeste qui aurait été accordé au roi de France à la diète n'aurait pas correspondu à l'honneur royal; deuxièmement, la condition de vassal du Saint-Empire que le roi aurait acquise en tenant l'Alsace en fief aurait permis à l'empereur de le mettre au ban de l'Empire, et même de prononcer une condamnation à mort à son encontre ${ }^{245}$. Même si ces dernières raisons sont hypothétiques, il est vrai que les contemporains de Louis XIV auraient jugé la condition de vassal du SaintEmpire comme quasi incompatible avec sa qualité de roi de France. De même que Laguille, Saint-Prest insiste sur le fait que le titre de landgrave d'Alsace que l'empereur continua à prendre, malgré cette cession, ne remit point en cause l'appartenance de cette province au royaume de France ${ }^{246}$.

jamais signé; de plus, sa validité était en principe limitée au terme du 30 septembre 1646 (cf. REPGEN, Satisfaktionsartikel).

244 Cf. SAINT-Prest, Histoire des traités, t. I, p. 446, qui conclut "que l'Empereur et les Etats de l'Empire consentirent tacitement que la Souveraineté de Sa Majesté s'étendît sur tous les Seigneurs qui relévent de ces Evêchez, ou qui ont leur[s] fiefs situez dans l'étenduë de leurs diocéses «. En revanche, sa traduction des articles relatifs aux cessions territoriales est impeccable. Ces articles sont parfois cités presque littéralement sans qu'on puisse pour autant parler d'une véritable traduction mot à mot, cf. ibid., p. 448-450.

245 On peut noter que Saint-Prest (ibid., p. 446) fait la même erreur qu'on peut détecter à un moment dans la correspondance des diplomates français en Westphalie et qui consiste à parler d'un siège du landgrave d'Alsace à la diète de l'Empire - or, le landgrave en tant que tel ne siégeait pas à la diète. En outre, au moment du congrès, Godefroy avait déjà évoqué la possibilité que le roi fût mis au ban de l'Empire.

246 Pour le souligner, il renvoie à la déclaration remise par les plénipotentiaires de France aux Impériaux, quand Boulanger, secrétaire de l'ambassade française au congrès de Westphalie, signa le traité préliminaire avec eux, le 11 novembre 1647; selon cette déclaration, cette signature ne devait pas être tenue pour valable si les Impériaux ne déclaraient pas par écrit que l'empereur et tous les princes de sa maison ne prendraient plus dorénavant le titre 
Au chapitre XII, Saint-Prest analyse les traités passés par le roi de France avec les électeurs de l'Empire. Au début de ce chapitre XII du livre IV, il explique correctement que le droit d'alliance, que non seulement les électeurs, mais tous les états de l'Empire ont de iure, leur a été contesté avant la paix de Westphalie, tandis que depuis 1648 il n'est plus remis en cause. Cependant, la conclusion de Saint-Prest, qui suggère que les états prétendaient être souverains, n'est pas conforme à la réalité - car Saint-Prest n'emploie pas le terme de »souveraineté« comme synonyme de supériorité territoriale, mais dans son sens absolu ${ }^{247}$. On doit encore noter qu'au début des chapitres et des sous-chapitres respectifs, SaintPrest a ajouté des observations sur les états de l'Empire et leurs différents collèges en général, ainsi que sur les états en particulier (et leurs titres), dont il résume les traités conclus avec les puissances étrangères et entre les princes eux-mêmes ${ }^{248}$. Qui plus est, dans ses remarques sur les traités passés entre l'empereur et les électeurs ou les états de l'Empire en général, Saint-Prest développe toute une théorie de leurs rapports constitutionnels.

Au début du livre VII, qui, lui, est consacré aux traités passés entre les empereurs et les autres princes et États de l'Europe, Saint-Prest évoque déjà le statut des empereurs en général. Il fait part au lecteur du peu d'estime qu'il fait de la dignité impériale, qui lui paraît presque ridicule:

Si les Empereurs d'à présent étoient Souverains de l'Univers, ainsi que les Empereurs Romains, dont ils se disent les Successeurs, se vantoient de l'être, je n'aurois pas été en peine de composer cette Histoire, puisque tous les autres Princes étant leurs Sujets, ils n'auroient pu suivant les principes que j'ai établis, passer avec eux des Traitez obligatoires qui sont les seuls dont je me suis proposé de parler en cet Ouvrage [...]. Mais comme après que la dignité Impériale fut sortie de la Maison de Souabe, les grandes dissentions \& le long interregne qui arrivérent dans l'Empire [au XIIIe siècle], donnérent lieu aux Princes \& aux villes d'Allemagne $\&$ d'Italie de se rendre presque entiérement Souverains chacun dans leur détroit [...], un

de landgrave d'Alsace, cf. ibid. On sait que l'empereur n'abandonna pas ce titre - comme d'autres monarques (tels que le roi de France) gardaient leurs titres sur les territoires qu'ils avaient perdus, pour renouveler éventuellement un jour leurs prétentions -; cependant, la possession française de l'Alsace ne fut pas affectée.

247 En effet, la supériorité territoriale est compatible avec l'appartenance à l'Empire d'une manière qui ne nécessite aucune explication, tandis que Saint-Prest oppose la souveraineté des ordres au fait qu'ils relèvent de l'Empire. Cf. ibid., p. 460: »Quoique tous les Princes d'Allemagne relévent de l'Empire, \& prennent de l'Empereur les investitures de leurs Etats, ils prétendent néanmoins être Souverains, \& que, si l'Empereur est le Chef de l'Empire, ils en sont les membres: de sorte qu'ils jouïssent de presque tous les droits de souveraineté \& prennent entr'autres celui de faire des alliances avec les Princes étrangers sans le consentement de l'Empereur. Ce droit leur avoit toûjours été contesté par les Empereurs qui regardoient ces Traitez d'alliances comme des attentats à l'autorité souveraine qu'ils s'attribuoient dans l'Empire; mais enfin ils ont été obligez de consentir par le Traité d'Osnabruk« que les princes jouissent du »droit de faire des alliances« dans certaines conditions. Si Saint-Prest restreint un peu la portée de ses propos en disant seulement que les princes de l'Empire ont "presque tous les droits de souveraineté«, il résulte de ses autres remarques sur leur condition qu'il les tient pour pratiquement souverains.

248 Au début du livre VII, qui traite des traités passés entre les empereurs et les autres États et princes européens, Saint-Prest explique les différents titres que les empereurs ont pris dans ces traités, cf. ibid., t. II, p. 125-137. 
Empereur qui n'auroit que ce qui lui revient en cette qualité, seroit plus foible \& plus pauvre que le moindre Gentilhomme d'Allemagne. C'est ce qui est cause que d'une part les Princes d'Allemagne \& d'Italie n'obéissant présentement aux Empereurs qu'autant qu'il leur plaît, sont quelquefois entrez en guerres contre eux, lesquelles ils ont ensuite terminées par des Traitez de paix; \& que d'autre part les Empereurs ayant souvent besoin du secours de ces Princes pour leur propre défense \& pour parvenir à leurs desseins, ils ont été obligez de leur confirmer les droits dont ils s'étoient emparez, $\&$ ont fait avec eux divers Traitez d'alliance 249 .

Saint-Prest n'accepte donc pas la théorie de la translatio Imperii. Pour lui, les empereurs du XVIII ${ }^{e}$ siècle ne sont pas les successeurs des anciens empereurs romains. Qui plus est, d'après Saint-Prest, les états de l'Empire ne dépendent en aucune manière de l'empereur ni du Saint-Empire. Saint-Prest déclare que non seulement les électeurs, mais tous les princes de l'Empire sont de véritables souverains: »Les Princes \& les autres Etats de l'Empire ne sont pas moins Souverains dans leurs territoires, que le sont les Electeurs dans leurs terres $\ll^{250}$.

En réalité, les rapports constitutionnels entre l'empereur et les états de l'Empire étaient de deux natures différentes: d'un côté, l'empereur concluait des traités avec les princes de l'Empire, et les deux parties étaient dans ce cas-là de véritables parties contractantes et par conséquent égales en droit; mais, de l'autre, l'empereur était le chef de l'Empire et, en cette qualité, il était le suzerain des états de l'Empire. Or, Saint-Prest réduit tous les rapports juridiques existant entre l'empereur et les ordres à des relations contractuelles. De cette manière, non seulement les véritables traités conclus par l'empereur avec une partie des états de l'Empire - comme le traité de Passau de 1552, la paix de Prague de $1635^{251}$, les clauses des traités de 1648 au sujet des affaires générales de l'Empire ${ }^{252}$ - sont évoqués dans le chapitre que Saint-Prest consacre aux traitẹ́s de l'empereur et des états de l'Empire, mais c'est aussi le cas de la paix de religion d'Augsbourg de $1555^{253}$ et des capitulations impériales ${ }^{254}$. Les articles de la Bulle d'or concernant les princes

249 Ibid., p. $125-126$.

250 Ibid., p. 231.

251 Cf. ibid., respectivement p. 138-142 et p. 143-147.

252 Cf. ibid., p. 148-169, en particulier p. 165-167 pour les droits des états de l'Empire. En revanche, les stipulations des traités de 1648 concernant seulement une partie des ordres sont évoquées passim, par exemple, pour la Bavière, p. 204-206; pour le Brandebourg, p. 214218; pour le Palatinat, p. 228-230; pour les archevêchés et évêchés d'Allemagne en général et pour certains d'entre eux en particulier, p. 234-238; pour la Hesse-Cassel, p. 278-280; pour les comtes de l'Empire et la noblesse immédiate, p. 296-310 (cf. aussi les renvois, p. 168-169).

253 Cf. ibid., p. 142-143.

254 Pour la capitulation entre l'empereur Ferdinand II et les électeurs, 1619, cf. ibid., p. 170 172; pour la capitulation de Ferdinand IV, 1653, p. 173-174; pour celle de Léopold Ier, 1658, p. 175-176. Pour les articles de la capitulation de Ferdinand II concernant les électeurs, cf. également p. 182-183; pour les articles de la capitulation de Ferdinand IV concernant les électeurs, p. 183-184; pour ceux de la capitulation de Léopold Ier concernant les électeurs, p. 184-185. Enfin, pour les articles dans les capitulations de 1653 et de 1658 concernant la promotion de nouveaux princes de l'Empire, cf. p. 232-233; pour l'article de la capitulation 
électeurs sont également mis au nombre des traités passés entre l'empereur et les électeurs 255 , alors que, du point de vue juridique, il s'agissait d'une constitution impériale au lieu d'un traité bilatéral ou multilatéral. En général, force est de constater que Saint-Prest découpe les documents et insère les articles tirés des mêmes traités dans les différents chapitres de son »Histoire des traités «. De cette façon, ces articles ne peuvent plus être interprétés en fonction du contexte dans lequel ils se trouvaient dans les traités. Néanmoins, l'ouvrage de Saint-Prest avait très certainement une grande valeur pour la connaissance du droit public germanique, puisque cet auteur abordait de nombreuses questions constitutionnelles 256 .

C'est vrai également pour un autre auteur qui écrivait pour les futurs diplomates, Abraham de Wicquefort. En effet, dans "L'Ambassadeur «, ce dernier utilise fréquemment le terme de »souverain « en parlant tant des véritables souverains que des états de l'Empire. Dans la traduction allemande de Sauter ${ }^{257}$, ce mot n'est pas traduit en allemand; en effet, au lieu de le traduire, Sauter emploie le mot étranger »souverain « en caractères latins, alors que le texte allemand est imprimé en lettres gothiques; il décline ce mot étranger tantôt comme un nom français, tantôt comme un nom allemand ${ }^{258}$. De la même manière, l'auteur a conservé le mot étranger français »Souveraineté « ${ }^{259}$. Même quand il s'agit des états de l'Empire, Sauter n'a pas traduit ce concept en allemand ${ }^{260}$. En effet, comme Wicquefort tenait les ordres pour souverains, il ne convenait pas de changer, dans la traduction de son ouvrage, la terminologie mettant en évidence leur souveraineté261. Même dans cette traduction établie par un juriste allemand, on peut donc lire que, en

de Léopold au sujet de l'Espagne, p. 345-346; pour celui concernant la Savoie, p. 358-359; au sujet de Modène, p. 363-364, etc.

255 Cf. ibid., p. 182.

256 Il évoque, par exemple, le traité de Francfort de 1658 entre les électeurs de Mayence et de Cologne au sujet de leur différend concernant leur droit de couronner les empereurs, cf. ibid., p. 441.

257 Pour la biographie de Johann Leonhard Sauter, un juriste et traducteur allemand de la deuxième moitié du XVIIe siècle, cf. Deutsches Biographisches Archiv I 1083, 151.

258 Cf. [Abraham] DE WICQUEFORT, L'Ambassadeur oder Staats=Bothschaffter/ Und dessen hohe fonctions, und Staats=Verrichtungen [...] Nunmehro aber in unsere Hoch=Teutsche Sprache ůbersetzet von Johann Leonhardt Sautern/ J.U.D. in Leipzig [...], Francfort/M. 1682, passim (cf., par exemple, les index de la première et de la deuxième partie s.v. »souverain « [fol. e2-e2' et fol. i]).

259 Cf., par exemple, ibid., p. 39.

${ }^{260} \mathrm{Cf}$., en particulier, sa traduction du chapitre IV, concernant le droit d'ambassade des princes de l'Empire (ibid., p. 51-70).

261 Pour cette raison, selon Wicquefort, on ne peut pas refuser aux états d'avoir des ambassadeurs sans remettre en question leur souveraineté, qu'ils ont obtenue par les traités de Westphalie comme pragmatique sanction de l'Empire: $\gg$ Wil demnach anjetzo nur noch dieses gedencken/ daß solcher respect denen Fürstlichen Personen nicht wol kỏnne versaget werden/man wolle ihnen denn ihre Souveraineté disputirlich machen/ welches dann eben so wenig wahrscheinlich ist/ daß die jenigen/ so sich dessen unterwinden würden sich dißfals selbst/als von welchen dieselbe bey denen Münsterischen Tractaten vermóge einer Pragmatischen Sanction ihnen zuerkennet wordē/ allermaßen sie sich dañ daselbst mit denen teutschen Fürsten als Souverainen Hăuptern in würckliche Tractaten eingelassen haben/ offenbarlich widersprechen müsten« (ibid., p. 52). 
vertu des traités de Westphalie et des capitulations signées par les empereurs Ferdinand III et Léopold Ier, les états de l'Empire peuvent »aller de pair " ("gleichgehen «) avec les têtes couronnées, bien qu'ils leur cèdent la préséance. Or, dans ce contexte, on note que Sauter admet l'existence d'un superlatif en allemand de l'adjectif »souverain « (»les têtes les plus souveraines«), alors que ce mot a déjà en lui-même le sens d'un superlatif 262 . L'empereur, pour sa part, a été le chef souverain de l'Empire (»ein souverain Haupt war«), mais il n'a plus cette qualité263. En revanche, le traducteur allemand reconnaît la souveraineté des princes de l'Empire, en les qualifiant de »Souverains« et leur puissance de »Souveraineté«, comme Wicquefort l'a fait dans l'original français ${ }^{264}$. À la différence de certains éditeurs scientifiques français, qui ont abondamment commenté, dans des notes de bas de page, les ouvrages qu'ils ont édités ou traduits, dans la deuxième moitié du XVIIe siècle et dans la première moitié du XVIIIe, Sauter s'est d'ailleurs abstenu d'ajouter à l'ouvrage de Wicquefort des commentaires approuvant ou réfutant ses hypothèses ${ }^{265}$. Sans aucun filtrage intentionnel, les opinions de cet auteur sont donc fidèlement traduites en allemand. Si un docteur allemand ne contredit pas ses assertions relatives à la souveraineté des états de l'Empire, peut-on alors reprocher à certains auteurs français d'avoir tenu ceux-ci pour des souverains?

Certes, les remarques de Wicquefort sur la Constitution du Saint-Empire ne sont pas des observations d'un auteur français. Mais Wicquefort a écrit en français, et les nombreuses éditions de son ouvrage font très certainement partie des manuels du parfait ambassadeur qui ont atteint un public très large parmi les diplomates, les ministres des cours et les hommes d'État aux XVIIe et XVIIIe siècles. On peut donc supposer qu'en considérant les princes de l'Empire comme souverains Wicquefort et Saint-Prest ont pu forger l'image qu'une partie considérable des diplomates s'est faite du Saint-Empire à cette époque.

262 »So versichern auch die mit Kăyser Ferdinand dem dritten/ und itzigem Leopoldo getroffene Capitulationes, benebenst denen Westphalischen Friedens=Tractaten/ die Teutschen Fứrsten ihre Rechte und Vorzüge/ als Krafft welcher sie mit den souverainsten Hâuptem gleich zugehen/ und den Rang/vermóge dessen sie niemand als denen gekróneten Hấuptern weichen dürffen/ zu praetendiren berechtiget seyn« (ibid., p. 58).

263 Ibid.

264 Cf., par exemple, ibid., p. 62-63.

265 Le traducteur a seulement ajouté une dédicace et une préface s'adressant aux lecteurs, ibid., fol. ):(2-[):(4'] et fol. ):( ):( - ):( ):( 3. Dans ces textes, il ne parle pas des opinions de Wicquefort concernant la Constitution de l'Empire. À la fin de la préface, il évoque la mode des Allemands qui veut qu'on ne traduise pas les mots étrangers français, italiens ou espagnols si ces termes décrivent mieux les choses dont on veut parler. Le traducteur note que beaucoup de mots étrangers français, espagnols et italiens sont entrés dans la langue allemande, en particulier dans le langage militaire, parce que ces nations sont responsables d'un plus grand nombre d'innovations techniques que les Allemands, ibid., fol. ):( ):( 2' - ):( ):( 3 . 


\section{Les géographes et l'histoire universelle}

Avant d'aborder la période suivante de la littérature française sur le droit public germanique, qui commence en 1740, il faut dire un mot des géographes et des historiens qui, dans leurs ouvrages de géographie ou d'histoire universelle, évoquaient des problèmes relatifs à la Constitution du Saint-Empire. Il faut aussi signaler que les mémoires historiques que conservent les Affaires étrangères pour la période 1684-1739 prouvent qu'on n'a pas oublié la dimension italienne du Saint Empire romain germanique ${ }^{266}$. Cela résulte clairement d'un »Abrégé historique sur l'Allemagne«, daté de 1736, qui, malgré son titre, ne se limite point à la seule partie allemande de l'Empire ${ }^{267}$. Cet $\gg$ Abrégé« mentionne les différents Éats territoriaux qui composent les dix cercles du Saint-Empire. Mais avant d'aborder cette division en cercles, il explique que l'»Empire Romain consiste aujourd'hui [en 1736] en deux principales parties qui sont: l'Allemagne, et l'Italie $\ll^{268}$. Cette première phrase du texte montre donc que si de nombreux documents parlent indifféremment de l'»Allemagne «, de l'»Empire« et de l'»Empire d'Allemagne«, à la fin du XVII' siècle et au XVIII' dire qu'on néglige la partie italienne du Saint-Empire, mais que, souvent, le souci littéraire d'obtenir une plus grande diversité stylistique peut expliquer le choix des différents termes. Notons toutefois que, pour assurer une plus grande clarté, l'auteur de ce mémoire parle, au début du texte, de l'»Empire Romain« (non pas de l'»Empire « tout court) et qu'il reprend cette dénomination en décrivant les territoires italiens ${ }^{269}$; en revanche, le fait que ce mémoire s'intitule »Abrégé historique sur l'Allemagne«, tout en comprenant l'Italie, atteste le caractère flou de la terminologie à cet égard. Outre l'Italie, l'abrégé inclut aussi la Bohême, qui ne faisait pas partie des dix cercles de 1'Empire, mais dont les relations avec les institutions impériales avaient été renforcées depuis $1708^{270}$. En ce qui concerne l'Italie, il est à noter que les territoires faisant partie du cercle du Haut-Rhin ne sont pas mentionnés dans le paragraphe concernant la description des cercles mais dans celui de l'Italie, sans qu'il soit fait mention de leur

266 Cela est vrai également pour les mémoires juridiques; cf., par exemple, la note »Sur les droits des Empereurs d'Allemagne en Italie«, »1744 décembre $31 \ll, » P a r$ N. L. Le Dran« (AE, MD All. 94 fol. 81-84'); en revanche, la note "Sur l'exercice de l'autorité impériale des Empereurs d'Allemagne en Italie «, »Par N. L. Le Dran au Dépôt des Affaires étrangères, le $27^{e}$ décembre 1715 « n'est en réalité que la copie d'une lettre du prince de Monaco de janvier 1699 (ibid., fol. 79-80). Pour les droits impériaux en Italie vus par les Français au début du XVIII ${ }^{\mathrm{e}}$ siècle, cf. par exemple Lille, bibliothèque municipale, fonds Godefroy, ms. 38 (mémoires historiques et lettres du cardinal Dubois, 1711-1722).

267 »Abrégé historique sur l'Allemagne«, copie: AE, MD All. 67 fol. 2-9; la datation »1736« est ajoutée d'une autre main, à gauche du titre (fol. 2).

268 Ibid., fol. 2.

269 Cf. ibid., fol. 8': »Les principales provinces et villes d'Italie en tant qu'elle fait partie de l'Empire Romain sont: [...] «.

270 Les pays composant le royaume de Bohême sont décrits ibid. 
appartenance à ce cercle d'Empire 271 . Quand il évoque la Savoie, l'auteur signale toutefois la charge de vicaire perpétuel de l'Empire qu'il occupait en Italie.

Quant aux géographes, il faut noter que, en 1696, Pierre Le Lorrain, abbé de Vallemont, publia un ouvrage intitulé "Les Elemens de l'histoire «272, qui connut un succès extraordinaire, dont témoignent ses nombreuses rééditions et ses traductions ${ }^{273}$. Vallemont évoquait les règnes des différents empereurs ${ }^{274}$. À travers son ouvrage, les lecteurs français apprenaient certains éléments fondamentaux de l'histoire allemande, par exemple le fait que Charles IV promulgua la Bulle d'or ${ }^{275}$.

En 1694, d'Audiffret publia sa "Geographie ancienne, moderne et historique«, dont un volume intégral était consacré à l'Allemagne ${ }^{276}$. En plus de la géographie proprement dite, d'Audiffret parlait aussi de l'histoire du Saint-Empire, de l'empereur, des états de l'Empire, de la diète, des cercles, etc., puisque ces sujets concernaient également la géographie politique de l'Allemagne. Un peu plus d'un quart de l'ouvrage concerne l'Allemagne en général, le reste traite de ses différentes parties. L'auteur offre d'abord un aperçu historique qui va du temps des anciens Germains à $1690^{277}$. Puis il décrit le système politique et les institutions du Saint-Empire ${ }^{278}$. Ensuite, il donne une idée générale de sa géographie et des pays héréditaires de la maison d'Autriche ${ }^{279}$, avant d'aborder les autres principautés et États allemands.

La partie qui concerne les institutions est la plus intéressante pour notre sujet. D'Audiffret y fournit des renseignements très précis sur certains aspects du droit public allemand, par exemple sur le fonctionnement de la diète de l'Empire ou sur la révision des procès qui avaient lieu devant les tribunaux suprêmes, le Conseil aulique et la Chambre impériale. L'auteur définit le Saint-Empire comme un État composé, dont tous les membres participent à la souveraineté, et expose les différentes théories existant sur sa forme de gouvernement, avant d'adhérer lui-même

271 Cf. ibid., fol. 8'-9.

272 P[ierre] L[E] L[ORRain] DE Vallemont, Les Elemens de l'histoire [...], 2 vol., Paris 1696.

${ }^{273}$ La deuxième édition parut en 2 t., Paris 1699; pour les fondements de l'histoire générale, notamment: t. II, chapitres I à IV, p. 1-44. À cela s'ajoutent les éditions de 1700,1702, 1708, 1714 (éditions de Paris et d'Amsterdam), 1729, 1745 et 1758 ainsi qu'une traduction italienne de 1748 , parue à Venise sous le titre »Gli elementi della storia«.

${ }^{274}$ Sa liste des »Empereurs Allemands « commence en 912, avec Conrad Ier, les empereurs précédents étant considérés comme Français. VALLEMONT termine avec Léopold Ier. Cf. ID., Les Elemens de l'histoire (1696), t. II, p. 543-550.

275 Cf. ibid., p. 548.

276 Cf. [Jean-Baptiste D'AUdIFFrET], La Geographie ancienne, moderne et historique[.] Tome troisième qui contient, l'Allemagne, Paris 1684. Cf. aussi Tome second, qui contient la France, les Pays-Bas, les Provinces-Unies, la Suisse, \& la Savoye, Paris 1694, p. 396-410 pour l'Alsace.

277 Ibid., p. [1]-96.

278 Ibid., p. 97-117.

279 Ibid., p. 118-129. 
à celle du status mixtus, qui, comme nous le disions, était très répandue en France dans la deuxième moitié du XVIIe siècle 280 :

L'Empire est composé d'un Chef $\&$ de plusieurs Membres, lesquels quoy qu'inegaux en forces, participent également à la Souveraineté du Corps; les Politiques ne sont pas tous d'un même sentiment touchant la forme de son Gouvernement, les uns veulent que c'est un Etat Monarchique par l'obligation où sont tous les Membres de demander à l'Empereur l'investiture de leurs Etats, \& de luy prêter le serment de fidelité; mais ceux qui soûtiennent cette opinion, donnent trop à l'authorité de l'Empereur, parce que l'Investiture que les Etats de l'Empire sont obligez de prendre, est une action de Vassaux \& non pas de Sujets; les autres pretendent que l'Empire est un Etat veritablement Aristocratique par le concours des suffrages des Princes dans les Assemblées, sans lesquels l'Empereur ne peut rien resoudre; mais comme la puissance de l'Empire n'est point indivisiblement dans les mains des Princes, \& qu'il y a encore d'autres Etats, \& les villes Imperiales qui y concourent, il est certain qu'on ne sçauroit l'appeler un Etat Aristocratique.

\section{Et de prendre lui-même position dans ce débat:}

il y en a [des auteurs] qui prennent un milieu entre ces deux opinions, en soûtenant que c'est un Gouvernement Mixte, c'est-à-dire, mêlé également du Monarchique $\&$ de l'Aristocratique, \& cette opinion me paroît la plus recevable \& la plus conforme à la Constitution de l'Empire, parce que si l'Empereur agit souverainement en certains cas, \& qu'il y ait des droits qui dépendent absolument de luy, comme ceux de Regale, de Justice, de Privileges \& d'exemptions; ses Decrets n'ont point de force s'ils ne sont confirmez par les Etats, de sorte que par cette dépendance mutuelle, il se fait un équilibre d'authorité qui modere la puissance du Chef, \& affermit l'independance \& la liberté des Membres 281 .

À cause de ce concours des ordres à la législation, d'Audiffret estime que: »La souveraineté de l'Empire réside dans la diète, ou Assemblée des Etats, les Allemans l'appellent Reichstag, c'est-à-dire, Journée de l'Empire« 282 . Ce rôle primordial de la diète était l'une des conséquences de la paix de Westphalie. En particulier, Jean Heiss et Ulric Obrecht avaient enseigné le droit constitutionnel des traités de Münster et d'Osnabrück aux Français. Dans son »Histoire de l'Empire«, Heiss compara la situation historique de l'Allemagne avant 1648 (première par-

280 Pour la réception de la théorie du status mixtus en France, on peut citer également un tract rédigé au moment de la création du neuvième électorat. Cet auteur se prononce contre la proposition de l'empereur d'accorder la dignité électorale à la maison de Hanovre, puisqu'il craint que cette modification n'entraîne un véritable changement de constitution: »il est certain que l'intérest des Electeurs et Etats de l'Empire dépend sans contradiction de ce que cette forme mixte de la république ne soit changée en aucune manière. Puisque dans icelle le chef et les membres jusqu'à présent se sont toujours bien trouvé[s] dans une bonne et salutaire harmonie, non plus que le nombre des électeurs soit augmenté, et ce que par cette multiplication, l'Aristocratie meslée avec la Monarchie de l'Empire; seroit réduite peu à peu ad statum oli $[\mathrm{g}]$ archicum «, bibliothèque de l'Arsenal, ms. 4135, document no 2 , fol. 33, 34-62' (citation fol. 52), intitulé: "Déclaration du droit Impérial en vertu duquel on ne peut rien changer dans les Loix fondamentales, ny dans le nombre des Electeurs y establis par tous les Etats de l'Empire sans une præalable délibération, libre suffragation et conclusion unanime de[s] trois collèges de l'Empire, veu que tous ses Princes et Etats se trouvent de facto en possession de ce droit, et ne peuvent être préjudiciez sans infraction des Loix fondamentales et autres constitutions de l'Empire «, texte anonyme, s.d.

281 Citations d'après AUDIFFRET, La Geographie ancienne, p. 97.

282 Ibid., p. 98. 
tie) à son droit public après la paix de Westphalie (deuxième partie). Obrecht mit la différence entre la souveraineté et la Landeshoheit, telle que la définissaient les traités de Münster et d'Osnabrück, au centre de ses explications sur ce problème fondamental du droit public allemand, qui concernait le règlement des différends dans les zones situées à la frontière du Saint-Empire et de la France.

\section{Conclusion}

À la différence des périodes antérieure et postérieure, l'époque qui va de 1684 à 1739 est caractérisée par la prédominance de quelques auteurs, surtout de Heiss et de ses successeurs. Très certainement, c'est le succès extraordinaire de Heiss qui explique que d'autres auteurs publient rarement des ouvrages sur l'histoire et sur le droit du Saint-Empire s'ils ne défendent des opinions qui diffèrent fondamentalement de ses idées. Parmi ces auteurs, Vayrac et les traducteurs de Chemnitz sont les plus importants. Or, force est de constater que la France a encore besoin d'historiens et de juristes originaires d'Allemagne ou de souche alsacienne pour se voir renseignée sur le droit public germanique, compte tenu de la faiblesse relative de ses propres effectifs. La théorie du status mixtus garde toute son importance, bien qu'elle ne soit pas unanimement acceptée, voire quelquefois vigoureusement contestée.

La diplomatie française, pour sa part, était toujours sous l'emprise de l'antagonisme entre les Bourbons et les Habsbourg, craignant un renforcement de la position constitutionnelle de l'empereur. En 1701, par exemple, Charles François de La Bonde d'Iberville, envoyé extraordinaire auprès du cercle électoral du Rhin (Kurrheinischer Kreis), conseilla au secrétaire d'État à la Guerre de faire la guerre à l'Allemagne, estimant que le Saint-Empire était un État composé divisé par mille intérêts, et que le roi devait absolument profiter de ses divisions internes avant que l'empereur n'y rétablît son autorité. D' Iberville proposa même de sacrifier les villes impériales aux princes de l'Empire, pour que ces derniers pussent agrandir leurs territoires ${ }^{283}$. Rappelant le temps de Charles Quint et de Ferdi-

283 Cf. SHD, AAT, A 1501, $\mathrm{n}^{\circ}$ 154, d' Iberville au ministre, Mayence, 12 mars 1701, original: »L'Allemagne est un corps composé d'estats de différentes espèces sous divers titres; les uns ecclésiastiques, les autres séculiers, des électeurs, des princes, des comtes, des villes impériales; tout cela divisé par mille intérests, et particulièrement par la différence des religions. Pour couper court, je dis, Monseigneur, que puisque nos ennemys ne vise $<n t>$ à rien moins qu'à nous écraser, il semble que le Roy ne doit pas hésiter à allumer le feu dans toute l'Europe s'il est possible, e $<t>$ surtout en Allemagne, et pour cela de sacriffier aux princes qui se voudront ranger de son party tout ce qui seroit à leur bienséance, et particulièrement les villes impériales. Il n'y en a presque point qui n'ait dans son voisinage quelque prince qui préféreroit à plusieurs millions le plaisir de l'unir à ses Estats. Ces réflexions, Monseigneur, viennent de gens habiles et fort zélez pour la religion catholique, qui comprennent très bien, d'une part, que les protestants donneroient la loy en Allemagne et mesme à l'Empereur s'ils avoient l'avantage sur la France et sur l'Espagne, et, de l'autre, que la ruine ou du moins un extrême affoiblissement de la république d'Holande seroit suivie du rétablissement du Roy 
nand $\mathrm{III}^{284}$, d'Iberville soulignait la nécessité de réagir rapidement afin de prévenir toute atteinte de l'empereur à la liberté des princes d'Allemagne 285 . C'est cette vision d'un pays divisé en un grand nombre de principautés souveraines qui caractérise également la vision de l'Empire chez Saint-Prest, mais les diplomates croient encore à la possibilité d'un rétablissement d'une autorité impériale absolue.

légitime d'Angleterre, dont les conséquences sont aisées à tirer par rapport <à> l'Allemagne «.

$284 \mathrm{Cf}$. ibid. $\mathrm{n}^{\circ} 72$, d'Iberville au ministre, Mayence, 3 février 1701, original.

$285 \mathrm{Cf}$. ibid. $\mathrm{n}^{\circ} 225$, d'Iberville au ministre, Mayence, 13 avril 1701, original: "Entre les intérestz généraux de la France, le plus grand, à $\mathrm{m}<\mathrm{on}>$ avis, Monseigneur, est de réprimer l'autorité que l'Empereur s'est acquise dans l'Emp<ire> depuis les dernières guerres. C'est un corps dont la puissance seroit beaucoup supérieure à celle du Roy si elle se trouvoit réunie en un seul souverain. [...] L'Empereur d'aujourd'huy, tout doux, tout dévôt, tout bénin qu'il est, n'a pas laissé de faire diverses entreprises que les plus hardis de ses prédécesseurs depuis quatre cens ans ont tentées inutilement. Je n'allégueray que l'érection de la Prusse en royaume, et l'établissement d'un neuvième électorat. [.. . ] Je dis donc, Monseigneur, qu'il est d'une nécessité absolue de prévenir les desseins de l'Empereur sur la liberté de l'Empire. Il va tascher de faire mettre en délibération à la Diète le poinct de la seureté publique; c'est-àdire proposer que l'Empire entier s'arme pour sa deffense, et qu'il se ligue avec les puissances voisines $\ll$. 